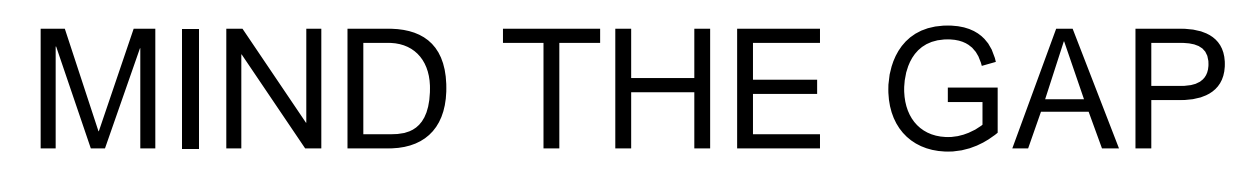

\title{
ASSESSING COOPERATION BETWEEN PHYSICIANS AND MANAGERS AND ITS ASSOCIATION WITH HOSPITAL PERFORMANCE
}

Hanneke A.H.J. Klopper-Kes 
Address of correspondence:

Hanneke Klopper-Kes

Broekdijk 69

7663TG Mander

The Netherlands

0031612826478

hannekeklopper@hotmail.com

Printed by Wöhrmann print service, Zutphen, the Netherlands 


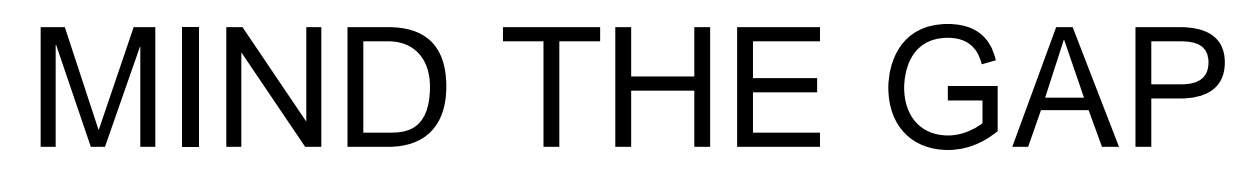

\title{
ASSESSING COOPERATION BETWEEN PHYSICIANS AND MANAGERS AND ITS ASSOCIATION WITH HOSPITAL PERFORMANCE
}

\author{
PROEFSCHRIFT
}

ter verkrijging van

de graad van doctor aan de Universiteit Twente, op gezag van de rector magnificus, prof. dr. H. Brinksma, volgens besluit van het College voor Promoties

in het openbaar te verdedigen

op woensdag 22 juni 2011 om 16.45 uur

door

Andrea Hendrika Johanna Klopper-Kes geboren op 22 juli 1964

te Haarlem 
Dit proefschrift is goedgekeurd door de promotoren:

Prof. dr. W.H. van Harten

Prof. dr. C.P.M. Wilderom

En de assistent promotor

Dr. S. Siesling

CCopyright 2011: A.H.J. Klopper-Kes, Mander, the Netherlands

All rights reserved. No part of this publication may be reproduced, stored in a retrieval system, or transmitted, in any form and by any means, electronic, photocopying, or otherwise, without the permission of the author.

ISBN : 978-90-365-3190-0

DOI nummer : $10.3990 / 1.9789036531900$ 
Promotiecommissie

Voorzitter / secretaris

Prof. dr. P.J.J.M. van Loon

Universiteit Twente

Promotoren:

Prof. dr. W.H. van Harten, arts

Universiteit Twente

Prof. dr. C.P.M. Wilderom

Universiteit Twente

Assistent promotor:

Dr. S. Siesling

Universiteit Twente

Leden

Prof. dr. H.J.J.M. Berden

Prof. dr. M.J. IJzerman

Prof. dr. J.H. Kingma

Prof. dr. A.P.W.P. van Montfort

Universiteit Tilburg

Universiteit Twente

Medisch Spectrum Twente

Universiteit Twente

Paranimfen

Nienke Meerdink

Dr. Sjef van Baal 


\section{Contents}

Preface/voorwoord

Chapter $1 \quad$ Introduction

Chapter 2 Effective cooperation influencing performance:

A study in Dutch hospitals

Chapter $3 \quad$ Quantifying culture gaps between physicians and managers in Dutch hospitals: A survey

Chapter $4 \quad$ Stereotypical images between physicians and managers in hospitals

Chapter $5 \quad$ Differences within the groups of physicians and managers in Dutch hospitals providing leads for intergroup cooperation

Chapter $6 \quad$ Culture differences between physicians and managers

and hospital performance: A quantitative exploration

Chapter $7 \quad$ Findings and conclusions

Nederlandse samenvatting

Dankwoord

Over de auteur/Short biography 


\section{Preface}

In December $2003 \mathrm{I}$ joined the IHI conference in New Orleans and heard Donald M. Berwick giving his opening speech "my right knee". This speech was about his own story of (bad) quality of care he received when having problems with his right knee. During this speech I got inspired and I wanted to take part in the opportunities to further improve health care in hospitals. Being a manager in a hospital I knew how difficult it is to effectively cooperate with physicians, and I also knew that this is not limited to managers. Physicians too find it very hard to cooperate effectively with managers. In my opinion this complicated relationship is linked with the quality issues Berwick mentioned. As I learned in discussions with colleagues from the Netherlands and other Western countries, this problem is widespread and it seems not to be influenced by the health care system. I therefore assumed that the complex relationship between physicians and managers has a professional cultural base. I wanted to learn more about this relationship, its impact on hospital performance and ways of improving the cooperation between physicians and managers.

In January 2004 I started reviewing the literature and in May that year I actually started the research.

In this thesis we address the complex cooperation between physicians and managers in hospitals by studying their deeply embedded professional differences and its influences on hospital performance. Our qualitative and quantitative research resulted in five consecutive articles, presented as chapters two to six.

In chapter two we describe a qualitative study concerning the cooperation between physicians and managers as well as aspects in that cooperation that can provide leads for interventions aimed at enhancing hospital performance.

In the third chapter we report on the development and first results of our culture gap questionnaire. This so called "GAHP-questionnaire" provides an opportunity to quantitatively report and elaborate on the size and content of differences between physicians and managers.

In the fourth chapter we apply intergroup theory to the hospital context in order to add a perspective into the known complex relationship between physicians and managers in hospitals. The resulting insights from this study may enrich current intervention schemes used in health care to facilitate organisational change. The stereotypical gap questionnaire enables quantitative measurement of the strength and size of stereotypical gaps between physicians and managers.

In the fifth chapter we analyse the intragroup variability within groups of physicians and managers in Dutch hospitals in order to identify subgroups that can be focused on when setting out to improve cooperation with the other group to implement organisational change.

In the sixth chapter we statistically associate the cooperation, measured as the size and content of differences between physicians and managers (culture, stereotypical, and satisfaction gaps), to quality performance in order to search for areas of performance that are influenced by their complex cooperation. 


\section{Voorwoord}

In december 2003 bezocht ik het IHI congres in New Orleans; de openingsspeech werd door Donald Berwick uitgesproken: "My right knee". Het was het relaas van zijn eigen ervaringen met de gezondheidszorg die van zorgwekkende kwaliteit waren. Don Berwick is een begaafd spreker en ik werd geïnspireerd door zijn speech. Op het congres was ook Wim van Harten aanwezig, die ik ken uit mijn tijd bij Revalidatiecentrum Het Roessingh. Wim heeft een leerstoel Kwaliteit aan de Universiteit Twente. Tijdens een gesprek met hem groeide het idee om onderzoek te gaan doen naar de samenwerking tussen artsen en managers in ziekenhuizen en de invloed die die heeft op kwaliteit. In mijn werk als manager in een ziekenhuis ervaar ik zelf de lastige samenwerking tussen artsen en managers. Doordat ik deze relatie nu onderzoek, merk ik in de omgang met artsen, maar ook met verpleegkundigen en andere zorgprofessionals, dat ik de problemen in de samenwerking op een andere wijze ervaar, omdat ik er nu vanuit een ander perspectief naar kan kijken. En sinds ik aan dit onderzoek begon, ervaar ik de complexe samenwerking veel meer als een interessant fenomeen in plaats van als een situatie die mij kan frustreren.

Het onderzoek heeft geresulteerd in vijf opeenvolgende artikelen die in dit boekje gepresenteerd worden als de hoofdstukken $2 \mathrm{t} / \mathrm{m} 6$. Het eerste hoofdstuk beschouwen wij als de algemene inleiding van deze thesis. Het tweede hoofdstuk handelt over de samenwerking tussen artsen en managers en benoemt aspecten in die samenwerking waar aanknopingspunten te vinden zijn op basis waarvan we interventies kunnen ontwikkelen die gericht zijn op het verbeteren van ziekenhuisresultaten. In het derde hoofdstuk worden de ontwikkeling (en de eerste empirische resultaten) van de cultuurvragenlijst beschreven. Met deze vragenlijst, genoemd de culture gap questionnaire, kan kwantitatief worden gemeten wat de grootte en de inhoud van de perceptuele verschillen tussen artsen en managers zijn, gebaseerd op de vigerende organisatiecultuur literatuur. In het vierde hoofdstuk gebruiken we de Image theorie, onderdeel van de Intergroep theorie en passen die toe op de ziekenhuiscontext. Hiermee wordt een perspectief toegevoegd aan de kennis van en het inzicht in de complexe relatie tussen artsen en managers. De inzichten die worden verkregen kunnen huidige interventiemogelijkheden verrijken en kunnen er ook voor zorgen dat er meer methodieken komen waarmee de gewenste verandering in organisaties zorgvuldig en efficiënt kan worden gefaciliteerd. In het vijfde hoofdstuk analyseren we de intragroep variabiliteit, dat betekent dat we kijken naar verschillen binnen de groepen artsen en managers, bij voorbeeld op basis van geslacht, leeftijd, soort arts, soort manager. Het doel is subgroepen binnen de groepen van artsen en managers te identificeren die significant minder grote verschillen laten zien ten opzichte van de andere groep. We identificeren die subgroepen vanuit de theoretische basis dat perceptuele verschillen zijn geassocieerd met samenwerking. In het zesde hoofdstuk associëren we statistisch de samenwerking tussen artsen en managers met de landelijke kwaliteitsindicatoren van de Inspectie voor de Gezondheidszorg. Op deze manier proberen we gebieden te vinden in de resultaten van ziekenhuizen die worden beïnvloed door de complexe relatie tussen artsen en managers. Het proefschrift wordt afgesloten met een algemene discussie en conclusie. 
Chapter 1

\section{Introduction}


Managing the various human and other resources of hospitals is more challenging than ever before (Berwick \& Nolan, 1995; Shortell et. al., 2004; Kaissi, 2005). This is influenced by several factors. First, a veritable explosion of knowledge, technological innovations and new "miracle drugs" result in innovative and improved opportunities for curing diseases, but have to be implemented both in the daily organisation of care and in the finances. Second, patients demand better information and an acceptable degree of safety and quality of care. However, budgets are under strain as the limitations of collective financing of health care become apparent. Western health care authorities are experimenting with the introduction of market elements, which in turn drives demand for enhanced process-transparency. A first step in response to these developments often involves creation of awareness of the issues, such as the reports on patient safety "To Err is Human" and the report on quality "Crossing the Quality Chasm" published by the US Institute of Medicine (Clemmer et. al., 1998; Berwick, 2004). After arousing the awareness the next steps involve improvements and innovation in professional and managerial practices, and changes to organisational structures, physical facilities, and also, importantly, organisational cultures. An initial assumption in our study is that organisational cultures, and more specified, the different views between physicians and managers in hospitals influence the performance of the hospital. This means that increased professional manageability in hospital organisations should not only be found in changing the coordinating mechanisms or re-structuring activities. A powerful managerial tool could very well be: taking into account the different views of physicians and managers in hospitals in order to create better mutual socialisation and cooperation and therewith enhance quality performance.

In hospitals the physicians took the lead on quality issues. This was reflected in the emphasis on and efforts in initiatives like medical audits and treatment guideline developments. These and other initiatives, aimed at improving and controlling the professional practices of physicians, were executed by the physicians' own professional groups. Klazinga (1996) states there are four phenomena that express the control over professional practices: specialty professional training, disciplinary law for physicians, quality management activities within scientific societies of medical specialties, and peer review among physicians in hospitals. In addition, Laffel and Blumenthal (1989) state that most quality assurance programs in health care remain focused only on the technical expertise and interpersonal skills of physicians, and pay little attention to other ways of creating quality, such as effective organisation and the ability to mobilise internal or external resources. Managerial challenges in hospitals are often dealt with through the introduction of new organisational concepts. In industrial environments, innovative organisational approaches and management technologies have proven to be effective in the creation of competitiveness (Peters \& Waterman, 1982; Womack et. al., 1990; Volberda et. al., 2005). The implementation of new management approaches (NMA) new at least for health care - such as Total Quality Management and Lean Management - may be helpful in achieving effectiveness of both cost and quality performance. Reported material on the exact degree of diffusion of NMA in hospitals is scarce and often self-reported by the agencies involved. Studies reporting on the adoption of TQM in health care organisations in the Netherlands showed only a limited degree of adoption (maximum of 10\%) and there is little reason to believe that the situation is different in other countries (Wagner, 2004). The same applies to the adoption of "breakthrough 
projects" or presumed "best practices". Given the fact that the pursuit of quality improvements through professional channels has proven to be extremely difficult, more effective cooperation between physicians and managers is assumed to be even more important for the adoption of NMA within hospitals, leading to improved quality performance.

Similar to the lead of physicians in quality, we see a historical progression in regard to hospital management. As hospital organisations got more and more complex, physicians became involved in tactical clinical work (such as the drafting of guidelines and the implementation of clinical pathways) and in strategic work (such as developing and deciding on long term organisational strategy). Responsibilities for physicians broadened even more as they were supposed to be concerned with the financial and economic affairs of the hospitals as well. Because of the growing financial and economic issues within health care organisations, hospitals at the same time developed a new professional class: the managers. A process of finding a new balance started. This balance had to be found between the response to the needs and demands of individual patients on the one hand and running practices in an organisational setting on the other. Moreover, the organisational responsibilities had to be divided between physicians and managers in hospitals. This resulted in an organisation with a "dual hierarchy" (Mintzberg, 1989): not only those in a formal management position had authority. The physicians formed a second "shadow" hierarchy and had, next to their clinical work, a crucial say in the hospital organisation (Pool, 1991). Therefore a conflict between the organisational requirements and the established norms of professional power and autonomy of physicians seemed imminent.

One of the problems in a professional organisation pertains to the differences of coordinating mechanisms. Managers coordinate by structuring the organisation into hierarchical positions. Leadership, based on hierarchy alone is clearly insufficient for solving the managerial problems in hospitals. According to Mintzberg (1989) the coordination among members of a professional group is largely based on the roles and skills learned from years of schooling and working in the peer group. For physicians and managers, these years of schooling and peer activities are very different. A physician claims and receives autonomy in the execution of his (or her) work based on expert authority. Managers in hospitals have to show organisational results (i.e., financial, human resource management, or of a quality type) which they cannot achieve without effective cooperation with physicians.

Physicians in hospitals have both a formal and informal influence on hospital organisations, mainly based on their traditional power and professional expertise. Their influences are exerted on operational, tactical and strategic levels. Because of the influences on the total organisation physicians have and the lack of hierarchical authority, it is important for managers in hospitals to search for other handling mechanisms such as organisational culture and shared values.

Working together, the aim is to achieve an effective cooperation (Shortell, 2004; Smalarz, 2006). For the manager it is challenging to respect the professionals' autonomy and at the same time manage the operational effects of the physicians' work 
in the organisation. Based on our own hospital experiences, we assume that cultural differences between physicians and managers in hospitals are associated with the way quality management initiatives are accepted and implemented, which is reflected by a degree of hospital performance. Literature of the past three decades underlines this correlation. Spurgeon and Barwell (1991), Berson et. al. (2008), Wilderom et. al. (2000), and Sackmann (2011) state that an effective organisational culture is one of the key factors differentiating successful organisations from less successful organisations. In these organisations, people are intrinsically motivated and are less dependent on hierarchical control (Chatman \& Flynn, 2001). If managers in hospitals fail to gain the commitment and active participation of the physicians in quality management initiatives, the implementation will very likely not succeed.

Until now, the implementation of quality management in hospitals focuses too much on improving practices and processes in organisational structural ways (Powell et. al., 2009). An example of this structural approach in the United States is the introduction of managed care. Examples of this in the Netherlands are the "breakthrough projects" as adopted by the CBO (The Dutch Quality Institute) and the introduction of quality indicators by health care authorities in many other countries as well. The available literature on the effectiveness of quality management in hospitals suggests that the main determinants for success are not so much the exact system, but rather the culture of the organisation and certain organisational factors. The degree of flexibility, innovativeness, multidisciplinary problem solving and quality-oriented leadership are seen as relevant factors, while bureaucracy, especially that found in larger organisations is seen to increase the difficulty of successful introduction of quality management initiatives (see, e.g., Shortell et. al., 1995; Weiner et. al., 1997; van Harten \& Schuring, 2003).

As culture influences our feelings of what "ought" to be done, often at a subconscious level, the assumption is that if members of hospital organisations succeed in finding shared values, the quality performance of the organisation (being the qualitative and quantitative results) will improve. In areas where the values are currently divergent, the adoption of quality management into techniques better fitting to the professional culture could lead to improved results. More data on nature and size of differences in cultures (i.e. culture gap) between physicians and managers in hospitals will help to enhance the understanding between the two groups, and, in turn, their cooperation and therewith hospital performance.

In this thesis we address the complex cooperation between physicians and managers in hospitals by studying their deeply embedded professional differences and its influences on hospital performance. Our qualitative and quantitative research resulted in five consecutive articles, presented as chapters two to six.

In chapter two we describe a qualitative study concerning the cooperation between physicians and managers as well as aspects in that cooperation that can provide leads for interventions aimed at enhancing hospital performance.

In the third chapter we report on the development and first results of our culture gap questionnaire. This so called "GAHP-questionnaire" provides an opportunity to quantitatively report and elaborate on the size and content of differences between physicians and managers. 
In the fourth chapter we apply intergroup theory to the hospital context in order to add a perspective into the known complex relationship between physicians and managers in hospitals. The resulting insights from this study may enrich current intervention schemes used in health care to facilitate organisational change. The stereotypical gap questionnaire enables quantitative measurement of the strength and size of stereotypical gaps between physicians and managers.

In the fifth chapter we analyse the intragroup variability within groups of physicians and managers in Dutch hospitals in order to identify subgroups that can be focused on when setting out to improve cooperation with the other group to implement organisational change.

In the sixth chapter we statistically associate the cooperation, measured as the size and content of differences between physicians and managers (culture, stereotypical, and satisfaction gaps), to quality performance in order to search for areas of performance that are influenced by their complex cooperation. 


\section{References}

Berson Y, Oreg S, Dvir T. CEO values, organizational culture and firm outcomes. J Organ Behav. 2008;29:615-33.

Berwick DM, Nolan TW. Overview: Cooperating for Improvement. Jt Comm J Qual Improv. 1995;21:573-577.

Berwick DM. Crossing the Quality Chasm: Health Care for the 21st Century. Washington: National Academy Press; 2004.

Chatman JA, Flynn FJ. The Influence of Demographic Heterogeneity on the Emergence and Consequences of Cooperative Norms in Work Teams. Acad Manage. 2001;44:95674.

Clemmer TP, Spuhler VJ, Berwick DM. Cooperation: the Foundation of Improvement. Ann Intern Med. 1998;128:1004-9.

Harten van WH, Schuring RW. Improvement Management in Health Care; Quality Management and Lean Management. In Hospital of the future. 3rd International Conference on the Management of Healthcare: University of Warwick; 2003.

Kaissi A. Manager-Physician Relationships: An Organizational Theory Perspective. Health Care Manage Rev. 2005;24:165-76.

Klazinga NS. Quality Management of Medical Specialist Care in the Netherland. PhD thesis. Overveen The Netherlands: Belvédère; 1996.

Laffel G, Blumenthal D. The Case for Using Industrial Quality Management Science in Health Care Organizations. JAMA. 1989;262:2869-73.

Mintzberg H, Mintzberg on Management. The Free Press, New York/London; 1989.

Peters TJ, Waterman RH. In Search of Excellence. Warner Books, Harper and Row, Publishers Inc: New York; 1982.

Pool J. Hospital Management: Integrating the Dual Hierarchy?. Int J Health Plann Manage. 1991;6:193-207.

Powell A, Rushmer R, Davies H. Effective quality improvement: Some necessary conditions. Br J Healthc manag. 2009;15:62-8.

Sackmann S. Culture and performance. In: Ashkanasy NM, Wilderom CPM, Peterson M. (Eds. $2^{\text {nd }}$ ed.). Handbook of Organizational Culture and Climate (pp. 188-224). Sage: Thousand Oaks CA; 2011. 
Shortell SM, O'Brien JL, Carman JM, Foster RW, Hughes EFX, Boerstler H, O'Connor EJ. Assessing the Impact of Continuous Quality Improvement/Total Quality Management: Concept versus Implementation. Health Serv Res. 1995;30:377-401.

Shortell SM, Marsteller JA, Lin M, Pearson ML, Wu SY, Mendel P, Cretin S, Rosen M. The Role of Perceived Team Effectiveness in Improving Chronic Illness Care. Med Care. 2004;42:1040-8.

Smalarz A. Physician group cultural dimensions and quality performance indicators: not all is equal. Health Care Manage Rev. 2006;31:179-87.

Spurgeon P, Barwell F. Implementing Change in the NHS. Chapman \& Hall: London, England; 1991.

Volberda HW, Van den Bosch FAJ, Jansen JJP. Smart Management \& Innovative Organizations. Erasmus innovation monitor: Rotterdam, The Netherlands; 2005.

Wagner EH. Effective Teamwork and Quality of Care. Med Care. 2004;42:1037-39.

Weiner BJ, Shortell SM, Alexander J. Promoting Clinical Involvement in Hospital Quality Improvement Efforts: The Effect on Top Management, Board, and Physician Leadership. Health Serv Res. 1997;32:491-510.

Wilderom CPM, Glunk U, Maslowski R. Organizational culture as a predictor of organizational performance. In: Ashkanasy NM, Wilderom CPM, Peterson M. (Eds.) Handbook of Organizational Culture and Climate. (pp. 193-209) Sage: Thousand Oaks CA; 2000.

Womack JP, Jones DT, Roos D. The Machine that Changed the World. Harper Collins Publishers: New York; 1990. 
Chapter 2

\section{Effective cooperation influencing performance, a study in Dutch hospitals}

Hanneke A.H.J. Klopper - Kes

Nienke Meerdink

Celeste P.M. Wilderom

Wim H. van Harten

The International Journal for Quality in Health Care

2011, Volume 23 pp. 94-99 
Objective This study focuses on the cooperation between physicians and managers and aspects in that cooperation that can provide leads for interventions aimed at enhancing hospital performance.

Design We performed a qualitative study on the cooperation between physicians and managers and the influence of that cooperation on hospital performance, and structured the resulting data according to the conditions of Allport's theory on intergroup conflicts. Setting General hospitals in the Netherlands.

Participants 30 physicians (surgical and internal) and managers (strategic, tactic and operational) working in five different hospitals.

Interventions In-depth interviews exploring the influence of cooperation between physicians and managers on hospital performance.

Main Outcome Measure Respondents confirmed the complexity of the relationship between physicians and managers and the link between their cooperation and hospital performance. Mentioned aspects such as power and status differences, clarity in decision making, and personal click, are important in determining the effectiveness of the cooperation between physicians and managers.

Results Our study suggests that the effectiveness of cooperation between physicians and managers is related to the uptake of quality initiatives and hospital performance. Conclusions The complex relationship between physicians and managers can be referred to as an intergroup conflict situation. We combined Allport's contact theory conditions with aspects found in our study leading to the following facilitating conditions: address common goals; create interdependent tasks; arrange the support of authorities; and respect the medical domain. They will enhance intra-hospital cooperation and therewith hospital performance.

Keywords hospital quality performance; intergroup conflict; professional culture; cooperation; physicians; managers

Paper type research paper 


\section{Introduction}

Managing hospitals is an increasing challenge (Berwick \& Nolan, 1995; Shortell et. al., 2004; Kaissi, 2005). Patients demand transparency and safe and high quality care; a veritable explosion of knowledge, technological innovations and expensive drugs result in improved opportunities for curing diseases. However, budgets are under strain as the limitations of collective financing of health care become apparent. Various Western health care authorities are experimenting with the introduction of market elements, emphasising the position of the patient, transparency of quality data and stimulating new entries; all contributing to an increasing demand for more overtly managed care and an emphasis on efficiency as a part of hospital performance (as defined by the WHO; 2003).

A first step in response to these developments often involves the creation of public awareness in order to create external pressure, as shown by the reports on patient safety ("To Err is Human"), 100,000 and 5 Million Lives Campaigns (IHI, 2006 and 2008) and quality ("Crossing the Quality Chasm") (Berwick, 2004). Laffel and Blumenthal (1989) state that most quality programs in health care remain focused on the technical expertise and interpersonal skills of physicians, and pay little attention to other ways of creating hospital quality, such as effective organisation and the ability to mobilise resources. Quality programs originate from industries where these initiatives were usually implemented by the management, with a top down approach (Rogers, 1995). In health care quality initiatives originate from a bottom up clinical, professional orientation and it was only recently broadened to include organisational practices (Van Harten, 1997). In addition, it is important to consider the specific conditions that can promote change in hospitals, such as, taking a whole-organisation approach and the active engagement of key personnel (Powel et. al., 2009). The work by Rogers (1995) underpins this and provides extra input for our argument. According to Berwick (2004) the participation of physicians is paramount for the uptake and therewith successful implementation of quality improvement in hospitals. One of the likely aspects influencing the slow uptake of quality programs are the well known difficulties in the cooperation (defined as "having to work together within one organisation") between physicians and managers (Edwards, 2003; Davies et. al., 2003).

The organisational setting in the Netherlands is such that general hospitals are nonprofit foundations. The majority of physicians are not employed by the hospital, but are associated with a hospital (usually one) and the physicians are partners in their own within-hospital firm where the accumulated fees are divided. Physicians depend on hospital policies for the allocation of staff (for example secretaries and nurses) and equipment, leading to a duality between autonomy and dependence of the physicians. Apart from this structure, the differences in professional cultures of both groups, defined as "the specific collection of values and norms that are shared by people and groups in an organisation and that control the way they interact with each other" (Hill \& Jones, 2001), lead to a challenging complex cooperation (Kaissi, 2005; Edwards, 2003; Davies et. al., 2003; Klopper et. al., 2009). Research shows that the problem regarding cooperation between physicians and managers is widespread in Western countries and has not been suitably solved yet (Wagner, 2004; Edwards, 2005; Donnelly et.al., 2009). 
Differences between physicians and managers have been described in various papers (Kaissi, 2005; Davies et. al., 2003; Rundall \& Davies, 2004; Davies et. al., 2007). One of the most apparent difficulties in managing hospitals arises from the differences between the goals of physicians and managers. A physician's primary goal is to optimally treat individual patients. The primary goal of managers is to provide continuity for the organisation and to deliver high-quality and cost-effective health care services to a given population. These differences in perspectives are an obvious source of potential conflict. For the manageability of hospitals, the professional autonomy and organisational position of physicians are key factors (Kaissi, 2005; Edwards, 2003; Davies et. al., 2003). Physicians claim and receive autonomy in programming and executing their work based on expert authority. Managers do not have automatic authority over physicians. Therefore it is essential for both groups to think and act collectively so as to secure cooperation for organisational improvements. Effective cooperation enables hospitals to deliver services that are both high quality and cost effective (Shortell et. al., 2004; Smalarz, 2006). Hafferty and Light (1995) saw that physician dominance was declining as a consequence of changes in national policies, and "consumerism" among patients. But there is sufficient evidence to expect that they will remain the dominant professional group in hospitals (Klazinga, 1996). Meterko et. al. (2004) showed a significant correlation between culture and patient satisfaction. In a Dutch national survey, covering all hospitals Sluijs (1999) found that the degree of the implementation of quality management is limited. She found leadership and professional involvement to be important factors for success. Literature on the effectiveness of quality management in health care suggests that the main determinants for success are not so much the exact system or systematic approach, but rather the culture of the organisation and certain organisational factors. According to Rogers (1995) the adoption or rejection of quality improvement is predominantly based on the social networks; it is highly influenced by the communication between physicians and managers (the social element of implementation). The relationship between cooperation and hospital performance has been pointed out, but there is a need for more empirical data on aspects and mechanisms influencing the cooperation (Edwards, 2003; Scott et. al., 2003). Although the relation between cooperation and performance has been studied (Shortell et. al., 2004; Wagner, 2004; Rundall \& Davies, 2004). Scott et. al. (2003) state that it is supported by "relatively little firm evidence" and conclude "considerable work remains to be done to provide better substantiated articulation of what these links might be - and what their implications are for health care policy and management" (pp. 115).

Physicians and managers are two professional groups whose cooperation within an organisation is rather complex. According to intergroup literature, members of both groups are likely to have an "us versus them" way of thinking; this is referred to as an intergroup conflict situation. Many papers which describe ways to enhance cooperation within intergroup settings are based on the contact theory of Allport (1954). Pettigrew and Tropp (2006) meta-analysed studies based on this theory (Allport, 1954) and found that it applies to a broad range of intergroup settings. Allport describes four (facilitating) conditions: common goals, no competition, the support of authorities and equal status. In intergroup conflict situations, people often exaggerate differences (Wright et. al., 2005) and information is filtered or directed to confirm negative images. In such a situation, it is 
very difficult to cooperate effectively. The organisational dynamics and processes between physicians and managers we analysed in this thesis, led to the derivation of a visual framework (see below), depicting the influence of cultural differences involved in effective cooperation between members of the two groups on hospital performance.

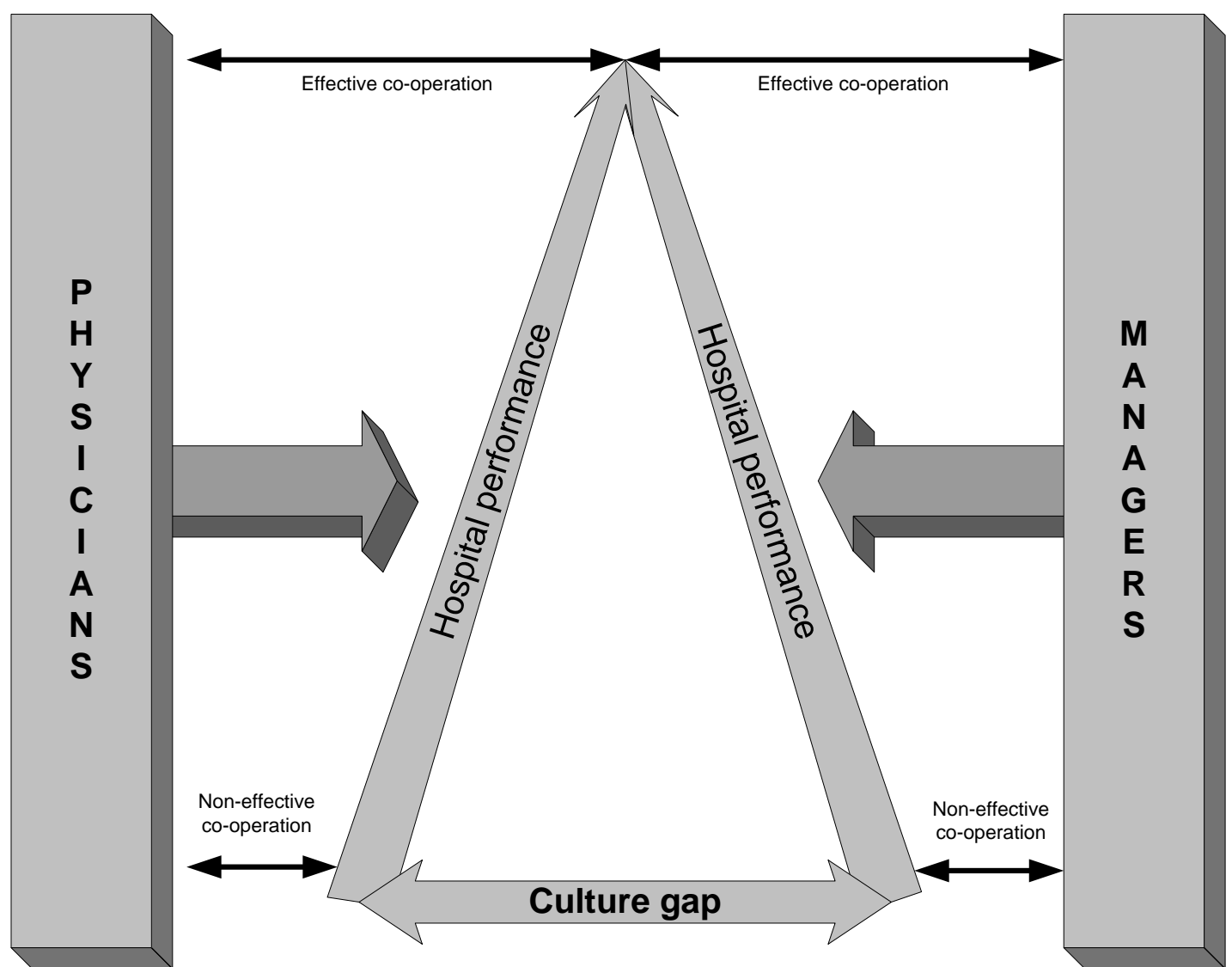

Figure 1: Influence of the cooperation between physicians and managers on hospital performance

\section{Methods}

Using the findings from literature and Allport's intergroup conflict conditions, we conducted 30 in-depth, semi-structured interviews with physicians and managers from 5 different general Dutch hospitals. We chose this method in order to explore the qualitative nuances in this relationship, as these are not very accessible through more quantitative research methods (Palakshappa \& Gordon, 2006). We queried our respondents about the way both groups value their cooperation and their view of the possible relation between that cooperation and hospital performance. The respondents were surgical and internal physicians as well as board members and managers at operational and tactical hospital levels. We interviewed three professionals from each group per hospital and three managers per hierarchical level, a number considered to be sufficient to explore a hospital's organisational culture (Gerowitz, 1998). According to Hofstede et. al. (1990) organisational practices reflect the culture within an organisation as to how things can best be done; practices are a key part of culture. We therefore asked the respondents about their perceptions of the daily practices regarding the cooperation between members of the other group. They were literally asked which 
aspects they would take into account to influence cooperation, satisfaction and hospital performance (Table 1).

Interview questions

Which aspects of cooperation between physicians and managers would you take into account when assessing this cooperation?

What are the factors that influence your satisfaction with cooperation between physicians and managers?

What are the factors that influence your satisfaction with hospital performance? Which aspects of the cooperation between physicians and managers, do you think, may affect hospital performance?

Table 1: Interview questions used in the study

The average length of the interviews was one and a half hours. We recorded and transcribed the interviews for analysis. From the literature we derived that the cooperation between physicians and managers can be seen as an intergroup conflict situation. Therefore, we categorised the data using Allport's conditions for overcoming intergroup conflict.

The first step in the analysis was that 2 authors read the transcripts independently, thus gaining an overview of the perceptions of the cooperation and aspects within that cooperation. They then independently categorised the mentioned aspects into Allport's conditions. The coding of the interpretation was verified by questioning whether the mentioned aspects really reflected Allport's conditions. Consequently, to minimise coders bias, we also asked a physician and a manager who were not involved in our study to categorise the aspects into the conditions. Differing viewpoints were discussed, until an agreement on the categorisation was reached.

\section{Results of the qualitative interviews}

In table 2 we present the data, categorised into the four conditions of Allport's contact theory (1954). showing that apart from the condition "support from authorities", all fields were covered in the responses. In the following we present the results of the interviews in the order of the sequence of the questions.

When asked which aspects of cooperation they would take into account when assessing this cooperation, managers mentioned the formal structure much more often than physicians. A topic of concern to managers is the hierarchical level at which decisions are made within the organisation. In contrast, physicians often want to deal with the board members or top management, even on some operational matters. More than half of the respondents found transparency of communication a relevant aspect. Both groups are concerned about clarity in decision-making and knowing where, how, and why decisions are made. Most important in the division of responsibilities is the way organisational and clinical responsibilities are distributed between physicians and managers, a manager noted: "Physicians have a large amount of clinical responsibilities, but they do not seem to take on the corresponding managerial responsibilities." The content of cooperation is linked to other aspects such as informal organisation, respect and trust. 


\begin{tabular}{|c|c|c|}
\hline Condition of Allport & Aspects mentioned by physicians & Aspects mentioned by managers \\
\hline \multirow[t]{4}{*}{1 Common goals } & Managers do not initiate quality & $\begin{array}{l}\text { The physicians goals do not always } \\
\text { align with the hospital goals }\end{array}$ \\
\hline & $\begin{array}{l}\text { We both want to provide good care for } \\
\text { patients }\end{array}$ & $\begin{array}{l}\text { Physicians are too focused on the } \\
\text { micro level (and not organisational } \\
\text { level) }\end{array}$ \\
\hline & We have conflicting interests & $\begin{array}{l}\text { Because of the introduction of market } \\
\text { elements, the interests between } \\
\text { physicians and managers divert }\end{array}$ \\
\hline & $\begin{array}{l}\text { Physicians are unaware of financial } \\
\text { results while management focuses on it }\end{array}$ & $\begin{array}{l}\text { We are unaware of each others goals, } \\
\text { but we both do the best we can }\end{array}$ \\
\hline \multirow[t]{7}{*}{2 No competetion } & $\begin{array}{l}\text { There is a lot of bureaucratic } \\
\text { administration }\end{array}$ & $\begin{array}{l}\text { Quality blossoms when physicians and } \\
\text { managers work well together }\end{array}$ \\
\hline & $\begin{array}{l}\text { Good convenants could be of benefit to } \\
\text { the cooperation }\end{array}$ & $\begin{array}{l}\text { A good balance is only possible with } \\
\text { good cooperation }\end{array}$ \\
\hline & $\begin{array}{l}\text { We are dependent on managers for } \\
\text { finances }\end{array}$ & $\begin{array}{l}\text { You can make decisions as a manager } \\
\text { but they are not good if you make them } \\
\text { without the doctor }\end{array}$ \\
\hline & $\begin{array}{l}\text { Working together with management } \\
\text { leads to better quality }\end{array}$ & Planning, if done together, works better \\
\hline & $\begin{array}{l}\text { The higher levels of management are } \\
\text { more difficult to work with }\end{array}$ & $\begin{array}{l}\text { Clarity of communication is hard to } \\
\text { achieve }\end{array}$ \\
\hline & $\begin{array}{l}\text { Less bureaucracy leads to better } \\
\text { cooperation }\end{array}$ & $\begin{array}{l}\text { Medical and managerial responsibilities } \\
\text { do not align }\end{array}$ \\
\hline & $\begin{array}{l}\text { Management should be easily } \\
\text { accessible }\end{array}$ & $\begin{array}{l}\text { Physicians have a large amount of } \\
\text { clinical responsibilities, but they do not } \\
\text { seem to take on the corresponding } \\
\text { managerial responsibilities }\end{array}$ \\
\hline $\begin{array}{l}\text { Support of } \\
\text { authorities }\end{array}$ & Not mentioned & Not mentioned \\
\hline \multirow{8}{*}{$\begin{array}{l}4 \text { Equal status / } \\
\text { respect the medical } \\
\text { domain }\end{array}$} & $\begin{array}{l}\text { We have been the core of the business } \\
\text { Management is an unavoidable evil }\end{array}$ & $\begin{array}{l}\text { The professional autonomy of } \\
\text { physicians hinders cooperation }\end{array}$ \\
\hline & $\begin{array}{l}\text { Attitude and capability of managers is } \\
\text { bad }\end{array}$ & $\begin{array}{l}\text { Many physicians only want to deal with } \\
\text { the highest possible hierarchical level of } \\
\text { managers }\end{array}$ \\
\hline & $\begin{array}{l}\text { Managers are deliberately frustrating } \\
\text { the physicians }\end{array}$ & $\begin{array}{l}\text { As long as you respect and trust each } \\
\text { other }\end{array}$ \\
\hline & $\begin{array}{l}\text { Decisions are made without the } \\
\text { consent of the physicians }\end{array}$ & \multirow[t]{5}{*}{ A personal click is very important } \\
\hline & $\begin{array}{l}\text { When managers are listening, you feel } \\
\text { respected }\end{array}$ & \\
\hline & Decision making should be transparent & \\
\hline & $\begin{array}{l}\text { We question the added value of } \\
\text { management }\end{array}$ & \\
\hline & $\begin{array}{l}\text { Managers have to understand the } \\
\text { organisational problems, and not } \\
\text { educate physicians on subjects they } \\
\text { can't judge }\end{array}$ & \\
\hline
\end{tabular}

Table 2: Condensed reflection of key aspects derived from the qualitative study, categorised into Allport's conditions 
Secondly, respondents were asked to note factors that have an impact on their satisfaction with cooperation between physicians and managers. More than half of the physicians said that the more visible management is, the easier things are accomplished. A typical remark made was that a "personal click" (i.e., a positive perception of the other group or person based on personal characteristics) is needed with trust, warmth, and respect. Also negative aspects of satisfaction were expressed, such as decision making without consent and conflicting interests, a typical remark is: "The attitude and capability of managers is bad." Managers were concerned about the unfamiliarity of physicians with their hospital financial results. Furthermore, all of the respondents agreed that cooperation is an absolute prerequisite to attain higher quality. Managers cannot just enforce organisational concepts unto physicians; and if physicians refuse to participate it will not succeed anyway.

Furthermore we asked respondents which factors influence the satisfaction with hospital performance. An illustration of the responses of managers is depicted in the following quote, "Many initiatives take place, but they lack a structured approach throughout the hospital." A typical physician response was "Physicians are not using their powers because they are too busy keeping their own shops running; quality initiatives take too much time." Furthermore most doctors are unfamiliar with the performance indicators, but all managers have clear opinions about them. This widens the differences between both groups.

Finally we asked which aspects of the cooperation between physicians and managers may affect a hospital's performance? All managers agreed that "physicians have very little steering power, but do have preventative power. Physicians have informal power, because they can form a front against management; they can influence quality, budget, and production." A physician stated: "Individual physicians are not that bad, but hospital quality would improve if they cooperated more" and "Cooperation needs to be good otherwise you cannot deliver good quality. I do not mean medical quality, but quality of care." Almost all physicians and managers agreed that when the relationship between physicians and managers fails, it ultimately harms the patient.

\section{Discussion}

The differences between the goals of hospital physicians and managers and the professional autonomy and organisational position of physicians are noted to be a key in the continuing problematic cooperation between physicians and managers (Klopper et. al., 2009; Edwards, 2005; Donnelly et. al., 2009). More empirical data, also on the mechanisms through which cooperation is related to hospital performance, is needed to design appropriate interventions to improve hospital performance.

The interviews offered insight into the effects of extant structures and human factors across both groups. The effect of organisational structures is reflected by the respondents in mentioning the lack of transparency in decision making and the accessibility of management. Blurred organisational structures seem to discourage the enthusiasm of individual physicians and managers to enhance hospital performance. These problems seem to be strengthened by the noted cultural factors like power differences, lack of mutual participation, respect, and trust. Inequality between 
physicians and managers seems to hinder their cooperation. This may be connected to the mentioned lack of "personal click" and unclear communication. Furthermore we found a number of aspects that could be seen as pitfalls: the questioning of the added value of management and the use of performance indicators, and the perceived emphasis on financial issues. Some might consider these to be platitudes, and may use them as an excuse for not participating in quality initiatives.

Although one would have expected to find aspects that indicate that traditional differences between physicians and managers are becoming less obvious (Hafferty \& Light, 1995), our results show that they are still substantial. Thus the complex relationship between physicians and managers can indeed be seen as an intergroup conflict situation (Klopper et. al., 2009). We structured our data and categorised it into Allport's conditions (1954) providing us with conditions that need to be met when designing interventions aimed at more effective cooperation. Note that in the interviews we did not find respondents referring to aspects categorised under his third condition, "support of authorities". This might be because our questions focused on the cooperation between physicians and managers and not on external conditions for that cooperation. Also from literature we know that the hierarchical structure in hospitals does not work for physicians, there is a "dual hierarchy" (Kaissi, 2005). We describe Allport's conditions using the key aspects found in our study, for the third condition we use the literature, and come to the following conclusions on improving cooperation between physicians and managers in hospitals.

1. In terms of "common goals": questioning the added value of management and indicators can be interpreted as an expression of not having common goals between physicians and managers. Many projects focus on either medical or organisational quality. If both types of goals are not included in a project, the risk is an emphasis on the differences between both groups, thereby eliciting the latent rivalry or intergroup competition. The intergroup literature has taught us the value of defining super-ordinate goals (Wright et.al., 2005) that address the needs of both groups and, at the same time, have one single goal instead of multiple goals.

2. The second condition in Allport's theory is "no competition". From the mentioned power differences and non-alignments of medical and managerial responsibilities we derive that quality initiatives are often seen by physicians as limiting their degree of professional autonomy. This is a potential source of conflict which strengthens feelings of competition and rivalry. In designing quality initiatives the tasks of both groups should be interdependent; the project needs the expertise of both professional domains to be successful. Furthermore, both groups should have the same level of understanding of the intervention.

3. The third condition is to "arrange the support of authorities". To enhance commitment, support of both professional and organisational authorities can be used: internal support by means of a medical board and board of directors, and external support by means of health inspectorates, scientific bodies and government agencies.

4. Allport's fourth condition is "equal status". From literature we can conclude that there is an inequality in status between physicians and managers (Klopper et. al., 2009) which is very difficult to "overcome". An effective quality initiative might consider the status gap by approaching the implementation from the medical domain, instead of only the 
commonly used managerial focus. We suggest a change in the label of this fourth generic condition for hospital settings into: "respect the medical domain".

In the introduction we referred to a few quality campaigns of the IHI. In one of their most recent initiatives ("the care bundles"), we recognise elements of Allport's conditions (1954). For every care bundle, super-ordinate goals ("5 million lives campaign"), as well as sub-goals for both professions are defined. Because expert authorities from all relevant disciplines are involved, both physicians and managers are encouraged to see the urgency of implementing these bundles. Although the bundles are often presented in a top-down way, they are developed specifically for the medical domain, which could be helpful in facilitating the uptake within hospitals. Further research could include a longitudinal action-research type case-study in which the above insights are applied in an intervention; it could also include other professions (for instance nurses, and physiotherapists) so that more (multidisciplinary) field knowledge can be gained on interventions that promote better inter-professional group relations in hospitals.

\section{Conclusion}

One of the key factors influencing the uptake of quality initiatives in hospitals is the cooperation between physicians and managers. From our qualitative study we found that (apart from the effects of formal structure) cultural factors influence the cooperation, such as status differences, clarity in decision making, and "personal click". The complex relationship between physicians and managers is based on their respective professional cultures. In literature, a situation like this is referred to as an intergroup situation (Wright et. al., 2005). We found that Allport's contact theory (1954) on improving intergroup relations fits the hospital setting. We applied the key factors of this theory to the aspects found in our study, leading to the following suggestions which can facilitate effective cooperation and therewith hospital performance: address common goals; create interdependent tasks; arrange the support of authorities; and respect the medical domain. Successful implementation of quality initiatives in hospitals needs a bottom-up approach with cooperative efforts by both physicians and managers, in order to improve performance and reduce unnecessary harm to patients. 


\section{References}

Allport GW. The nature of prejudice. Reading: Addison-Wesley; 1954.

Berwick DM, Nolan TW. Overview: Cooperating for Improvement. Jt Comm J Qual Improv. 1995;21:573-7.

Berwick DM. Crossing the Quality Chasm: Health Care for the 21st Century. Washington: National Academy Press; 2004.

Davies HTO, Hodges CL, Rundall TG. Views of doctors and managers on the doctormanager relationship in the NHS. BMJ. 2003;326:626-8.

Davies HTO, Mannion R, Jacobs R, Powell A, Marshall M. Exploring the Relationship between Senior Management Team Culture and Hospital Performance. Med Care Res Rev. 2007;64:46-65.

Donnelly P, Edwards N, Christie S, Naylor R, Dixon J, McKeon A, Maynard A, Field S, Farrar M. Roundtable. Will the penny drop for clinical mangers? Health Serv J. 2009;19:24-9.

Edwards N. Doctors and managers: poor relationships may be damaging patients: what can be done? Qual Saf Health Care. 2003;12:21-4.

Edwards N. Doctors and managers: Building a new relationship. Clin Med. 2005;5:5779.

Gerowitz MB. Do TQM interventions change management culture? Findings and implications. Qual Manag Health Care. 1998;6:1-11.

Hafferty F, Light D. Professional Dynamics and the Changing Nature of Medical Work. J Health Soc Behav. 1995; extra issue:132-53.

Harten van WH. Bouwen aan een Kwaliteitssysteem in de Revalidatiezorg. PhD thesis. Enschede, The Netherlands: Roessingh Research and Development; 1997.

Hill CWL, Jones GR. Strategic Management. Boston: Houghton Mifflin; 2001.

Hofstede G, Neuijen B, Ohayv DD, Sanders G: Measuring organizational cultures: a qualitative and quantitative study across twenty cases. Adm Sci Q. 1990;2:286-316.

Kaissi A. Manager-Physician Relationships: an Organizational Theory Perspective. Health Care Manage Rev. 2005;24:165-76.

Klazinga NS. Quality Management of Medical Specialist Care in the Netherland. PhD thesis. Overveen, The Netherlands: Belvédère; 1996. 
Klopper AHJ, Meerdink N, Harten Van WH, Wilderom CPM. Stereotypical images between physicians and managers in hospitals. J Health Organ Manag. 2009;23:216-24.

Laffel G, Blumenthal D. The Case for Using Industrial Quality Management Science in Health Care Organizations. JAMA. 1989;262:2869-73.

Meterko M, Mohr DC, Young GJ. Teamwork Culture and Patient Satisfaction in Hospitals. Med Care. 2004;42:492-8.

Palakshappa N, Gordon M. Using a multi-method qualitative approach to examine collaborative relationships. Qual Market Res. 2006;9:389-403.

Pettigrew TF, Tropp LR. A meta-analytic test of intergroup contact theory. J Pers Soc Psychol. 2006;90:751-83.

Powell A, Rushmer R, Davies H. Effective quality improvement: Some necessary conditions. Br J Healthc Manag. 2009;15:62-8.

Rogers EM. Lessons for Guidelines from the Diffusion of Innovations. Jt Comm Acc Health Org. 1995;21:324-8.

Rundall TG, Davies HTO. Doctor-manager relationships in the United States and the United Kingdom. J Health Manag. 2004;22:90-6.

Scott T, Mannion R, Marshall M, Davies H. Does organisational culture influence health care performance? A review of the evidence. J Health Serv Res Policy. 2003;8:105-17.

Shortell SM, Marsteller JA, Lin M, Pearson ML, Wu SY, Mendel P, Cretin S, Rosen M. The Role of Perceived Team Effectiveness in Improving Chronic Illness Care. Med Care. 2004;42:1040-8.

Sluijs EM, Dekker J. Diffusion of a Quality Improvement Program among Allied Health Professionals. Int J Qual Health Care. 1999;11:337-44.

Smalarz A. Physician Group Cultural Dimensions and Quality Performance Indicators: Not All Is Equal. Health Care Manage Rev. 2006;31:179-87.

Wagner EH. Effective Teamwork and Quality of Care. Med Care. 2004;42:1037-9.

World Health Organization. Report on a WHO workshop: Measuring hospital performance to improve the quality of care in Europe: A need for clarifying the concepts and defining the main dimensions. Copenhagen: January 2003:1-17.

Wright SC, Brody SW, Aron A. Intergroup contact: Still our best hope for improving intergroup relations. In Social Psychology of Prejudice: Historical and Contemporary Issues. Seattle: Lewinian Press; 2005. 


\section{Chapter 3}

\section{Quantifying culture gaps between physicians and managers in Dutch hospitals: a survey}

Hanneke A.H.J. Klopper - Kes

Sabine Siesling

Nienke Meerdink

Celeste P.M. Wilderom

Wim H. van Harten 


\section{Abstract}

\section{Background}

The demands in hospitals for safety and quality, combined with limitations in financing health care require effective cooperation between physicians and managers. The complex relationship between both groups has been described in literature. We aim to add a perspective to literature, by developing a questionnaire which provides an opportunity to quantitatively report and elaborate on the size and content of differences between physicians and managers. Insight gained from use of the questionnaire might enable us to reflect on these differences and could provide practical tools to improve cooperation between physicians and managers, with an aim to enhance hospital performance.

\section{Methods}

The CG-questionnaire was developed by adjusting, pre-testing, and shortening Kralewski's questionnaire, and appeared suitable to measure culture gaps. It was shortened by exploratory factor analysis, using principal-axis factoring extraction with Varimax rotation. The CG-questionnaire was sent to all physicians and managers within 37 Dutch general hospitals. ANOVA and paired sample T-tests were used to determine significant differences between perceptions of daily work practices based in both professional cultures; culture gaps. The size and content of culture gaps were determined with descriptive statistics.

\section{Results}

The total response (27\%) consisted of 929 physicians and 310 managers. The Cronbachs alpha's were $0.70-0.79$. Statistical analyses showed many differences; culture gaps were found in the present situation; they were even larger in the preferred situation. Differences between both groups can be classified into three categories: (1) culture gaps in the present situation and not in the preferred, (2) culture gaps in the preferred situation and not in the present, and (3) culture gaps in both situations.

\section{Conclusions}


With data from the CG-questionnaire it is now possible to measure the size and content of culture gaps between physicians and managers in hospitals. Results gained with the CG-questionnaire enables hospitals to reflect on these differences. Combining the results, we distinguished three categories of increasing complexity. We linked these three categories to three methods from intergroup literature (enhanced information, contact and ultimately meta cognition) which could help to improve the cooperation between physicians and managers. 


\section{Background}

The history of the development of hospital organisations and the wider scope of quality initiatives shows that cooperation between physicians and managers is becoming of paramount importance to enhance hospital performance (Klazinga, 1996). Hospitals are charged with developing internal organisations where solid quality and cost effectiveness go hand in hand (Berwick \& Nolan, 1995; Shortell et. al., 2004a; Shortell et. al., 2004b). More and more quality initiatives are being promoted in the public domain (100,000 and 5 Million Lives Campaigns IHI, 2006-2008, and the report on quality "Crossing the Quality Chasm" published by the US Institute of Medicine, 2004) which increases the demand of patients for higher transparency in the quality of care. Moreover, new treatments are made possible by technological innovations, resulting in improved opportunities to cure diseases. However, budgets are under strain and the limitations of collective health care financing become apparent. Physicians increasingly have to work closely together with managers and have to negotiate for resources and the organisation of their clinical practices (Klazinga, 1996). New quality (management) techniques (integrating financial and quality management) have been initiated to meet the aforementioned challenges in the hospital organisation (Caldwell, 2006). These quality initiatives usually do not take professional standards into account and often lead to an increasing influence of managers over quality and efficiency measures that influences the work done by physicians. One of the consequences is that physicians may feel that their autonomy is being threatened and resist the implementation (Edwards, 2003).

In the hospital setting there are well known difficulties in the cooperation between physicians and managers (Davies et. al., 2003; Edwards, 2003; FitzGerald, 1994; Raelin, 1991; Shortell et. al., 2005). The cooperation is even more complicated because of the differences in professional cultures between both groups (Raelin, 1991). Given the described complex context, insight is needed into the content and size of the differences between physicians and managers. Theoretically, the concept of professional culture differences between physicians and managers is apparent in various ways. Schein (1996) conceptualises organisational culture into three layers: basic assumptions, 
artifacts, and values and beliefs. The basic assumptions are mainly implicit and therefore not directly measurable by quantitative means. The artifacts are the distinguishable expressions of organisational culture. When you walk into a hospital, the different professional groups are immediately apparent. For example, physicians almost always wear their white coats and stethoscopes, some even during lunch or management meetings. This distinguishes them from all other groups in the hospital. Managers are less visible with regard to their appearances. They do, however, differ from physicians, for example, in their use of language (management jargon) which is very often not understood by physicians (Anderson \& Pulich, 2002). The operationalisation of artifacts is mainly applicable for qualitative research purposes. We wanted to study the differences between physicians and managers quantitatively; when collecting our data we asked for perceptions of daily practices which were based on Schein's third culture layer: values and beliefs. According to Hofstede et. al. (1990) the largest part of a firm's culture is "organisational practices". Organisational practices reflect the collective wisdom within an organisation as to how things can best be done. Practices are a key visible part of culture. We refer to different perceptions of practices, based on the inherent professional culture dissimilarities between physicians and managers (Raelin, 1991), as culture gaps. The complex cooperation based on differences in professional cultures between physicians and managers combined with the fact that both groups are working within the same organisational setting, can be seen as an intergroup conflict setting (Klopper et. al., 2009). From intergroup literature we know that larger differences between groups correlate with reduced performances (Cox, 2003; Gerson et. al., 2004; Pettigrew \& Tropp, 2006; Roberts \& Perryman, 2007; Taylor, 2006). In intergroup conflict settings, people tend to exaggerate differences between both groups, leading to stereotyping (Tajfel, 1982). When a group has stereotypical beliefs about another group, information is filtered towards the stereotypical image of the other group, leading to negative images. In this process, it is very hard to work with an open attitude with the other group. Intergroup literature also provides methods to enhance cooperation in intergroup conflict situations (Allport, 1954; Ben-Ari, 2004; Easen et. al., 2000; Ross, 1997). 


\section{Measurement of culture gaps}

We based our CG-questionnaire on Kralewski's work (1996; 2005) on the culture of medical group practices. It uses underlying issues in health care (such as the need for more efficacy, safety, and quality of care) that are major issues in all western countries (Williams et. al., 2007). Kralewski et. al.(2005) identified nine relevant organisational culture dimensions in medical group practices. Kralewski's questionnaire has been used among medical group practices, but originated from Reynolds (1986) which reviewed five major publications about organisational cultures in industry. After several field studies, Kralewski et. al. refined their initial culture instrument into a questionnaire on culture in medical group practices (Kralewski et. al., 2005). The questionnaire was validated by a large sample of 267 medical group practices, and contains the following nine dimensions: "collegiality", "information emphasis", "quality emphasis", "organisational identity", "cohesiveness", "business emphasis", "organisational trust", "innovation", and "autonomy". Kaissi et. al. (2004) used Kralewski's questionnaire to study the influence of culture of medical group practices on types of quality programs used. Smalarz (2006) used the survey instrument to study the effect of physician group cultural dimensions on quality performance indicators. In all the studies, Kralewski's questionnaire appeared relevant, reliable, and valid to measure organisational culture within and between hospitals. It captures the culture of medical group practices at an organisational level and was used as the starting point for our study.

An extra feature was added to the Kralewski questionnaire by asking about the present and preferred situation. When asking about the way practices are perceived in the present situation, we searched for the negotiated order between physicians and managers. Answers to statements in the present situation represent organisational reality as perceived by physicians and managers. We postulated that differences in answers in the present situation between the two professional groups reveal culture gaps in the way both groups perceive reality. Additionally, answers to statements in the preferred situation represent the desired order (Berrio, 2003). We postulate that differences in answers in the preferred situation between physicians and managers reveal culture gaps, based on their inherent professional cultures. If culture gaps in the preferred situation are larger compared to the present situation, it could mean that 
physicians and managers would change the system when acting without the other party. In this case there is a latent conflict between physicians and managers. The larger the size of the culture gaps the larger the latent conflict between both professional groups.

This study adds a perspective to the literature, from a methodological point of view, to improve insight into the complex relationship between physicians and managers. We applied the questionnaire by Kralewski et. al. (further referred to as "Kralewski's questionnaire") (2005) to the hospital setting and developed the CG-questionnaire which is suitable to measure the size and content of differences between physicians and managers as culture gaps. In intergroup literature, the explanatory effect of differences between (professional) groups has been shown in many settings (Ben-Ari, 2004; Easen et. al., 2000; Pettigrew \& Tropp, 2006; Ross, 1997; Taylor, 2006), and might be of use for the hospital setting as well. Insight gained from the data from the questionnaire might enable us to reflect on the differences and could provide practical tools with which the cooperation between physicians and managers could be improved, ultimately as a benefit for a hospital's performance.

\section{Methods}

In this paper we report the development of the CG-questionnaire as well as the results from our use of this instrument to assess culture gaps between physicians and managers in a representative sample of Dutch general hospitals. To obtain the national data, we split the research into three separate studies. Firstly we developed a Dutch questionnaire by translating and slightly adapting Kralewski's (2005) questionnaire on the cultures of medical group practices and we pre-tested it. Secondly, we sent the resulting adjusted Dutch questionnaire to 445 physicians and 137 managers in five different Dutch general hospitals. With the collected data we carried out statistical analyses to then develop the CG-questionnaire. Thirdly, in order to obtain nationally representative data, we sent the CG-questionnaire to all physicians $(n=3941)$ and managers $(n=680)$ in 37 Dutch general hospitals. This study does not require ethical approval. The three successive studies are presented below.

\section{Qualitative pretest, study 1}


We translated and back translated Kralewski's culture questionnaire; then Kralewski's statements had to be aligned with the Dutch system features. No changes were needed in the original statements related to the hospital setting. The only two alterations were related to the differences between American and Dutch health care systems. Most hospitals in the Netherlands are non-profit foundations. It is only recently that market elements have been introduced, such as free negotiations on the price of $20 \%$ of the volume of hospital care and facilitating new market entries. The majority of physicians is not employed by the hospital, but is associated with a hospital (usually one) and the physicians are partners in their own within-hospital firm. In the within-hospital firms the accumulated fees are divided. Physicians depend on hospital policies for the allocation of staff (for example secretaries and nurses) and equipment. In the Dutch structure physicians have economic autonomy because of the way they are paid, but they are economically dependent on operational and staff support in the hospital. Physicians are organised as the "medical staff", commonly without hierarchy, and they mandate an internal board which has to be consulted on important organisational and medical issues by the executive hospital board. Following from the above we altered two survey statements in the dimension "business emphasis" linked to the financial system, focusing to a lesser degree on commercialisation in hospital care. In the Dutch system the degree of market regulation is expected to remain considerably higher than the situation in the United States. The statements which we changed were:

- "Maximising revenue is our highest priority" into: "Reducing costs is our highest priority".

- "We won't add a piece of equipment if it won't make money" into: "When purchasing medical equipment financial considerations are an important factor".

In order to have six statements per dimension, we added 15 statements concerning work practices which conform to medical protocols, multidisciplinary cooperation, working atmosphere, and the involvement of physicians in the policy and the mission of the organisation. Because our goal is different from Kralewski et. al., we added a dimension, also consisting of six statements, directly assessing the level of cooperation 
between physicians and managers and, accordingly, the extent to which there are culture gaps.

For our qualitative pretest we selected 15 representative respondents from four Dutch general hospitals, located in both rural and urban settings, and asked physicians in both surgical and internal medical specialties as well as board members and managers in different hierarchical positions. We piloted the questionnaire by asking the respondents to complete it, in our presence. The Dutch pretesting questionnaire contained 60 statements with a double five-point Likert scale, which assessed the respondents' personal perceptions of practices in the hospital in the present and preferred situation. During the interviews we posed a set of 13 questions about the clarity, redundancy, lay out, relevance, and other format-related aspects of the Dutch questionnaire. If a respondent criticised one of the statements, it meant that the questionnaire was not completely clear. After every interview we improved the clarity of the language used in the Dutch questionnaire, until there were no further such remarks.

\section{Development of the Culture Gaps Questionnaire, study 2 Methodology}

An important criterion for a usable questionnaire is that it needs to be short in order to receive better response rates (Edwards et. al., 2002). We sent the adjusted questionnaire to five different general hospitals in the Netherlands ( 445 physicians and 137 managers). These hospitals were chosen for their geographical location and size in order to cover differences between urban and rural areas and small, medium, and large general hospitals. We analysed the data of the respondents, 166 physicians (response rate $37 \%$ ), and 71 managers (response rate $52 \%$ ), with future usage and shortening in mind. We checked for potential selectivity and found that the division between physicians and managers regarding the demographic characteristics is comparable to the original sample. Therefore we feel the group of respondents reflects the total group. We shortened the questionnaire mainly through an exploratory factor analysis, using principal-axis factoring extraction with Varimax rotation. The adequate (smallest) number of factors was determined by using the Eigenvalue criteria. Factors having an Eigenvalue larger than 1.0 were included. A loading above 0.50 was chosen as the 
criterion of acceptance as a factor for the present perceptions and above 0.60 for the preferred perceptions. In the case of cross loadings (in two different factors) the highest loading after rotation was taken. The reliability of the adjusted Dutch questionnaire was determined using the Cronbach's alpha. We considered a score above 0.65 to implicate a sufficient internal consistency.

In order to shorten the questionnaire we determined the reliability and the correlation between the list with and without a certain statement with an item-total correlation test. The item-total correlation was the correlation between the item and the sum score calculated without that particular item. If the item-total correlation was below 0.20 , the statement was removed from the list. The item with the lowest score was deleted first, and then the item-total correlation was calculated again. This was repeated until all itemtotal correlations were above 0.20 . Subsequently we determined the Cronbach's alpha score. Repeating the factor analysis with the shortened list, the total variance explained was determined. In order to finalise a valid, reliable and relevant version of the CGquestionnaire, we compared the outcomes of the analyses of all four categories (physicians/managers and present/preferred situation, assuming the factor structure in all categories was the same) with the statements found in the item-total correlation test. When a statement scored in at least three categories, it was included in the CGquestionnaire. To statistically finalise the shortening of our list we combined the statements that had been identified with the factor analysis (with Varimax rotation) with the statements which revealed significant differences (ANOVA). We took at least two statements per initial Kralewski dimension that scored significant culture gaps in at least one of the five hospitals. If only one statement scored in a dimension, based on the factor analysis, we took a second statement based on the culture gaps scores.

\section{Results}

Table 1 presents the results of the factor analyses and the item-total correlations. The Cronbach's alphas for the four different groups varied from 0.87 to 0.90 . The factor analysis revealed 19 to 20 components, with different components per group. For the present situation we selected statements with loadings above 0.50 for the present situation which resulted in 42 statements for the physicians and 43 statements for the 
managers. In the preferred situation the loading was set on 0.60 , due to the fact that the remaining number of statements would have been too high when taking a loading of 0.50 . For the preferred situation the results were 30 and 29 statements, respectively. The item-total correlation reduced the set of statements to 19 items. Of these reduced sets the Cronbach's alphas ranged from 0.70 to 0.79 , while the number of components ranged from six to eight. The explained variance ranged from $56 \%$ to $63 \%$. Combining the statements which were included in the questionnaire (after the factor analysis with Varimax rotation and item-total correlation) (Table 1) with the statements that revealed culture gaps, led to a selection of 20 statements with at least two statements per initial Kralewski dimension. Table 2 shows our final CG-questionnaire.[insert table 1 and table 2]

\section{National data collection with the Culture Gaps Questionnaire, study 3 Methodology}

Agreement from the general hospitals was needed for the purpose of obtaining a list of physicians and managers to whom the questionnaire could be sent. Therefore we needed the consent and participation of the boards of the hospitals. In our national study, 37 out of a total 86 Dutch general hospitals agreed to participate. These 37 hospitals were spread throughout the country in terms of size and location; therefore we believe we can generalise our findings to the national level. We e-mailed an invitation to all physicians $(N=3941)$ and managers $(N=680)$ within the 37 hospitals, who had agreed to participate, to complete the questionnaire on our website. This led to a total $\mathrm{N}$ of 4621 . After three months the physicians and managers in 11 hospitals who had not responded were reminded with a hard copy sent by post. The remaining physicians and managers in the other 26 hospitals were reminded by e-mail.

The reliability of the total CG-questionnaire was determined with the Cronbach's alpha. Paired sample T-tests and ANOVA were used to determine significant differences between answers to the statements between physicians and managers. We analysed differences between physicians and managers, using individual data, pooled over the whole data for the present and the preferred situation and we compared the present and preferred situation. A p-value below 0.05 was considered to be statistically significant. 
The magnitude and direction of culture gaps were determined with descriptive statistics (mean, standard deviation and the lower and upper bound of the $95 \%$ confidence interval).

\section{Results}

In this study we developed a concise, valid questionnaire based on Kralewski et. al. (Kralewski et. al., 1996;2005). The Cronbach's alphas on all four categories (Table 1) are above 0.70 (meaning a high consistency). With an ANOVA we show that the CGquestionnaire is able to reveal culture gaps between physicians and managers in Dutch hospitals. The CG-questionnaire gives a quantitative foundation to the size and content of culture gaps. We pooled the data, but the individual data were used for factor analysis. As a result, the chance of failing to reject statements based on an inappropriate factor analysis, due to pooling the hospitals, is minor.

The average response rate among physicians was $24 \%(n=929)$ and among managers $46 \%(n=310)$, leading to a total response rate of $27 \%(n=1239)$. This response resembled our qualitative and quantitative pilot study (which had a response rate of $35 \%$ ). As mentioned before, the responding hospitals reflected the national division of urbanisation, size and type of hospital. Moreover, our response rates do not deviate much from response rates in comparable Dutch studies (Kruijthof, 2005). The ratio between physicians and managers from the separate hospitals in the study was comparable to the division of these professions in most general hospitals in the Netherlands. Based on the arguments mentioned above, our results can be seen as reflecting the actual culture gaps between physicians and managers in Dutch general hospitals.

\section{Culture gaps between physicians and managers}

Table 3 presents the results of the main study on culture gaps between physicians and managers on a total group level both for the present and the preferred situation. The Cronbach's alphas of the national data collection was 0.70 and 0.75 for the 20 statements concerning the present situation and 0.76 and 0.79 for the preferred situation. [insert table 3] 
In the present situation 15 out of 20 statements scored statistically significant differences between physicians and managers (ANOVA, p-value $<0.05$ ). Six of these 15 statements were answered in the opposite direction (agreeing (score $>3$ ) versus disagreeing (score $<3)$ ). As to statement 6 (autonomy of physicians), statement 16 (about provision of information to improve cost-effectiveness) and statement 18 (about trust in decisions made by the board of directors), physicians do not agree, whereas managers do agree. Statement 7 (about collegiality among physicians), statement 9 (about open discussion of clinical failures) and statement 14 (about methods to include new technologies) show the opposite: physicians agree and managers disagree. In the preferred situation there are 16 out of 20 statements scoring statistically significant differences between physicians and managers (ANOVA, $p$-value $<0.05$ ). The only statement that does not score a statistically significant difference between physicians and managers in both the present and preferred situation is statement 12 (about belonging to the group).

\section{Culture gaps between present and preferred practices on total group level}

As shown in Table 3, physicians scored differently in 18 out of the 20 statements between the present and the preferred situation. Eight statements even scored differences of over one point. The largest gaps were found in the statements about the compensation plan, the methods that assure practice change to include new technologies, provision of information, and trust in the board of directors. The only two statements not scoring differences were about informal consultation (no. 1) and about the feeling that physicians are autonomous but practice in the same organisation for the support services (no. 6). Managers scored differently in 19 out of the 20 statements between the present and the preferred situation. Half of the statements evaluated by the managers scored differences of one point. Examples of the biggest differences are about relying on computer based information, the close collegial relationship among physicians, and the open discussion on clinical failures. The managers scored no differences on the statement about the condition of professional autonomy for the quality of health care (no. 20).

\section{Discussion}


The many large gap sizes in the different culture aspects, uncovered by this study confirm that focusing on rational organisational elements (process analysis, hierarchical and financial structures) may not be sufficient to improve hospital quality. Moreover, the cultural dimension, when thinking about organisational improvement, can be addressed more specifically. Our results support the literature: a focus on cooperation with an explicit eye for intergroup differences should be added to organisational improvement methods (Kaissi et. al., 2004; Reynolds, 1986; Williams et. al., 2007). With data from the CG-questionnaire it is now possible to measure the size and content of gaps between physicians and managers in the hospital setting. The CG-questionnaire enables us to reflect on these differences and provides practical tools for the hospital organisation and for future research.

The results of the qualitative pretest and the subsequent quantitative studies confirm the findings in the literature (Davies et. al., 2003; Edwards, 2003; Raelin, 1991), that there are large differences between physicians and managers. We measured the differences in both how physicians and managers perceive the organisational work practices (present situation) and in the way both groups wish reality to be changed (preferred situation). Differences between both groups in the present and preferred situation can be classified into three categories: (1) culture gaps in the present situation and not in the preferred, (2) culture gaps in the preferred situation and not in the present, and (3) culture gaps in both situations. From an intergroup theoretical point of view these categories require different methodological approaches to improve cooperation between culturally different groups (Ben-Ari, 2004). Clearly, the Intergroup literature can provide us with new insights and methods to enhance cooperation in the professional culture difference setting between physicians and managers. Ben-Ari (2004) describes three types of methods that can be used to lessen intergroup conflict: the information method, the contact method, and the meta cognition method. All three methods are based on the idea that an increased understanding of the other group enhances cooperation. The three different intergroup methods were applied to the three categories of results of our study, as discussed below. 
In our results, three statements scored culture gaps in the first category; differences in the present situation and not in the preferred situation (Table 3). Apparently there is a difference in the way both groups perceive reality. For instance, physicians and managers both agree on the fact that safety and quality in patient care should be guaranteed, but disagree on the level of implementation in the current situation (physicians are more satisfied). In this case physicians and managers do not show an inherent difference in cultures, but differences in perceived practices (based on the professional cultures that both groups have). In this first category the information method from intergroup literature might be effective to lessen the differences between both groups, because the differences are not based on inherent cultures but on differences in perceptions of daily practices. The information method is based on the theory that knowledge about the other group lessens the stereotypes and therefore enhances cooperation. The method consists of providing objective information about the other group (Triandis, 1980). The limitation of the information method is that if the intergroup differences are too large, this approach will not be sufficient on its own (Ben-Ari, 2004).

In the second category, four statements scored culture gaps between physicians and managers in the preferred situation and not in the present situation. For instance, publicising about and mentioning the innovativeness of plans and relying on computerbased registration is preferred more by managers than by physicians. Physicians, on the other hand, prefer more informal consultations (Table 3). This means that both groups adjust their daily practices to hospital reality. If physicians and managers were given the choice to change the daily practices individually, physicians would change it in a different way than managers would. An intervention that might help in this case could be a method based on Allport's contact theory (1954). This theory has been applied in many studies and has proven its value (Pettigrew \& Tropp, 20006). The contact theory maintains that contact between members of different groups enhances cooperation. There are four conditions to be met for the contact to be effective: having common goals, no competition between groups, support by the authorities, and equal status (Allport, 1954). For example, the intervention could be a project in which both groups are given an assignment to mutually design a plan that integrates preferred situations for both groups. 
The third category shows 12 statements that score culture gaps in the present and the preferred situation; these statements reveal the most imminent aspects of the culture gaps. Therefore, these are presumably the most difficult aspects to change within a hospital organisation. Physicians' values of the professional autonomy and collegiality among physicians are higher than among managers. Consequently, the physicians scored even higher in the preferred situation. Managers value the registration of adverse events and the trust in the decisions made by the Board of Directors was higher in the current situation compared to the physicians. Managers want it to be even higher in the preferred situation. The situation in which both the preferred and the present situation are different, can be seen as a persisting intergroup conflict situation. From intergroup literature, the third approach, meta cognition, facilitates the overcoming of cognitive obstructions, preventing openness towards information about the other group. A training program could provide insight into the way cognition works and therefore the awareness of one's own prejudices towards the other group. This, in turn, provides the opportunity to reflect on the sources of prejudice. Insight into meta cognitive processes can change people's perceptions and behaviour (Strack \& Hannover, 1996).

Methodologically, in the process of transforming Kralewski's questionnaire into the CGquestionnaire, the extra dimension added to the initial nine dimensions was not confirmed to be a one-dimensional construct and, therefore did not add information. Therefore we decided not to include these additional six statements in that dimension into further data analysis, nor in the CG-questionnaire. Statistically, we could not confirm Kralewski's nine dimensions. We checked whether the scores in the factor analysis with Varimax rotation were caused by the additional statements, when compared to the original Kralewski questionnaire (2005), but that was not the case. We repeated the factor analysis with Varimax rotation on the results of the original, but translated statements. This also did not show the initial nine dimensions. The following factors could have caused this. First, our goal was different from the initial goal of Kralewski's questionnaire; the CG-questionnaire intends to measure the size and content of culture gaps between physicians and managers. Kralewski's questionnaire is used to differentiate between medical groups. Second, the Dutch hospital system differs from the situation in the USA with exclusively non-profit type organisations and more 
pronounced central regulation. The socio-economic structure possibly influences the way physicians and managers (co)operate. This is also why we altered two statements earlier and added one statement (to the dimension business emphasis) before the pretest; these three statements have been incorporated into the final set of 20 statements comprising our CG-questionnaire. Although statistically we could not confirm the dimensions of Kralewski et. al., the CG-questionnaire meets our research objective because data gained with the questionnaire gives us leads as practical tools to enhance cooperation between both groups. The high Cronbachs alphas $(0.70$ and 0.75 present, 0.76 and 0.79 preferred) of the CG-questionnaire show that the statements in the questionnaire form a coherent construct.

Despite the differences between the goal of our study and Kralewski's goal, and the different national settings of the researches, the underlying issues in health care (such as the need for more efficacy, safety, and quality of care) are also relevant in health care elsewhere (Edwards, 2003; Raelin, 1991; Shortell et. al., 2004; Williams et. al., 2007). Therefore, it could be of interest for hospital organisations outside of the Netherlands to apply the CG-questionnaire. The applicability and validity should be studied before using the CG-questionnaire in other countries. However, there are a number of countries in which the validation process would be easier because of the similarity in the way in which their health care is organised. These countries are for example: Germany, Belgium, France and the Scandinavian countries.

Further research could focus on the relation between different gap sizes between physicians and managers and the effectiveness of the cooperation; it is possible that a small gap could be hypothesised as causing possible productive friction. Either studies covering large numbers in cross sectional designs, or longitudinal studies using interventions, could lead to new and creative insights to significantly enhance the effectiveness of the cooperation.

\section{Conclusions}

The results of our study confirm the existence of the presumed latent conflict between physicians and managers and show that, below the surface of the daily practices, the 
relationship between (members of) both groups is tense, leading to suboptimal cooperation. This might decrease hospital performance, and could ultimately harm patients. When implementing change, hospitals could use the CG-questionnaire to gain data on the content and size of culture gaps between physicians and managers in order to better substantiate the chosen methods used for organisational improvement. Combining results from the present and preferred culture gaps, we arrived at three categories of increasing complexity. We linked these categories to the three methods described in the intergroup literature to help develop the interventions. Interventions based on intergroup literature (enhanced information, contact and ultimately meta cognition) could help improve the cooperation between physicians and managers. At the very least, our findings will increase the awareness of the importance of tension, which is kept below the surface, and ultimately hindering effective cooperation. Our results may stimulate research into the relation between the size and content of culture gaps that hinder cooperation and affect the performance of hospitals.

The adjusted questionnaire and the full rotated matrix of the factor analysis can be obtained from the authors by email. 


\section{References}

Allport GW. The nature of prejudice. Reading: Addison-Wesley; 1954.

Anderson P, Pulich M. Managerial competencies necessary in today's dynamic health care environment. Health Care Manag. 2002;21:1-11.

Ben-Ari R. Coping with the Jewish-Arab Conflict: a comparison among three models. J Soc Issues. 2004;60:307-22.

Berrio AA. An Organizational Culture Assessment Using the Competing Values Framework: A Profile of Ohio State University Extension.

[http://www.joe.org/joe/2003april/a3.php] website

Journal of Extension. 2003;41.

Berwick DM, Nolan TW. Overview: Cooperating for Improvement.

Jt Comm J Qual Improv. 1995;21:573-7.

Berwick DM. Crossing the Quality Chasm: Health Care for the 21st Century. Washington: National Academy Press; 2004.

Caldwell C. Lean-Six Sigma: tools for rapid cycle cost reduction.

Healthc Financ Manage. 2006;60:96-8.

Cox KB. The Effects of Intrapersonal, Intragroup, and Intergroup Conflict on Team

Performance Effectiveness and Work Satisfaction. Nurs Adm Q. 2003;27:153-63.

Davies HTO, Hodges CL, Rundall TG. Views of doctors and managers on the doctormanager relationship in the NHS. BMJ. 2003;326:626-8.

Easen P, Atkins M, Dyson A. Inter-professional collaboration and conceptualizations of practice. Child Soc. 2000;14:355-67.

Edwards P, Roberts I, Clarke M, DiGuiseppi C, Pratap S, Wentz R, Kwan I. Increasing response rates to postal questionnaires: systematic review. BMJ. 2002;324:1183.

Edwards N. Doctors and managers: poor relationships may be damaging patients - what can be done? Qual Saf Health Care. 2003;12:21-4.

FitzGerald L. Moving clinicians into management: a professional challenge or threat? J Manag Med. 1994;8:32-44.

Gershon RRM, Stone PW, Bakken S, Larson E. Measurement of organizational culture and climate in healthcare. J Nurse Adm. 2004;34:33-40. 
Hofstede G, Neuijen B, Ohayv DD, Sanders G. Measuring organizational cultures: a qualitative and quantitative study across twenty cases. Adm Sci Q. 1990;2:286-316.

Kaissi A, Kralewski J, Curoe A, Dowd B, Silversmith J. How does the culture of medical group practices influence the types of programs used to assure quality of care? Health Care Manage Rev. 2004;2:129-38.

Klazinga NS. Quality management of medical specialist care in the Netherlands. PhD thesis. Overveen: Belvédère; 1996.

Klopper AHJ, Meerdink N, van Harten WH, Wilderom CPM. Stereotypical images between physicians and managers in hospitals. J Health Organ Manag. 2009;23:216-24.

Kralewski JE, Dowd BE, Kaissi A, Curoe A, Rockwood T. Measuring the culture of medical group practices. Health Care Manage Rev. 2005;30:184-93.

Kralewski JE, Wingert TD, Barbouche MH. Assessing the culture of medical group practices. Med Care. 1996;34:377-88.

Kruijthof K. Doctors orders. PhD thesis. Nieuwegein, the Netherlands: Badoux; 2005.

Pettigrew TF, Tropp LR. A meta-analytic test of intergroup contact theory. J Pers Soc Psychol. 2006;90:751-83.

Raelin JA. The clash of cultures: managers managing professionals. Boston: Harvard Business School Press; 1991.

Reynolds PD. Organizational culture as related to industry, position and performance: a preliminary report. J Manag Stud. 1986;23:333-45.

Roberts V, Perryman MM. Creating a culture for health care quality and safety. Health Care Manag. 2007;26:155-8.

Ross MH. The relevance of culture for the study of political psychology and ethnic conflict. Polit Psychol. 1997;18:299-326.

Schein EH. Culture: the missing concept in organization studies. Adm Sci Q. 1996;41:229-40.

Shortell SM, Zimmerman JE, Rousseau DM, Gillies RR, Wagner DP, Draper EA, Knaus WA, Duffy J. The performance of intensive care units: does good management make a difference?

Med Care. 2004;32:508-28a.

Shortell SM, Marsteller JA, Lin M, Pearson ML, Wu SY, Mendel P, Cretin S, Rosen M. The role of perceived team effectiveness in improving chronic illness care. Med Care. 2004;42:1040-8b. 
Shortell SM, Schmittdiel J, Wang MC, Li R, Gillies RR, Casalino LP, Bodenheimer T, Rundall TG. An empirical assessment of high-performing medical groups: results from a national study. Med Care Res Rev. 2005;62:407-34.

Smalarz A. Physician group cultural dimensions and quality performance indicators: not all is equal. Health Care Manage Rev. 2006;31:179-87.

Strack F, Hannover B. Awareness of influence as a precondition for implementing correctional goals. In The psychology of action: Linking cognition and motivation to behavior. Gollwitzer PM, Bargh JA. (eds) New York: Guilford Press; 1996:579-96.

Tajfel H. Social psychology of intergroup relations. Annu Rev Psychol. 1982;33:1-39.

Taylor S. Educating future practitioners of social work and law: exploring the origins of inter-professional misunderstanding. Child Youth Serv Rev. 2006;28:638-53.

Triandis HC. Cultural training, cognitive complexity, and interpersonal attitude. In Crosscultural perspectives on learning. Brislin R, Bochner S, Lonner W. (eds.) New York: Wiley; 1980:39-77.

Williams ES, Manwell LB, Konrad TR, Linzer M. The relationship of organizational culture, stress, satisfaction, and burnout with physician-reported error and suboptimal patient care: Results from the MEMO study. Health Care Manage Rev. 2007;32:203-12. 


\section{Tables}

Table 1: Statistical results in chronological order used for the development of the CG-Questionnaire $(n=237)$

\begin{tabular}{lllll}
\hline Order & $\begin{array}{l}\text { Physician } \\
\text { Present }\end{array}$ & $\begin{array}{l}\text { Manager } \\
\text { Present }\end{array}$ & $\begin{array}{l}\text { Physician } \\
\text { Preferred }\end{array}$ & $\begin{array}{l}\text { Manager } \\
\text { Preferred }\end{array}$ \\
\hline Number of questionnaires & 166 & 71 & 166 & 71 \\
\hline Number of statements & 60 & 60 & 60 & 60 \\
\hline $\begin{array}{l}\text { Cronbach's alpha, on } 60 \\
\text { statements }\end{array}$ & 0.88 & 0.87 & 0.90 & 0.87 \\
\hline $\begin{array}{l}\text { Number of components } \\
\text { (factor analysis) }\end{array}$ & 20 & 20 & 19 & 20 \\
\hline $\begin{array}{l}\text { Number of statements with } \\
\text { loadings above 0.50 in the } \\
\text { present situation, 0.60 in } \\
\text { the preferred situation }\end{array}$ & 43 & 30 & 29 \\
\hline $\begin{array}{l}\text { Number of statements with } \\
\text { a loading above 0.20 after } \\
\text { an item-total correlation }\end{array}$ & & 28 & 23 & 19 \\
\hline $\begin{array}{l}\text { Cronbach's alpha on the } \\
\text { reduced set }\end{array}$ & 0.75 & 0.70 & 0.79 & 0.76 \\
\hline $\begin{array}{l}\text { Number of components } \\
\text { (factor analysis) }\end{array}$ & 7 & 6 & 6 & 7 \\
\hline \begin{tabular}{l} 
Explained variance \\
\hline
\end{tabular} & $61 \%$ & $56 \%$ & $63 \%$ \\
\hline
\end{tabular}


Table 2: Statements in the CG-Questionnaire, rubricated in accordance with the Kralewski dimensions (* adapted statements from / $* *$ added statements to the original Kralewski questionnaire)

\begin{tabular}{|c|c|c|}
\hline $\begin{array}{l}\text { Kralewski } \\
\text { dimension }\end{array}$ & $\begin{array}{l}1- \\
20\end{array}$ & In our hospital... \\
\hline \multirow[t]{3}{*}{ Collegiality } & 1 & There is a great deal of informal consultation. \\
\hline & 7 & $\begin{array}{l}\text { There is a close collegial relationship among } \\
\text { the physicians. }\end{array}$ \\
\hline & 12 & $\begin{array}{l}\text { There is a strong sense of belonging to the } \\
\text { group. }\end{array}$ \\
\hline \multirow[t]{2}{*}{$\begin{array}{l}\text { Information } \\
\text { emphasis }\end{array}$} & 2 & $\begin{array}{l}\text { We rely heavily on computer-based } \\
\text { information when seeing a patient. }\end{array}$ \\
\hline & 8 & $\begin{array}{l}\text { We have very good methods to assure that } \\
\text { our physicians change their practices to } \\
\text { include new technologies and research } \\
\text { findings. }\end{array}$ \\
\hline \multirow[t]{3}{*}{$\begin{array}{l}\text { Quality } \\
\text { emphasis }\end{array}$} & 4 & $\begin{array}{l}\text { We encourage internal reporting of patient } \\
\text { care adverse events. }\end{array}$ \\
\hline & 9 & $\begin{array}{l}\text { There is an open discussion about clinical } \\
\text { failures. }\end{array}$ \\
\hline & 13 & We emphasize patient satisfaction. \\
\hline \multirow[t]{2}{*}{$\begin{array}{l}\text { Management } \\
\text { style }\end{array}$} & 5 & $\begin{array}{l}\text { The business office and administration are } \\
\text { considered to be a very important part of our } \\
\text { hospital. }\end{array}$ \\
\hline & 16 & $\begin{array}{l}\text { We expect our administrators to obtain and } \\
\text { provide us with information that helps us } \\
\text { improve the cost-effectiveness of our patient } \\
\text { care. }\end{array}$ \\
\hline \multirow[t]{2}{*}{ Cohesiveness } & 10 & $\begin{array}{l}\text { There is widespread agreement about most } \\
\text { moral/ethical issues. }\end{array}$ \\
\hline & 14 & $\begin{array}{l}\text { A rapid change occurs in clinical practice } \\
\text { among our physicians when studies indicate } \\
\text { that we can improve quality/reduce costs. }\end{array}$ \\
\hline \multirow[t]{2}{*}{$\begin{array}{l}\text { Business } \\
\text { emphasis }\end{array}$} & $15^{*}$ & $\begin{array}{l}\text { When purchasing medical equipment, } \\
\text { financial considerations are an important } \\
\text { factor. }\end{array}$ \\
\hline & $17 * *$ & $\begin{array}{l}\text { We only hire an extra physician if he/she is } \\
\text { cost-effective. }\end{array}$ \\
\hline \multirow[t]{2}{*}{$\begin{array}{l}\text { Organizational } \\
\text { trust }\end{array}$} & 3 & $\begin{array}{l}\text { Our compensation plan rewards physicians } \\
\text { who work hard for our hospital. }\end{array}$ \\
\hline & $18 * *$ & $\begin{array}{l}\text { There is a high degree of trust in the } \\
\text { decisions made by the board of directors. }\end{array}$ \\
\hline
\end{tabular}




\begin{tabular}{lll}
\hline Innovativeness & 11 & $\begin{array}{l}\text { Innovations by our medial doctors are highly } \\
\text { publicized. }\end{array}$ \\
\cline { 2 - 4 } & $19^{* *}$ & $\begin{array}{l}\text { Our policy plans always mention innovative } \\
\text { health care items. }\end{array}$ \\
\hline Autonomy & 6 & $\begin{array}{l}\text { There is a feeling that physicians are } \\
\text { autonomous but practice in the same } \\
\text { organization for support services }\end{array}$ \\
\cline { 2 - 3 } $20^{* *}$ & $\begin{array}{l}\text { The professional autonomy of physicians is } \\
\text { an important condition for the quality of } \\
\text { health care. }\end{array}$ \\
\hline
\end{tabular}


Table 3: Results of the CG-Questionnaire; statement 1 - 20 ANOVA ( $p$-value, significance 0.05$)$, mean and standard deviations of physicians and managers $(n=1239)$

\begin{tabular}{|c|c|c|c|c|c|c|}
\hline & Present & & & Preferred & & \\
\hline & $\begin{array}{l}\text { Physicians } \\
\text { mean } \\
(\mathrm{SD})\end{array}$ & $\begin{array}{l}\text { Managers } \\
\text { mean } \\
(\mathrm{SD})\end{array}$ & $\begin{array}{l}\text { ANOVA } \\
\text { p-level }\end{array}$ & $\begin{array}{l}\text { Physicians } \\
\text { mean } \\
(\mathrm{SD})\end{array}$ & $\begin{array}{l}\text { Managers } \\
\text { mean } \\
(\mathrm{SD})\end{array}$ & $\begin{array}{l}\text { ANOVA } \\
\text { p-level }\end{array}$ \\
\hline 1 & $\begin{array}{l}3.63 \\
(0.904)\end{array}$ & $\begin{array}{l}3.70 \\
(0.843)\end{array}$ & 0.243 & $\begin{array}{l}\mathbf{3 . 7 0} \\
(0.952)\end{array}$ & $\begin{array}{l}3.30 \\
(0.875) \\
\end{array}$ & $<0.0001$ \\
\hline 2 & $\begin{array}{l}\mathbf{2 . 9 8} \\
(1.033)\end{array}$ & $\begin{array}{l}\mathbf{2 . 9 7} \\
(0.995)\end{array}$ & 0.924 & $\begin{array}{l}\mathbf{3 . 7 5} \\
(0.950)\end{array}$ & $\begin{array}{l}\mathbf{4 . 1 5} \\
(0.778)\end{array}$ & $<0.0001$ \\
\hline 3 & $\begin{array}{l}\mathbf{2 . 1 3} \\
(0.982)\end{array}$ & $\begin{array}{l}\mathbf{2 . 5 6} \\
(0.956)\end{array}$ & 0.000 & $\begin{array}{l}\mathbf{4 . 0 3} \\
(0.901)\end{array}$ & $\begin{array}{l}\mathbf{3 . 6 1} \\
(0.913)\end{array}$ & $<0.0001$ \\
\hline 4 & $\begin{array}{l}3.60 \\
(0.960)\end{array}$ & $\begin{array}{l}\mathbf{3 . 7 4} \\
(0.924)\end{array}$ & 0.022 & $\begin{array}{l}4.46 \\
(0.616)\end{array}$ & $\begin{array}{l}\mathbf{4 . 6 8} \\
(0.526)\end{array}$ & $<0.0001$ \\
\hline 5 & $\begin{array}{l}\mathbf{3 . 5 9} \\
(0.921)\end{array}$ & $\begin{array}{l}\mathbf{3 . 0 0} \\
(0.908)\end{array}$ & 0.000 & $\begin{array}{l}\mathbf{3 . 2 9} \\
(0.970)\end{array}$ & $\begin{array}{l}\mathbf{3 . 8 2} \\
(0.731)\end{array}$ & $<0.0001$ \\
\hline 6 & $\begin{array}{l}\mathbf{2 . 5 5} \\
(0.985)\end{array}$ & $\begin{array}{l}\mathbf{3 . 1 8} \\
(1.035)\end{array}$ & 0.000 & $\begin{array}{l}\mathbf{2 . 4 9} \\
(1.174)\end{array}$ & $\begin{array}{l}\mathbf{2 . 0 1} \\
(0.921)\end{array}$ & $<0.0001$ \\
\hline 7 & $\begin{array}{l}3.27 \\
(0.969)\end{array}$ & $\begin{array}{l}\mathbf{2 . 7 7} \\
(0.900)\end{array}$ & 0.000 & $\begin{array}{l}4.32 \\
(0.667)\end{array}$ & $\begin{array}{l}4.04 \\
(0.665)\end{array}$ & $<0.0001$ \\
\hline 8 & $\begin{array}{l}\mathbf{2 . 7 9} \\
(0.950)\end{array}$ & $\begin{array}{l}\mathbf{2 . 6 3} \\
(0.825)\end{array}$ & 0.007 & $\begin{array}{l}4.20 \\
(0.720)\end{array}$ & $\begin{array}{l}\mathbf{4 . 2 4} \\
(0.615)\end{array}$ & 0.336 \\
\hline 9 & $\begin{array}{l}3.12 \\
(0.995)\end{array}$ & $\begin{array}{l}\mathbf{2 . 6 0} \\
(0.885)\end{array}$ & 0.000 & $\begin{array}{l}\mathbf{4 . 4 0} \\
(0.685)\end{array}$ & $\begin{array}{l}\mathbf{4 . 4 5} \\
(0.630)\end{array}$ & 0.256 \\
\hline 10 & $\begin{array}{l}\mathbf{3 . 5 9} \\
(0.830)\end{array}$ & $\begin{array}{l}3.40 \\
(0.817)\end{array}$ & 0.000 & $\begin{array}{l}4.17 \\
(0.694)\end{array}$ & $\begin{array}{l}\mathbf{4 . 2 1} \\
(0.645)\end{array}$ & 0.403 \\
\hline 11 & $\begin{array}{l}\mathbf{3 . 2 4} \\
(1.021)\end{array}$ & $\begin{array}{l}\mathbf{3 . 1 4} \\
(1.016)\end{array}$ & 0.126 & $\begin{array}{l}3.75 \\
(0.903)\end{array}$ & $\begin{array}{l}4.27 \\
(0.658)\end{array}$ & $<0.0001$ \\
\hline 12 & $\begin{array}{l}3.11 \\
(0.970)\end{array}$ & $\begin{array}{l}3.20 \\
(0.936)\end{array}$ & 0.185 & $\begin{array}{l}3.99 \\
(0.730)\end{array}$ & $\begin{array}{l}\mathbf{3 . 9 9} \\
(0.710)\end{array}$ & 0.982 \\
\hline 13 & $\begin{array}{l}\mathbf{4 . 0 0} \\
(0.816)\end{array}$ & $\begin{array}{l}\mathbf{3 . 7 9} \\
(0.835)\end{array}$ & 0.000 & $\begin{array}{l}4.57 \\
(0.599)\end{array}$ & $\begin{array}{l}\mathbf{4 . 7 5} \\
(0.481)\end{array}$ & $<0.0001$ \\
\hline 14 & $\begin{array}{l}\mathbf{3 . 1 1} \\
(0.959)\end{array}$ & $\begin{array}{l}\mathbf{2 . 8 9} \\
(0.880)\end{array}$ & 0.000 & $\begin{array}{l}4.28 \\
(0.677)\end{array}$ & $\begin{array}{l}\mathbf{4 . 4 1} \\
(0.610)\end{array}$ & 0.004 \\
\hline 15 & $\begin{array}{l}\mathbf{4 . 3 6} \\
(0.774)\end{array}$ & $\begin{array}{l}4.09 \\
(0.840)\end{array}$ & 0.000 & $\begin{array}{l}\mathbf{3 . 1 0} \\
(1.027)\end{array}$ & $\begin{array}{l}3.72 \\
(0.846)\end{array}$ & $<0.0001$ \\
\hline 16 & $\begin{array}{l}\mathbf{2 . 7 1} \\
(1.076)\end{array}$ & $\begin{array}{l}\mathbf{3 . 2 0} \\
(1.027)\end{array}$ & 0.000 & $\begin{array}{l}4.19 \\
(0.770)\end{array}$ & $\begin{array}{l}4.57 \\
(0.586)\end{array}$ & $<0.0001$ \\
\hline 17 & $\begin{array}{l}\mathbf{3 . 4 8} \\
(1.100)\end{array}$ & $\begin{array}{l}\mathbf{3 . 2 3} \\
(1.050)\end{array}$ & 0.000 & $\begin{array}{l}3.26 \\
(1.068)\end{array}$ & $\begin{array}{l}\mathbf{3 . 8 5} \\
(0.877)\end{array}$ & $<0.0001$ \\
\hline 18 & $\begin{array}{l}\mathbf{2 . 9 4} \\
(0.967)\end{array}$ & $\begin{array}{l}3.27 \\
(0.899)\end{array}$ & 0.000 & $\begin{array}{l}4.25 \\
(0.739)\end{array}$ & $\begin{array}{l}\mathbf{4 . 3 9} \\
(0.602)\end{array}$ & 0.002 \\
\hline 19 & $\begin{array}{l}\mathbf{3 . 8 4} \\
(0.829)\end{array}$ & $\begin{array}{l}3.90 \\
(0.872)\end{array}$ & 0.282 & $\begin{array}{l}4.03 \\
(0.775)\end{array}$ & $\begin{array}{l}\mathbf{4 . 3 2} \\
(0.671)\end{array}$ & $<0.0001$ \\
\hline 20 & $\begin{array}{l}3.66 \\
(0.951)\end{array}$ & $\begin{array}{l}3.51 \\
(0.827)\end{array}$ & 0.013 & $\begin{array}{l}\mathbf{4 . 2 4} \\
(0.825)\end{array}$ & $\begin{array}{l}\mathbf{3 . 4 5} \\
(0.894)\end{array}$ & $<0.0001$ \\
\hline
\end{tabular}




\section{Chapter 4}

\section{Stereotypical images between physicians and managers in hospitals}

Hanneke A.H.J. Klopper - Kes

Nienke Meerdink

Wim H. van Harten

Celeste P.M. Wilderom

Journal of Health, Organization and Management

2009, Volume 23, pp. 216-224 


\begin{abstract}
Purpose This study aims to apply the Image theory to the hospital context in order to add a perspective into the known complex relationship between physicians and hospital managers. This insight can enrich current intervention schemes used in health care to facilitate organisational change.
\end{abstract}

Design/methodology/approach In this study we apply the Image theory of Alexander et. al. (2005a/b) on the known complex intergroup context of physicians and hospital managers. The theory is operationalised in relative status, power and goal incompatibility.

Findings The data shows the three variables are highly relevant and representative. Hospital managers see physicians as higher in professional status and power, and having different goals. Physicians see hospital managers to have higher power, lower status and different goals. The study validates the applicability of the Image theory in the Dutch hospital context. This results in a questionnaire suitable for performing a quick scan on the strength and direction of intergroup stereotyping within hospital organisations.

Originality/Value Data from the questionnaire gives the opportunity to have insight in the way physicians and hospital managers perceive each other. This insight helps to focus attention on bottlenecks and possibilities in enhancing the cooperation between physicians and hospital managers. Research on the relationship between physicians and hospital managers is scarce and mostly of a qualitative nature. Our study is executed in both a qualitative and quantitative way, which enables us to empirically and statistically validate the data. The resulting questionnaire is applicable on an organisational intergroup level, while the focus in the extant literature is mostly on the interpersonal or intragroup level.

Keywords Stereotypical images; Cooperation; Hospital management; Quick scan Paper type Research paper 


\section{Introduction}

In this article we aim to explore the factors influencing the challenging complex relationship between physicians and hospital managers (Fitzgerald, 1994; Shortell et. al., 1994; Anderson \& Pullich, 2002; Dopson et. al., 2002; Davies, 2003; Kaissi, 2005; Plochg et. al., 2003). Physicians and hospital managers can be seen as two professional groups working within the same organisational setting. Both groups of actors are attached to their reference group (both emotionally and cognitively) and therefore have an own "social identity". Tajfel (1982, pp. 255) defines social identity as "knowledge that one belongs to a certain social group (or groups) together with the value and emotional significance attached to that group membership". Raelin (1991, pp. 1) describes the difficulties in the cooperation between physicans and hospital managers as: "The inherent conflict between managers and professionals results basically from a clash of cultures: the corporate culture, which captures the commitment of managers, and the professional culture, which socialises professionals". A situation like this can be seen as an intergroup conflict setting which has been studied in many research areas. Alexander et. al. (2005a/b) studied an interethnic conflict setting with the Image theory, this theory seems applicable for research in the hospital setting.

This paper presents the first application of the Image theory in a hospital setting. Out of intergroup literature we know that members of different cultural groups tend to exaggerate the experienced differences and diminish similarities (Tajfel, 1978; Turner et. al., 1987). Between different cultural groups there is a tendency to directly attribute characteristics to all individuals belonging to the other group (the outgroup). Therefore all members of an outgroup are seen as different compared to members of the ingroup. Such generalisations can lead to wrong conclusions about individual members of the outgroup, resulting in an intergroup conflict. The importance of intergroup conflict is stressed in organisational behavioural literature as recent studies show a relationship between efficacy of cooperation between groups and performance (Davies et. al., 2003; Berwick, 2004; Mohammed \& Angell, 2004; Mycek, 2004; Robyn \& Stone, 2004; Hinds \& Mortensen, 2005). In literature intergroup conflict commonly has a negative influence on performance. However, Jehn and Mannix (2001) specify the relationship between cooperation and performance as depending on the kind of conflicts. They found task, relationship and process conflicts have a different impact on the performance in the intergroup setting. Advanced technological innovations and external demands by patients, insurers and government lead to the necessity of improving quality of care for instance through the translation and implementation of operations management techniques. According to Galinsky (2002, pp. 105): "Conflict and stereotyping between groups in an organisation can hinder the ability of an organisation to maximise its potential".

This study focuses on applying the Image theory to the hospital setting in order to enlarge comprehension of the known complex intergroup work relations between physicians and hospital managers. Above this, applicability of the Image theory in the hospital setting could also provide new interventions (proven to be appropriate in other research areas) to enhance the cooperation between physicians and hospital managers, and therewith performance. We investigate one of the strongest expressions of intergroup differences: stereotypical images. 


\section{Theory}

This study is based on the Image theory (Alexander et. al., 2005a) because it emphasises the "role of intergroup context and perceived intergroup relations in shaping the content of social stereotypes" (pp. 781). In intergroup situations, perceptions of the outgroup determine the way reality is experienced. Diverse perceptions are derived from different scores on goal incompatibility, relative status and relative power (Alexander et. al., 2005a, pp. 783). In health care literature these three variables seem to be applicable to explore the physician-hospital manager relationship. Developments in health care (such as standardisation and reports on performance indicators (Davies, 2003) raise the issue of relative power and status and goal differences between physicians and hospital managers. In health care settings there is a complex division of power between physicians and hospital managers (Ashburner et. al., 1996; Addicott \& Ferlie, 2007). Hunter (1996) states that "The cookbook variety (i.e. every aspect of medical care can be described in a protocol or clinical pathway) is seen as threatening both to the status of professionals and to the power and privileges they enjoy, as well as to the nonscientific aspects of professional work based on experience and judgment" (pp. 800). On the other hand, Edwards (2003) states that "In the United Kingdom doctors are still the most trusted of all professions" and "Rather than seeing guidelines and accountability systems as a threat to autonomy there is an argument that they are an essential adjunct to if' (pp. 21). Both groups have the power to influence the primary process, whereas it is obvious that the managers influence is more indirect, for example through financial or staffing conditions. From the above we can conclude that the three variables power, status and goal incompatibility are possible key variables to study perceptions of the context physicians and hospital managers are working in (Alexander et. al., 2005a): Relative power is the degree of perceived inequalities in economic and political resources that can affect relevant outcomes for the ingroup.

Relative status is the degree of perceived differences in social and professional position and the perceived importance of the role of the ingroup in the hospital relative to the outgroup.

Goal incompatibility is the degree of perceived dissimilarity in the goals of the ingroup relative to the outgroup.

There is an extensive amount of research on how to overcome potential difficulties in problematic intergroup contexts (Sherif, 1954;1961; Galinsky, 2002; Jehn et. al., 1999). From these studies it was concluded that contact alone is not enough, a way of cooperation has to be found to reach effective contact. Galinsky (2002) mentions the importance of superordinate goals. Superordinate goals create a state of interdependence between groups and create common problems along. The goal of this study is to add a perspective to the known complex relationship between physicians and hospital managers, with the intention of enriching current intervention schemes which can help to facilitate more effective cooperation between members of both groups.

\section{Methods}

The questionnaire we developed is based on the Image theory instrument of Alexander et. al. (2005a/b). We adapted this instrument to the hospital context so that the focus is on perceptions of physicians on hospital managers and vice versa. In order to enhance 
reliability and validity of the study, we verified the translation of our questionnaire by back translating it into the original language by an independent translator. The questionnaire we developed aims to measure the power, status and goal differences perceived by physicians and hospital managers. Perceptions of relative status and relative power are assessed with two questions comparing physicians and hospital managers $(1=$ the outgroup scores lower than the ingroup to $7=$ the outgroup scores higher than the ingroup). The same is done for measuring perceptions of goal incompatibility (scoring $1=$ strongly disagree to $7=$ strongly agree) on three questions. To explore the stereotypical images physicians and hospital managers have about each other, 26 statements (based on the statements from the Image theory (Alexander et. al., 2005a)) are adapted to the hospital context. The statements are assessed with a 7-point Likert scale $(1=$ strongly disagree to $7=$ strongly agree).

In order to ensure the appropriateness of each of the questions and statements to the hospital context we further investigated and analysed the adapted questionnaire by interviewing nine physicians from surgical, internal and supportive specialties and six hospital managers, board members and hospital managers in different hierarchical positions from different hospitals. The respondents were interviewed about their perceptions of the relationship between physicians and hospital managers within their hospital. Furthermore we asked the respondents to fill out the questionnaire, in our presence. Concludingly we posed 11 questions about the clarity, redundancy, lay out, relevancy and other format related aspects of the questionnaire. The interviews were recorded on tape and accordingly laid down in writing. The interviews were semistructured, and the same questions were posed to all respondents. Every interview lasted approximately one hour. Based on the comments of respondents we improved the clarity of the language used in the questionnaire after every interview until there were no further remarks.

For our quantitative study the questionnaire was sent to all physicians and hospital managers of four different Dutch general hospitals $(\mathrm{N}=400)$. The hospitals were chosen on their geographical location and size in order to cover differences between urban and rural areas and small, medium, and large general hospitals. This increases the likelihood of generalisability of the conclusions to all Dutch general hospitals.

\section{Findings}

From the 400 questionnaires sent, the response rate was $41.5 \%$, consisting of 107 physicians and 59 managers. The sampling distribution is maintained: $64.5 \%$ of the respondents are physicians and $35.5 \%$ are hospital managers. In order to obtain the Cronbach's alpha the data were split in 2 groups: physicians and hospital managers. For both groups the Cronbach's alpha is high. Physicians score a 0.938 and hospital managers score a 0.840 , hence the questionnaire seems to measure a uni-dimensional construct. This conclusion is supported by the results of a factor analysis.

The standard deviations on questions about perceptions of professional status, power and goal incompatibility show there is a high intragroup cohesiveness within the group of physicians and within the group of hospital managers (see Table 1). 


\begin{tabular}{|c|c|c|c|c|c|c|}
\hline & & $\mathbf{N}$ & Min & $\operatorname{Max}$ & Mean & Std. Deviation \\
\hline \multirow{5}{*}{$\begin{array}{l}\text { Medical } \\
\text { doctors' } \\
\text { perceptions } \\
\text { about hospital } \\
\text { managers }\end{array}$} & Professional status & 103 & 1 & 6 & 3.07 & 1.031 \\
\hline & Power & 103 & 1 & 7 & 4.69 & 1.475 \\
\hline & $\begin{array}{l}\text { Overall goal: delivery } \\
\text { of care }\end{array}$ & 104 & 1 & 7 & 5.09 & 1.981 \\
\hline & Subgoals & 102 & 1 & 7 & 5.14 & 1.724 \\
\hline & Scope & 103 & 1 & 7 & 4.93 & 1.745 \\
\hline \multirow{5}{*}{$\begin{array}{l}\text { Hospital } \\
\text { managers' } \\
\text { perceptions } \\
\text { about medical } \\
\text { doctors }\end{array}$} & Professional status & 59 & 2 & 7 & 5.24 & 1.104 \\
\hline & Power & 59 & 2 & 7 & 5.29 & 0.966 \\
\hline & $\begin{array}{l}\text { Overall goal: delivery } \\
\text { of care }\end{array}$ & 59 & 1 & 7 & 5.08 & 1.932 \\
\hline & Subgoals & 59 & 2 & 7 & 5.20 & 1.362 \\
\hline & Scope & 59 & 3 & 7 & 5.95 & 0.936 \\
\hline
\end{tabular}

Table 1: Descriptive statistics of medical doctors $(n=107)$ and hospital managers $(n=59)$ about status, power and goal incompatibility

\section{Conclusion and Discussion}

Results of both the pilot and quantitative study confirm the applicability of the Image theory to the hospital organisational context. The three variables (power, status and goal incompatibility) distinguish between the groups of physicians and hospital managers.

Power, status and goal incompatibility give a good insight in the direction and strength of the stereotypical image of the outgroup, while it took a limited amount of data to be gathered. The 26 statements illustrate the content of the stereotypical images both groups have about each other (see table 2).

The scores on professional status clearly show both groups agree on the higher professional status of physicians. The scores on power show both groups disagree on who is higher in power. Physicians see hospital managers as being higher in power and hospital managers see physicians as being higher in power. This means both groups feel relatively "powerless" in the same organisation. Both groups perceive a goal incompatibility with the outgroup. This result points at a possible level of friction between both groups.

According to Alexander et. al., (2005a/b), stereotypical images of physicians lead to a behavioural orientation of defensive protection towards the outgroup (the hospital managers). This means physicians will a priori probably tend not to accept suggested organisational improvements by hospital managers. Above this, in addition possible organisational improvements, leading to changes in daily medical practices are not likely to be proposed by physicians to hospital managers.

In analogy, stereotypical images of hospital managers could lead to feelings of resistance toward the outgroup (Alexander et. al., 2005a/b). This can resolve in negative interpretations by hospital managers concerning acts performed by physicians, possibly leading to an emplification of existing stereotypical images. These mechanisms may 
hamper the establishment of more effective cooperation between the two professional groups.

These results are supported by the interviews with both physicians and hospital managers. Both groups stated that an "understanding of each other" would be very important to have a healthy relationship and "this was often not the case". A hospital manager stated that "if they should know what I could offer them, and know what kind of things they could all use me for, our relationship and cooperation would not be such a problem." There are misunderstandings on the professional and personal level ("Why would I need a hospital manager?", "Why don't physicians see what I mean?", and "They are just stubborn and do not want to listen to what I have to say and add", both physicians and hospital managers stated this). Hospital managers think physicians do not understand why hospital managers are there and physicians think hospital managers do not understand the essential needs for physicians. Important for the aim of our study is to find areas where these differences can be overcome.

\section{Hospital managers are seen by physicians as}

Not to be good leaders with the best intentions for the hospital

Pushing the limit, they try to go as far as possible

Enjoying to get it their way, even if this will spoil things for others

Not deserving an equal influence on the organisation

Threatening physicians in their status and power

Not aware of what is important for physicians

Physicians are seen by hospital managers as

Lacking insight in the long term

Stubborn, they would rather have a conflicting discussion than talk sense

when solving a point of disagreement

Not to be good leaders with the best intentions for the hospital

Ruthless and try to stay in power as long as they are the biggest and the strongest

Pushing the limit, they try to go as far as possible

Trying to avoid control

Arrogant and convinced they are superior to other groups

Not trying to avoid any conflict with hospital managers

Enjoying to get it their way, even if this will spoil things for others

Not working hard for a good relationship with management

Not aware of which added value hospital managers can offer

Table 2: Statements illustrating the content of stereotypical images of physicians and hospital managers.

The Image theory gives insight in the direction and strength of stereotypical images based on differences in power and status and goal incompatibility. This insight could be input for possible interventions to diminish stereotypes. Jehn et. al. $(1997 ; 1999 ; 2001)$ performed several studies on group conflict and related performance, describing relationship-, task- and process conflicts. Relationship and process conflict are negatively related to group performance and satisfaction of the group members. On the other hand, a moderate level of task conflict has a positive effect on performance on 
complex cognitive tasks. Our results mainly point towards a relationship- and process conflict between physicians and hospital managers, and not so much a task conflict. A possible way of intervening in the intergroup conflict between physicians and hospital managers is by defining superordinate goals (and deducted complex cognitive problems, (Galinsky, 2002)) and therewith create a state of interdependence. This could lead to enhanced cooperation between both groups and will facilitate the process of diminishing the relation- and process conflict (Jehn \& Mannix, 2001). Practically this means when physicians and hospital managers are cooperating in a project, focus of the project manager should be at defining superordinate goals on which both groups agree and for which both groups need each other to achieve the defined goals. For example, our research showed both groups highly value a more effective cooperation among each other and share a focus on patient related problems. When defining project goals, the perspective from the patient's point of view could be helpful to overcome the goal incompatibility between physicians and hospital managers we found in our study. Task conflict could be benificial in the cooperation and forthcoming performance (Jehn \& Mannix, 2001). Defining complex themes around a superordinate goal, in which differences of viewpoints and opinions have to be discussed, might enhance project outcomes. An example of this could be the introduction of market elements and its translation in the hospital organisation. This creates a possible external threat and therewith a superordinate goal of for example preservation of patientvolumes. Project methods should aim at discussing how to safeguard patientflows on a rational level. The probable different viewpoints physicians and managers have on solutions for the problem can be seen as a task conflict (physicians will probably focus on extra capacity, while managers search for more efficiency). If a project manager handels this well, the focus will be on task conflicts in stead of relationship- or process conflicts. "The mututal collaboration necessary for successful completion of an interdependent task, promotes a desire for accurate knowledge of one's partner in order to anticipate their actions and thus individuating information is utilised over stereotypes" (Galinsky, 2002, pp. 95). Purposeful defining superordinate goals and using the positive effects of task conflict could be the input for reducing relationship conflict. Future research should be aimed at exploring these conclusions.

The study is performed in Dutch general hospitals, therefore, the applicability of the questionnaire is only confirmed in this setting. Based on literature review and the results of this study we expect the questionnaire to be suitable for other health care settings, such as academic, non-Dutch, profit and categorical hospitals. However, before applying the Image theory in other settings, validation is required. The need for effective cooperation between members of professional groups within hospitals is not restricted to physicians and hospital managers. The applicability of the questionnaire should be validated for other groups (nurses, physiotherapists, psychologists etc.) in their intergroup relation in the hospital setting.

Based on the relevance of the three variables, mean scores and the standard deviations presented in table 1 we come to a concise questionnaire. With this questionnaire it is possible to perform a quick scan suitable for measuring stereotypical images between physicians and hospital managers (see Table 3). We chose to use a 10 point Likert scale because this scale is very well known within the Dutch system, every number has a known value. A 10 point scale also gives the opportunity for a high variation in answering for respondents. 
Quick scan

What is the level of power physicians have on hospital policy?

What is the level of power hospital managers have on hospital policy?

What is the level of professional status of physicians?

What is the level of professional status of hospital managers?

To what extent align professional goals of physicians and hospital managers?

Table 3: Quick scan measuring stereotypical images between physicians and hospital managers

This research validates the applicabality of the Image theory in the hospital setting and gives insight in the strength and direction of the stereotypical images between physicians and hospital managers. A balance has to be found between physicians seeing organisational improvements as limiting the professional freedom and possibilities and hospital managers seeing physicians as being stubborn and not seeing the greater picture. Insight in the strength and direction of status and power differences and goal incompatibility between physicians and hospital managers can be the input for defining the difficulties both groups are faced with when cooperating. When phsycians and hospital managers diminish relationship- and process conflict and focus on task conflicts, the effectiveness of cooperation is likely to rise. A startingpoint for improving the balance and cooperation could be the area we found common understanding between physicians and hospital managers: patient related problems. Based on knowledge from the Image theory, we recommend to start improving the hospital organisation on the micro level. Focusing on improving patient processes on an operational level can align medical and organisational goals, because this is an area where medical professional and organisational improvements can go hand in hand. This could lead to a better cooperation between physicians and hospital managers so that improvements on organisational level will be possible to execute. 


\section{References}

Addicott R, Ferlie E. Understanding power relationship in health care networks. J Health Organ Manage. 2007;21:393-406.

Alexander MG, Brewer MB, Livingston RW. Putting stereotype content in context: Image theory and interethnic stereotypes. J Pers Soc Psychol. 2005a;31:781-94.

Alexander MG, Levin S, Henry PJ. Image theory, social identity and social dominance: structural characteristics and individual motives underlying international images. Pol Psychol. 2005b;26:27-45.

Anderson P, Pulich M. Managerial Competencies Necessary in Today's Dynamic Health Care Environment. Health Care Manage. Vol. 2002;21:1-11.

Ashburner L, Ferlie E, FitzGerald L. Organizational transformation and top-down change: the case of the NHS. Brit J Manage. 1996;7:1-16.

Berwick DM. Crossing the Quality Chasm: Health Care for the 21st Century. Washington: National Academy Press; 2004.

Davies HTO, Hodges CL, Rundall TG. Views of doctors and managers on the doctormanager relationship in the NHS. BMJ. 2003;326:626-8.

Davies HTO. Trends in doctor-manager relationships. BMJ. 2003;326:646-649.

Dopson S, FitzGerald L, Ferlie E, Gabbay J, Locock L. No magic targets! Changing clinical practice to become more evidence based. Health Care Manage Rev. 2002;27:35-47.

Edwards N. Doctors and managers: poor relationships may be damaging patients what can be done? Qual Saf Health Care. 2003;12:21-24.

FitzGerald L. Moving clinicians into management: a professional challenge or threat? J Manage Med. 1994;8:32-44.

Galinsky AD. Creating and reducing intergroup conflict: the role of perspective taking in effecting out-group evaluations", Research on managing groups and teams. 2002;4:85113.

Hinds PJ, Mortensen M. Understanding conflict in geographically distributed teams: the moderating effects of shared identity, shared context, and spontaneous communication. Organ Sci. 2005;16:290-307.

Hunter DJ. The changing roles of health care personnel in health and health care management. Soc Sci Med. 1996;43:799-808. 
Jehn KA. A qualitative analysis of conflict types and dimensions in organization groups Admin Sci Quart. 1997;42:530-57.

Jehn KA, Nortkraft GB, Neale MA. When differences make a difference. A field study of diversity conflict and performance in work groups. Admin Sci Quart. 1999;44:741-63.

Jehn KA, Mannix E. The dynamic nature of conflict: a longitudinal study of intragroup conflict and group performance. Acad Manage J. 2001;44:238-51.

Kaissi A. Manager-Physician Relationships: an Organisational Theory Perspective. Health Care Manage Rev. 2005;24:165-76.

Mohammed S, Angell LC. Surface- and deep-level diversity in workgroups: examining the moderating effects of team orientation and team process on relationship conflict. $J$ Organ Behav. 2004;25:1015-39.

Mycek S. Getting to know you, an open dialogue between the board and physicians will jump-start better relations. Trustee. 2004;4:23-5.

Plochg T, Lombarts K, Witman Y, Klazinga N. Problems in Dutch hospitals resemble those in British hospitals. BMJ. 2003;22:656.

Raelin JA. The clash of cultures: managers managing professionals. Boston: Harvard Business School Press; 1991.

Robyn RM, Stone PW. Measurement of organizational culture and climate in healthcare. Jona. 2004;34:33-9.

Sherif M, Harvey OJ, White BJ, Hood WR, Sherif CW. Intergroup conflict and cooperation: the Robbers Cave experiment. available at: http://psychclassics.yorku.ca/Sherif/chap1.htm (accessed 14 Octobre 2007); 1954/1964.

Shortell SM, Zimmerman JE, Rousseau DM, Gillies RR, Wagner DP, Draper EA, Knaus WA, Duffy J. The performance of intensive care units: does good management make a difference? Med Care. 1994;32:508-25.

Tajfel H. Differentiation between social groups: studies in the social psychology of intergroup relations. London: Academic press; 1978.

Tajfel H. Social psychology of intergroup relations. Annu Rev Psychol. 1082;33:1-39.

Turner JC, Hogg MA, Oakes PJ, Reicher SD, Wetherell MS. Rediscovering the social group: a self-categorization theory. Oxford: Blackwell; 1987. 


\title{
Chapter 5
}

\section{Differences within the groups of physicians and managers in Dutch hospitals providing leads for intergroup cooperation}

\author{
Hanneke A.H.J. Klopper - Kes \\ Nienke Meerdink \\ Andrew Vincent \\ Celeste P.M. Wilderom \\ Sabine Siesling \\ Wim H. van Harten
}




\section{Abstract}

Background: Effective cooperation between physicians and managers is difficult to achieve but is an important factor in successfully implementing improvement initiatives in hospitals. Intergroup literature suggests that large differences between groups hinder effective cooperation.

Purposes: Analyse the variation on culture,- stereotype,- and satisfaction scores, within groups of physicians and managers, to identify subgroups that can be focused on when effective cooperation with the other group is needed.

Methodology: We used the GAHP-questionnaire which assesses the size and content of differences on culture, stereotyping, and satisfaction within and between groups of physicians and managers. The GAHP-questionnaire was sent to all physicians and managers of 46 Dutch general hospitals. Unadjusted and adjusted linear mixed effect models were used to determine significant intragroup differences, related to the demographic characteristics age and gender. For physicians we also analysed profession, influences of management participation, and type of medical staff organisation. For managers we included the hierarchical position.

Findings: The response included in the analyses consisted of 888 physicians (24\%) and 280 managers (45\%) from 37 hospitals. The Cronbach's alphas were 0.70 to 0.79 . Statistical analysis indicated many differences between the subgroups. Managers have a more homogeneous scoring pattern compared to physicians, though executive managers score the smallest gaps with physicians on relative power. For the physicians we see that the subgroups with characteristics female, medical, and physicians who participate in management more than $25 \%$ of their time, have the least differences with manager scores. 
Practice implications: This study shows that diversity within the groups of physicians and managers provides leads to identify members of subgroups, who differ less from members of the other group. The results of our study could be used by hospital organisations to prevent staff-management conflicts and to create multidisciplinary teams that are more likely to cooperate effectively.

Keywords: intergroup theory, cooperation, physicians, managers, hospital management, quality improvement. 


\section{Introduction}

Hospitals in Western countries are stimulated to improve quality of care and efficiency by the strengthened position of the patient and through the introduction of new financial structures that link quality performance with financial stimuli (for example pay for performance and managed care). One of the means to foster organisational performance is implementation of quality management. Literature emphasises effective cooperation as one of the key factors in accomplishing this objective (Shortell, 2000, 2004, 2005; Taylor 2006; Roberts \& Perryman, 2007; Klopper et. al., 2011). Cooperation between physicians and managers is an important factor that influences the effectiveness of an organisation, due to the decisive influence that these groups have in policy decisions on healthcare quality (FitzGerald, 1994; Davies et. al., 2003). Increasingly, improvement initiatives contain elements from "operations management" such as EFQM- and Baldridge models, disease management and process redesign. Physicians are easily estranged from these as they seldom explicitly refer to professional standards and often are seen as manager-initiated (Maclaughlin \& Kaluzny, 1990). Smalarz (2006) assumes that the culture of collegiality in a physician group might even create resistance to quality improvement initiatives. Apart from this, physicians feel that quality initiatives often focus on efficiency improvement instead of improvement of medical practices (Klopper et. al., 2009) and that the managerial values dominate physicians' professional values (Edwards, 2003). On the other side, quality improvements initiated by physicians, such as protocols and guidelines (Klazinga, 1996), often lack involvement and support of managers. 
Kaissi et. al. (2005) conclude that the goal for physicians is to deliver best care for each individual patient. Managers, on the other hand, strive for a hospital organisation which can provide continuity of care for all patients. Whereas physicians highly value their professional standards and autonomy, managers value hospital wide standardisation and structures. The different views physicians and managers have on organisational and professional practices hinder the increasing need for effective cooperation between both groups and therewith hospital performance. Raelin (1991) and Golden et. al. (2000) describe the complex relationship between both groups as a "professional clash". Davies et. al. (2003) point out that the views of physicians and managers differ depending on their role in the organisation. They conclude that the divergence between both groups should be addressed to avoid difficulties in implementing modernisations.

Given the described complex context, insight is needed into the content and size of the differences between physicians and managers. Schein (1996) conceptualises organisational culture into three layers: basic assumptions, artifacts, and values and beliefs. The basic assumptions are mainly implicit and therefore not directly measurable. The artifacts are the distinguishable expressions of organisational culture. When you walk into a hospital, the different professional groups are immediately apparent. For example, physicians almost always wear their white coats and stethoscopes, some even during lunch or management meetings. This distinguishes them from all other groups in the hospital. Managers are less visible with regard to their appearances. They do, however, differ from physicians, for example in their use of language (management jargon) which is very often not understood by physicians (Klopper, 2011). Studying artifacts is mainly feasible in qualitative research. We wanted to study the differences 
between physicians and managers quantitatively, aiming at perceptions of daily practices related to Schein's third culture layer: values and beliefs. We refer to different perceptions, based on the described culture dissimilarities between physicians and managers (Klopper et. al., 2010), as gaps.

The complex cooperation, related to differences in professional cultures between physicians and managers, combined with the fact that both groups are working within the same organisational setting, can be seen as an intergroup conflict setting (Turner et. al., 1987). In intergroup conflict settings, people tend to exaggerate differences between both groups, leading to stereotyping (Alexander et. al., 2005a). When a group has stereotypical beliefs about another group, information is filtered towards the stereotypical image of the other group, leading to negative images, making it hard to cooperate with members from the other group. Members of different cultural groups tend to exaggerate the experienced differences and diminish similarities (Turner et. al., 1987) and different cultural groups tend to attribute characteristics to all individuals belonging to the other group (the outgroup). The larger the differences, the more difficult it will be to effectively cooperate (Klopper et. al., 2010; Ross, 1997; Easen et. al., 2000; Gershon et. al., 2004; Taylor, 2006; Roberts \& Perryman, 2007). As recent studies show a relationship between efficacy of cooperation between groups and performance the concepts of differing culture perceptions and intergroup conflict may be valuable in analysing the underlying mechanisms of successful cooperation (Davies et. al., 2003; Mohammed \& Angell, 2004; Mycek, 2004; Robyn \& Stone, 2004). The organisational dynamics between physicians and managers and the influence on hospital performance of cultural differences involved in effective cooperation are depicted in a graphic (Figure 1, Klopper et. al., 2011). 
In this study we elaborate on the intragroup differences by measuring subgroup differences based on culture related perceptions, stereotyping, and satisfaction scores. We searched for members within the groups of physicians and managers, which show most resemblance with members of the other group.

\section{Hypotheses related to culture, intergroup stereotypes and satisfaction} differences.

Pettigrew and Tropp (2006) presented a meta-analytic test of intergroup contact theory with 713 independent samples from 515 studies. From this extensive review we learn that meaningful contact between two groups lessens stereotypical behaviour (smaller stereotypical gaps) and therewith enhances cooperation. According to the Intergroup Similarity-Attraction hypothesis (Turner, 1982), cooperative intergroup relations can best be achieved when members of the groups experience similarity with outgroup members (Rokeach, 1980). The assumed mechanism in the similarity-attraction hypothesis is that if an initiative is embraced by a member of the own group, this initiative is more likely to be accepted by the other group members (Turner, 1982). Earlier we described that culture related aspects, stereotyping, and satisfaction scores can be used to identify differences within (intragroup) and between (intergroup) the groups of managers and physicians (Klopper et. al., 2009/2010).

The extant healthcare literature has surprisingly few studies concerning the intragroup differences of physicians and managers. We hypothesise these differences into three types of characteristics: differences based on demographics, on types of activity, and on employment characteristics. 
Demographic differences within the groups of physicians have been studied predominantly from a physician / patient point of view (Bertakis et. al., 1995). In the literature we see differences within the groups of physicians and managers based on gender (Stockard et. al., 1988; Roter et. al., 2002; Van Vugt et. al., 2007), and age (Morris \& Sherman, 1981; Kalleberg \& Loscocco, 1983) related to style of work, communication, and motivation. Data on employment with the hospital or association in the within hospital firm of physicians suggest that problems with cooperation and lack of social competence exist in both subgroups (Lens \& Van der Wal, 1994).

Executive and mid-line managers have a greater distance from the hospital work floor than front-line managers who work closely together with physicians. Literature suggests that especially mid-level managers experience difficulties in achieving their goals (Patrick, 2006). In terms of the activity based characteristics there is some literature already, showing that physicians who take op management tasks (Schneller, et. al., 1997; Scholten \& Van der Grinten, 2002; Malcolm, et. al., 2003, Kruijthof, 2005) become more involved in the hospital organisation and develop better cooperation with managers.

Hypothesis 1: There are differences on culture- and stereotyping scores within the groups of physicians and managers based on demographic characteristics.

Hypothesis 2: physicians employed by or having their own within hospital firm, do not show significant intragroup differences.

Hypothesis 3: front-line managers will score smaller differences with physicians than mid-line and executive managers. 
Hypothesis 4: Physicians who are not involved in organisational activities score significantly larger differences to managers than physicians with such involvement.

\section{Methods}

The differences between physicians and managers were measured with the GAHPquestionnaire (Table 1). The GAHP-questionnaire was validated in two studies in five Dutch hospitals (Klopper et. al., 2009/2010). The reliability of the questionnaire was determined with the Cronbach's alpha. Paired sample T-tests and ANOVA were used to determine significant differences between answers to the statements between physicians and managers. A p-value below 0.05 was considered to be statistically significant. The magnitude and direction of gaps were determined with descriptive statistics (mean, standard deviation and the lower and upper bound of the $95 \%$ confidence interval). The Cronbach's alphas were above 0.70 (meaning a high consistency). We showed that the GAHP-questionnaire is able to reveal culture gaps between physicians and managers in Dutch hospitals. The GAHP-questionnaire is a survey instrument, comprising of three different approaches (Klopper et. al., 2009/2010): "culture gaps", "stereotypical gaps", and "satisfaction gaps". Culture gaps were operationalised in 20 statements asking about the perception of daily practices each on a five-point Likert scale going from full agreement to total disagreement; respondents were asked to score for both the present and preferred situation (Klopper et. al., 2010). The actual organisational reality, as perceived by members of both groups, is reflected in answers given on statements about the present situation. In the daily hospital reality physicians and managers have to negotiate and this determines the perceptions both groups have about the present situation; answers given to the statements in the preferred situation reflect the desired situation, (Berrio, 2003) revealing the inherent 
cultures of physicians and managers. The larger the size of a culture gap, the larger the latent conflict between the two professional groups. If a culture gap in the preferred situation has a different content or is larger compared to the present situation, it could mean that physicians and managers would change their practice or organisation, when acting without the other party. In such a case there could be tension between members of the groups which can lead to a potentially stressful relationship. The second approach is based on the image theory (Alexander et. al., 2005a/b; Klopper et. al., 2009); the instrument measures stereotypical images between physicians and managers and consists of five questions on a 10 point scale going from "hardly any" to "extremely much". Four questions concern the relative power on hospital policy and professional status of physicians and managers. The fifth question assesses the goal compatibility between both groups. The differences in scores on the questions about relative power, status and goal compatibility are further referred to as "stereotypical gaps". The third approach contains three questions on a 10-point scale assessing satisfaction with quality-of-care, cooperation, and the way innovations were implemented (further referred to as "satisfaction gaps") (Klopper et. al., 2010).

Ten different gaps were derived from the three components of the GAHP-questionnaire: two from the culture gaps (present and preferred gap), five from the stereotypical images (power and status of physicians, power and status of managers, and goal incompatibility), and three from the satisfaction questions (quality, innovation, and cooperation). The gaps were calculated as the magnitude of the difference of all pairings of physicians and managers working within the same institution. For the two culturegaps, the magnitudes of the differences between the two individuals were summed over 
the 20 culture gap questions. The association between the size of gaps and particular factors (physician and manager characteristics) were assessed using (mixed effect model) likelihood ratio tests.

Apart from the measurement of the ten gaps, we asked the respondents for demographic and other characteristics including gender, age, type of profession (surgical, medical, diagnostic), and hierarchical position of managers (executive, midlevel or front-line). For physicians we added the degree of management participation and association with, or employed with the hospital.

The associations between the ten gaps and the professional subgroups were determined using both unadjusted and adjusted linear mixed effects models. The unadjusted models consisted of either a solitary subgroup variable or pair of subgroup variates with their interaction. These models addressed the following two questions (1) which subgroups have the smallest gaps? and (2) Which pair of subgroups is most (dis)similar? A sensitivity analysis was performed by ensuring that any significant results were unaffected by the inclusion of the remaining individual characteristics as confounders (see Table 2). In these models two non-nested random intercepts were implemented using the physician and manager variates as random grouping variables. Due to the non-normality of the gap distributions, the analysis was on squareroot transformed gaps. Given the large number of multiple tests performed we report both the $p$-values and the false discovery rates (FDR) for associations with FDR values less than 0.3 (Strimmer, 2008). The intraclass correlations were calculated as the ratio of the within-individual and total variances. The within-individual variance is the sum of the 
variance estimates of the two random effects (physicians and managers) in the linear mixed effects models, which included personal characteristics (see Table 2) as fixed effects. Differences in the response rates, age (grouped as 35-44, 45-54, 55+) and gender between participating physicians and managers were tested using CochranMantel-Haenszel tests stratified by institution. Associations between return rates and the location and type of hospital were tested using logistic mixed effects models with hospital as the random grouping variate. QQ-plots were used to determine appropriate normality transformations for all questionnaire outcomes and associated gaps. All analyses were performed using R v2.9.2.

\section{Findings}

In 2007 there were 86 general hospitals in the Netherlands, of these 46 agreed to participate in our study, and in May 2007 a total of 3941 physicians and 680 managers received an invitation to complete the questionnaire on our website. The participating general hospitals were classified as small, medium, large, and teaching hospitals, and geographically spread over The Netherlands. At the end of the study period, October 2007, there were responses from both physicians and managers from 37 hospitals. Responses were also received from an additional 9 hospitals, but they were excluded as there was not a response from at least one manager and one physician in these hospitals. The response rate for the 37 hospitals analysed in this study for physicians was $24 \%$ (888/3701) and for managers $45 \%$ (280/616), $p<0.0001$. We performed nonrespondent analyses which indicated that the return rates for the two groups of professionals was not significantly associated with either location (physicians $p=0.91$; and managers $p=0.07$ ) or institute type (physicians $p=0.57$; and managers $p=0.33$ ). Table 2 provides an overview of the characteristics of the groups of physicians and managers.

The majority of the participating professionals were male and between 45 and 54 years of age. The representation of females in management was higher $(35 \%)$ than in the 
physicians group (24\%) $(\mathrm{p}=0.0002)$. In reverse, there was a lower representation of managers over 54 years (14\%) than physicians over 54 years $(22 \%)(p=0.002) .56 \%$ of the participating physicians reported performing no managerial tasks, $19 \%$ spent up to $10 \%$ of their time on such tasks and $25 \%$ spent between $11 \%$ and $50 \%$. Seven physicians reported spending more than $50 \%$ of their time on managerial tasks, however they still identified themselves as physicians.

There are many intragroup differences within the groups of physicians and managers related to personal characteristics. Although there are subgroups which show smaller differences towards the other group, intergroup differences between physicians and managers are larger than the differences within both groups.

Table 3a presents the estimates, standard deviations, $p$-values, and FDRs of the associations between the (squareroot transformed) within-institute gaps for the different levels of the professional subgroups. Table $3 \mathrm{~b}$ present the pairs of professional subgroups when there was a statistically significant interaction between the subgroups. Both tables report results for FDRs less than 0.3. For clarity we only report the unadjusted results as the adjusted results were qualitatively similar in the multivariate models. The intraclass correlations for the ten gaps range from 0.4 to 0.7 (see Table 4).

\section{Discussion and Conclusion}

Based on the results we could confirm the first hypothesis that there are differences within the groups of physicians and managers related to gender. Female physicians are most similar in their reported satisfaction with innovation, quality and cooperation levels with managers. We did not find strong differences among physicians and among 
managers based on age. In view of the large intergroup differences, it is not reasonable to expect that differences between physicians and managers will "automatically" cease over time with a younger generation. In our results we found that the scoring pattern of the medical group of physicians on the stereotypical gaps show the smallest differences with the scoring pattern of managers In addition we found that in terms of goal setting, surgical physicians and mid-line managers score the largest gaps.

For the characteristic of the physicians on employment with or being associated with the within hospital firm, hypotheses 2 is confirmed; physicians employed by or having their own within hospital firm, do not show significant intragroup differences.

Executive managers are most similar to physicians in their perception of the power (influence) of managers, while front-line managers have the greatest difference. Executive managers have almost similar opinions on manager influence as female physicians, but greatly differ from male physicians. We therefore conclude that hypothesis 3 is not supported by our data. The significant differences found within the groups of managers points at a totally different mechanism that merits further study.

Hypothesis 4 was confirmed by our results: the more time a physician spends doing managerial tasks, the more similar he/she is to managers in terms of the power (influence) of physicians and the preferred working conditions. Although we did not study whether this is because the physicians who participate in management have differing perceptions at the start or that their perceptions change when they participate in management, these results underline the positive effect of the efforts taken by hospitals to implement structures that involve physicians in management. Further research is required to investigate the most suitable candidates and the optimal balance between physicians' medical and managerial tasks. 
There is a higher diversity in perceptions, stereotypical images and satisfaction scores among physicians than managers on the total group level; apart from the more homogeneous scoring pattern the latter are more outspoken (absolute scores) in their answering. Although physicians share their professional training background, the heterogeneous scoring pattern points at differences in the daily practices and related values. For managers the converse may be true; they have a more homogeneous scoring pattern. Although they do not share a professional training, a reason might be that they are addressed by the hospital as a group, adhering to alike managerial organisational goals. From intergroup literature (Cunningham, 2006) we learn that cooperation is hardest when more homogeneous groups merge with more diverse groups. This might be one of the reasons for the complex cooperation between physicians and managers.

We assumed large differences between physicians and managers in hospitals and, as a consequence, conflicting cultural values that may lead to non effective cooperation. The authors are aware of the fact that in practice there are many ways in which physicians and managers in hospitals work together successfully. Furthermore, it could be argued that some degree of friction (constructive friction) between the two groups is necessary to create a productive cooperation (Carsten et. al., 2006). In line with an extensive body of literature, we studied the differences and not the similarities between both groups. We doubt whether taking a similarity focus would reveal useful insights to improve cooperation but cannot rule that out. 
A limitation for this study is that culture related research has to be executed on measurable expressions of culture (Schein, 1996; Sackmann, 2011), such as perspectives, behaviour, values, rationalisation, emotions, beliefs and opinions. In our study we selectively asked for perceptions of daily practices, perceived differences in power, status and goal compatibility and satisfaction with innovation, cooperation, and quality of care. Although we feel that our data sufficiently reflect gaps in culture and stereotyping, assessing aspects such as behaviour and emotions could have offered added value in view of leads to improve cooperation. This would rather ask for a multiple method approach such as adding direct observation or focus groups.

A future line of research could also be to include other professional groups (nurses, paramedics, etc) who are essential for multidisciplinary clinical work and quality of care. Future research might also study whether effective cooperation can be influenced by an education program that either aims to lessen the perceptual differences or creates awareness about the effects differences might have on the relationship between members of subgroups that show large differences towards the other group. However those showing the largest differences might also have the least interest in this type of activity, so a reward such as accreditation points or financial bonus could help to lower this hurdle.

The results and conclusions of this study are based on data gathered in Dutch hospitals. Although the particular socio-economic structure of the Netherlands may have possible influence on the way physicians and managers (co)operate, the underlying issues in health care (such as the need for more efficacy, safety, and quality of care) are relevant 
in all Western countries. Furthermore, literature describes the complex relationship between physicians and managers as a universal problem.

\section{Practice implications}

The diversity within both the groups of physicians and managers provides opportunities to identify members of subgroups who are more likely to share opinions on working conditions. We found support for the assumption that physicians who participate more than $25 \%$ of their time in management tasks show significantly smaller differences with managers than colleagues with lower participation levels. Within the group of physicians, female and medical specialists also show smaller differences with managers. This can be used as an entrance point for initiatives to improve cooperation. Our results indicate several potential intergroup conflicts, for example the relatively large differences between surgical physicians and mid-line managers. Because of their positions in the core hospital processes, these potential conflict merits exploring efforts from intergroup theory aimed to lessen these differences, such as: create interdependent tasks and improve communication (Pettigrew \& Tropp, 2006). Executive managers and female managers indicated the smallest differences, but on the whole, managers had fewer subgroups with distinctly different responses. From intergroup literature (Cunningham, 2006) we learn also that intergroup bias is highest when more homogeneous groups (managers) merge with more heterogeneous groups (physicians). Hospitals with such intra and between group perceptions should be aware of this, because it is likely to have a negative impact on effective cooperation. 
Our study provides insight in possible consequences of the composition of groups cooperating in hospitals, on the effectiveness of that group, and provides opportunities for policy makers to select participants for those groups in a more focused way. 


\section{Tables}

Table 1: Questions of the GAHP-questionnaire

\section{Culture gap}

In our hospital...

There is a great deal of informal consultation.

There is a close collegial relationship among the physicians.

There is a strong sense of belonging to the group.

We rely heavily on computer based information when seeing a patient.

We have very good methods to assure that our physicians change their practices to include new technologies and research findings.

We encourage internal reporting of patient care adverse events.

There is an open discussion about clinical failures.

We emphasise patient satisfaction.

The business office and administration are considered to be a very important part of our hospital.

We expect our administrators to obtain and provide us with information that helps us improve the cost effectiveness of our patient care.

There is widespread agreement about most moral/ethical issues.

A rapid change occurs in clinical practice among our physicians when studies indicate that we can improve quality/reduce costs.

When purchasing medical equipment, financial considerations are an important factor.

We only hire an extra physician if he/she is cost effective.

Our compensation plan rewards physicians who work hard for our hospital.

There is a high degree of trust in the decisions made by the board of directors.

Innovations by our physicians are highly publicised.

Our policy plans always mention innovative healthcare items.

There is a feeling that physicians are autonomous but practice in the same organisation for support services.

The professional autonomy of physicians is an important condition for the quality of healthcare.

Stereotypical gap

What is the level of power physicians have on hospital policy?

What is the level of power hospital managers have on hospital policy?

What is the level of professional status of physicians?

What is the level of professional status of hospital managers?

To what extent align professional goals of physicians and hospital managers?

Satisfaction gap

How satisfied are you with the quality of healthcare in this hospital?

How satisfied are you with the cooperation between physicians and hospital managers?

How satisfied are you with the implementation of quality improvements in your hospital? 
Table 2: Characteristics within the groups of physicians and managers

\begin{tabular}{|c|c|c|c|}
\hline & $\begin{array}{c}\text { Manager } \\
\mathrm{N}=\mathbf{2 8 0}\end{array}$ & $\begin{array}{c}\text { Physician } \\
N=888\end{array}$ & $\begin{array}{c}\text { Total } \\
\mathrm{N}=1168\end{array}$ \\
\hline \multicolumn{4}{|l|}{ Age } \\
\hline$<44$ & 96 (34\%) & 320 (36\%) & 416 (36\%) \\
\hline $45-54$ & 144 (51\%) & 373 (42\%) & 517 (44\%) \\
\hline $55+$ & 40 (14\%) & $195(22 \%)$ & 235 (20\%) \\
\hline \multicolumn{4}{|l|}{ Gender } \\
\hline female & 99 (35\%) & $213(24 \%)$ & 312 (27\%) \\
\hline male & $181(65 \%)$ & 675 (76\%) & 856 (73\%) \\
\hline \multicolumn{4}{|l|}{ Specialism } \\
\hline medical & & $326(37 \%)$ & 326 (28\%) \\
\hline diagnostic & & $163(18 \%)$ & 163 (14\%) \\
\hline surgical & & $298(34 \%)$ & 298 (26\%) \\
\hline other & & $101(11 \%)$ & $101(9 \%)$ \\
\hline \multicolumn{4}{|l|}{ Manager Type } \\
\hline Front-line & 91 (32\%) & & 91 (8\%) \\
\hline Mid-level & $122(44 \%)$ & & $122(10 \%)$ \\
\hline Executive & $61(22 \%)$ & & $61(5 \%)$ \\
\hline Other & $6(2 \%)$ & & $6(<1 \%)$ \\
\hline
\end{tabular}

Employment

own withinhospital firm employed by hospital within hospital firm other

Management Tasks

$\begin{array}{ccc} & 544(61 \%) & 544(47 \%) \\ 280(100 \%) & 260(29 \%) & 260(22 \%) \\ & 75(8 \%) & 75(6 \%) \\ & 9(1 \%) & 9(<1 \%) \\ & 500(56 \%) & 500(43 \%) \\ 280(100 \%) & 165(19 \%) & 165(14 \%) \\ & 223(25 \%) & 503(43 \%)\end{array}$


Table 3: The estimates, $p$-values, and FDRs of the associations between the (squareroot transformed) within-institute gaps and (a) the professional subgroups (b) pairs of professional subgroups. We report associations whose FDRs are less than 0.3 for the unadjusted model

\section{Table 3a}

\section{Culture gap -} preferred

Power physicians

Power physicians managers

Satisfaction

Culture gap present
Management tasks (phy)

$\begin{array}{rrrrr}0 \% & 4.11 & 0.0259 & <0.0001 & 0.01 \\ 0-10 \% & 4.04 & 0.0375 & & \\ >10 \% & 3.96 & 0.0332 & & \end{array}$

Management tasks (phy)

$\begin{array}{rrrrr}0 \% & 1.22 & 0.0297 & 0.0001 & 0.012 \\ 0-10 \% & 1.19 & 0.0439 & & \\ >10 \% & 1.05 & 0.0387 & & \end{array}$

Specialisation (phy) medica diagnostic

1.09

1.17

Surgical

Other

1.25

1.17

0.0338

0.001

0.0444

0.0349

0.0542

0.01

0.042
FDR

0.0414

0.002

0.066

0.0366

0.0494

Management

0.957

tasks (phy)

$\begin{array}{rcccc}0 \% & 1.02 & 0.0244 & 0.02 & 0.2 \\ 0-10 \% & 0.925 & 0.0374 & & \\ >10 \% & 0.944 & 0.0326 & & \end{array}$

Satisfaction Type (man)

Front-line

Mid-level

1.04

0.03

0.02

0.21

Executive

0.943

0.0263

0.982

0.0337

Management tasks (phy)

$$
0 \%
$$

4.47

0.0265

0.03

0.22

$\begin{array}{ccc}0-10 \% & 4.4 & 0.0363 \\ >10 \% & 4.39 & 0.0325\end{array}$


Goals Type (man)

Front-line

1.08

0.0306

0.03

Table

Mid-level

1.06

0.0269

Executive

1.17

0.035

Power (man)

Goals

Gender (Phy) Type (Man)

pvalue FDR

\begin{tabular}{|c|c|c|c|c|}
\hline $\begin{array}{r}\text { Power (man) } \\
\text { Goals }\end{array}$ & $\begin{array}{r}\text { Gender (Phy) } \\
\text { Specialisation (Phy) }\end{array}$ & $\begin{array}{r}\text { Type (Man) } \\
\text { Type (Man) } \\
\text { Gender } \\
\text { (Man) }\end{array}$ & $\begin{array}{l}0.001 \\
0.001\end{array}$ & $\begin{array}{l}0.043 \\
0.047\end{array}$ \\
\hline $\begin{array}{r}\text { Culture gap - } \\
\text { present } \\
\text { Culture qap - }\end{array}$ & Type (Phy) & Age (Man) & 0.01 & 0.13 \\
\hline $\begin{array}{r}\text { present } \\
\text { Quality }\end{array}$ & $\begin{array}{l}\text { Specialisation (Phy) } \\
\text { Specialisation (Phy) }\end{array}$ & $\begin{array}{r}\text { Age (Man) } \\
\text { Age (Man) } \\
\text { Gender }\end{array}$ & $\begin{array}{l}0.01 \\
0.01\end{array}$ & $\begin{array}{l}0.15 \\
0.15\end{array}$ \\
\hline $\begin{array}{c}\text { Status (man) } \\
\text { Satisfaction }\end{array}$ & $\begin{array}{r}\text { Gender (Phy) } \\
\text { Type (Phy) }\end{array}$ & $\begin{array}{r}\text { (Man) } \\
\text { Age (Man) }\end{array}$ & $\begin{array}{l}0.01 \\
0.02\end{array}$ & $\begin{array}{l}0.18 \\
0.19\end{array}$ \\
\hline $\begin{array}{r}\text { Innovation } \\
\text { Culture gap - }\end{array}$ & Specialisation (Phy) & Type (Man) & 0.02 & 0.2 \\
\hline present & $\begin{array}{r}\text { Age (Phy) } \\
\text { Management tasks }\end{array}$ & Age (Man) & 0.02 & 0.21 \\
\hline Goals & (Phy) & $\begin{array}{l}\text { Type (Man) } \\
\text { Gender }\end{array}$ & 0.03 & 0.22 \\
\hline $\begin{array}{l}\text { Power (man) } \\
\text { Innovation }\end{array}$ & $\begin{array}{r}\text { Specialisation (Phy) } \\
\text { Management tasks } \\
\text { (Phy) }\end{array}$ & $\begin{array}{r}\text { (Man) } \\
\text { Gender } \\
\text { (Man) }\end{array}$ & 0.03 & 0.23 \\
\hline
\end{tabular}


Table 4: Intraclass correlations for the ten gaps

\section{Variance Estimate}

Gap Physician Manager Residual ICC

$\begin{array}{lllll}\text { Quality } & 0.09 & 0.06 & 0.2 & 0.43\end{array}$

$\begin{array}{lllll}\text { Innovation } & 0.15 & 0.04 & 0.25 & 0.44\end{array}$

$\begin{array}{lllll}\text { Satisfaction } & 0.15 & 0.04 & 0.23 & 0.46\end{array}$

$\begin{array}{cllll}\text { Power Physicians } & 0.23 & 0.08 & 0.12 & 0.72 \\ \text { Power Managers } & 0.12 & 0.12 & 0.15 & 0.62\end{array}$

$\begin{array}{rrrrr}\text { Power Managers } & 0.12 & 0.12 & 0.15 & 0.62 \\ \text { Status Physicians } & 0.12 & 0.06 & 0.2 & 0.47\end{array}$

$\begin{array}{lllll}\text { Status Managers } & 0.12 & 0.05 & 0.24 & 0.41\end{array}$

$\begin{array}{lllll}\text { Goals } & 0.13 & 0.05 & 0.24 & 0.43\end{array}$

$\begin{array}{lllll}\text { Present Gap } & 0.12 & 0.09 & 0.14 & 0.6\end{array}$

$\begin{array}{lllll}\text { Preferred Gap } & 0.15 & 0.07 & 0.14 & 0.61\end{array}$ 
Figure 1: Influence of the cooperation between physicians and managers on hospital performance (Klopper et. al., 2011)

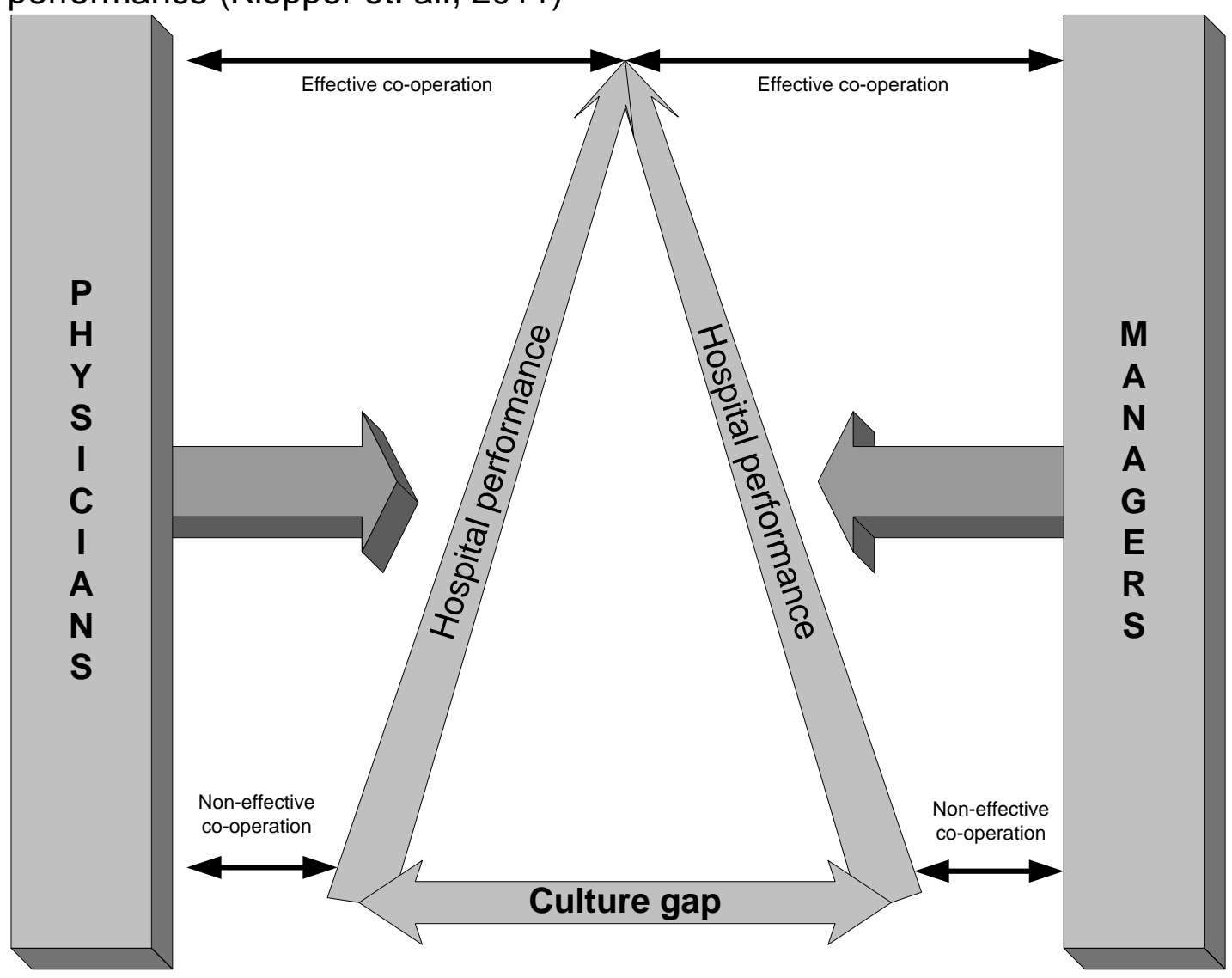


Box 1: Description of the Dutch hospital system

General hospitals in the Netherlands are non-profit foundations. It is only recently that market elements have been introduced, such as free negotiations on the price of $20 \%$ of the volume of hospital care and facilitating new market entries. The majority of physicians is not employed by the hospital, but is associated with a hospital (usually one) and the physicians are partners in their own within-hospital firm. In the withinhospital firms the accumulated fees are divided. Physicians usually perform all their activities within the hospital, charge the fees directly or through the hospital and depend on hospital policies for the allocation of staff (for example secretaries and nurses) and equipment. Physicians are organised in a "medical staff", and they elect a board which has to be consulted on important organisational and medical issues by the executive hospital board. 


\section{References}

Alexander MG, Brewer MB, Livingston RW. Putting stereotype content in context: Image theory and interethnic stereotypes. J Pers Soc Psychol. 2005a;31:781-94.

Alexander MG, Levin S, Henry PJ. Image theory, social identity and social dominance: structural characteristics and individual motives underlying international images. Pol Psychol. 2005b;26:27-45.

Bertakis KD, Helms LJ, Callahan EJ, Azaris R. The influence of gender on physicians practice style. Med Care. 1995;33:407-16.

Berrio AA. An organizational culture assessment using the competing values framework: a profile of Ohio State University extension. 2003. Accessed October 8, 2010. J Extension website, 2, Available at:

http://www.joe.org/joe/2003april/a3.php

Carsten W, De Dreu W, Beersma B. Conflict in organizations: Beyond Effectiveness and Performance. Eur J Work Organ Psychol. 2006;14:105-17.

Cunningham GB. The Influence of Group Diversity on Intergroup Bias Following Recategorization. J Soc Psychol. 2006;146:533-47.

Davies HTO, Hodges CL, Rundall TG. Views of doctors and managers on the doctormanager relationship in the NHS. BMJ. 2003;326:626. 
Easen P, Atkins M, Dyson A. Inter-professional collaboration and conceptualizations of practice. Child Soc. 2000;14:355-67.

Edwards N. Doctors and managers: poor relationships may be damaging patients what can be done? Qual Saf Health Care (Suppl 1). 2003;12:21-4.

FitzGerald L. Moving clinicians into management: a professional challenge or threat? J Manage Med. 1994;8:32-44.

Gershon RRM, Stone PW, Bakken S. Measurement of organizational culture and climate in healthcare. J Nurse Admin. 2004;34:33-40.

Golden BR, Dukerich JM, Fabian FH. The interpretation and resolution of resource allocation issues in professional organizations: a critical examination of the professionalmanager dichotomy. J Manage Stud. 2000;37:1157-87.

Kaissi A. Manager-physician relationships: an organizational theory perspective. Health Care Manage Rev. 2005;24:165-76.

Kalleberg AL, Loscocco KA. Aging, values, and reward: explaining age differences in job satisfaction. Am Soc Rev. 1983;48:78-90. 
Klazinga NS. Quality management of medical specialist care in the Netherlands. PhD thesis, Overveen: Belvedere; 1996.

Klopper AHJ, Meerdink N, Van Harten WH, Wilderom CPM. Stereotypical images between physicians and managers in hospitals. J Health Organ Manage. 2009;2:216-24.

Klopper AHJ, Siesling S, Meerdink N, Wilderom CPM, Van Harten WH. Quantifying culture gaps between physicians and managers in Dutch hospitals: A survey. BMC Health Serv Res. 2010;10:86.

Klopper AHJ, Meerdink N, Wilderom CPM, Van Harten WH. Effective Cooperation Influencing Performance, A Study in Dutch Hospitals. Int J Qual Health Care. 2011;23:94-9.

Kruijthof K. Doctors orders. PhD thesis. Nieuwegein, the Netherlands: Badoux; 2005.

Lens P, Van der Wal G. Een onderzoek naar dysfunctioneren van specialisten. Nederlands Tijdschrift voor Geneeskunde. 1994;138:1127-31.

MacLaughlin CP, Kaluzny AD. Total Quality Management in Health: Making it Works. Health Care Manage Rev. 1990;15:7-14. 
Malcolm L, Wright L, Barnett P, Hendry C. Building a successful partnership between management and clinical leadership: experience from New Zealand. BMJ. 2003;326:653-4.

Morris JH, Sherman JD. Generalizability of an organizational commitment model. Ac Manage J. 1981;24:512-26.

Mohammed S, Angell LC. Surface- and deep-level diversity in workgroups: examining the moderating effects of team orientation and team process on relationship conflict. $\mathrm{J}$ Organ Behav. 2004;25:1015-39.

Mycek S. Getting to know you, an open dialogue between the board and physicians will jump-start better relations. Trustee. 2004;4:23-5.

Patrick A. The effect of structural empowerment and perceived organizational support on middle level nurse managers' role satisfaction. J Nurs Manage. 2006;14:13-22.

Pettigrew TF, Tropp LR. A meta-analytic test of intergroup contact theory. J Person Soc Psychol. 2006;90:751-83.

Raelin JA. The clash of cultures: managers managing professionals. Boston: Harvard Business School Press; 1991. 
Roberts V, Perryman MM. Creating a culture for health care quality and safety. Health Care Manag. 2007;26:155-8.

Robyn RM, Stone PW. Measurement of organizational culture and climate in healthcare. Jona. 2004;34:33-9.

Rokeach M. Some unresolved issues in theories of believes, attitudes, and values. Symposium on Motivation. 1980;27:261-304.

Ross $\mathrm{MH}$. The relevance of culture for the study of political psychology and ethnic conflict. Polit Psychol. 1997;18:299-326.

Roter DL, Hall JA, Aoki Y. Physician gender effects in medical communication. JAMA. 2002;288:756-64.

Schein EH. Culture: the missing concept in organization studies. Admin Sci Quart. 1996;41:229-40.

Sackmann S. Culture and performance. In: Ashkanasy NM, Wilderom CPM, Peterson M. (Eds. 2nd ed.). Handbook of Organizational Culture and Climate. Thousand Oaks CA: Sage; 2011.

Schneller ES, Greenwald HP, Richardson ML, Ott JA. The physicians executive: Role in the adaptation of American medicine. Health Care Manage Rev. 1997;2:90-6. 
Scholten GRM, Van der Grinten TED. Integrating medical specialists and hospitals. The growing relevance of collective organisation of medical specialists for Dutch hospital governance. Health Pol. 1997;62:131-39.

Shortell SM, Jones RH, Rademaker AW. Assessing the impact of total quality management and organizational culture of multiple outcomes of care for coronary artery bypass graft surgery patients. Med Care. 2000;38:207-17.

Shortell SM, Marsteller JA, Lin M. The role of perceived team effectiveness in improving chronic illness care. Med Care. 2004;42:1040-8.

Shortell SM, Schmittdiel J, Wang MC. An empirical assessment of high-performing medical groups: results from a national study. Med Care. 2005;62:407-34.

Smalarz A. Physician Group Cultural Dimensions and Quality Performance Indicators: Not All Is Equal. Health Care Manage Rev. 2006;31:179-87.

Stockard J, Van de Kragt AJC, Dodge PJ. Gender roles and behavior in social dilemmas: are there sex differences in cooperation and in its justification? Soc Psychol Quart. 1988;51:154-63.

Strimmer KA. Unified approach to false discovery rate estimation. BMC Bioinfor. 2008;9:1-14. 
Taylor S. Educating future practitioners of social work and law: exploring the origins of inter-professional misunderstanding. Child Youth Serv Rev. 2006;28:638-53.

Turner JC. Towards a cognitive redefinition of the social group. In: Tajfel H. (Ed.) Social identity and intergroup relations (pp. 15-44). Cambridge: Cambridge University Press; 1982.

Van Vugt M, De Cremer D, Jansen DP. Gender differences in cooperation and competition: the male-warrior hypothesis. Psychol Sci. 2007;18:19-23. 


\section{Chapter 6}

\section{Culture differences between physicians and managers and hospital performance: a quantitative exploration}

Hanneke A.H.J. Klopper - Kes

Andrew Vincent

Nienke Meerdink

Celeste P.M. Wilderom

Sabine Siesling

Wim H. van Harten 


\begin{abstract}
Objectives To explore the association between culture related differences between physicians and managers that may reflect the effects of cooperation on different areas of performance in hospitals.

Design We relate differences (gaps) between physicians and managers to the level of performance of hospitals. Intergroup literature suggests that large differences between groups hinder effective cooperation. Differences are measured with the Hospital Gap questionnaire, resulting in ten within-institution gap scores: two culture gaps, five stereotypical gaps, and three gaps measuring satisfaction with cooperation, quality and innovation. Hospital performance is measured by 25 indicators, as defined by the Dutch Healthcare Inspectorate. The associations between gaps and performance were determined using (un)adjusted linear regression models. Both significance and False Discovery Rates (FDR) are reported.

Setting Dutch General hospitals.

Participants 888 physicians and 280 managers from 37 hospitals.

Results The association between effectiveness of cooperation of physicians and managers and 25 hospital indicators is mapped out on three performance categories which are graded in number and strength of statistical associations. The first category shows the strongest associations (FDR 0.2), for example inpatient satisfaction and solvability. The second category shows weaker but still significant associations. Examples are: the number of AAA and OCR surgery. The indicators in the third category (for example mamma and colon re-operations) show no significant associations. Conclusions Cooperation between physicians and managers, measured through culture related differences between physicians and managers, is associated with performance of an organisational nature. This study identifies specific areas which have a strong link with cooperation: solvability, patient satisfaction and heart failure readmission. The quality of monodisciplinary medical performance seems less influenced by cooperation with managers. Furthermore, the results in our study are discussed in the context of intergroup theories and provide leads to possible interventions facilitating effective cooperation and therewith hospital performance.
\end{abstract}

Keywords: cooperation, physicians, managers, quality, performance

What is already known on this subject:

The relationship between physicians and managers has been described as complex and non effective and having a relationship with hospital performance.

What this study adds:

We contribute to the current empirical knowledge by quantifying the cooperation and statistically associating it to hospital performance. We identify specific areas which are influenced by cooperation. Furthermore, we combine the results of our study with intergroup theories, leading to methods which could facilitate effective cooperation and hospital performance. 


\section{Introduction}

The changing environment, in which there is a strain on budgets, a constant stream of innovative technologies and more demanding patients, calls for improvement of a range of performance aspects in hospitals. Insurers and governments increasingly try to relate financial rewards to performance, either through pay for performance programs, as in the USA, or through the introduction of market elements or managed competition as is the case in various European countries.

Parallel to the shift towards managed competition, quality management in hospitals gradually developed from the professional domain towards a systemic organisational issue (Grol, 2001). Initially, physicians took the lead on their own professional level (Klazinga, 1996). This was reflected in the emphasis on initiatives like medical audit, guideline development, and improvement of the professional practice setting, mostly executed by the physician's own peer group. Managers, on the other hand, tend to focus on financial and organisational performance. Since the end of the twentieth century a combined focus emerges, shifting towards a combination of professional and managerial instruments and performance targets. This is initially reflected by the introduction of total quality management, continuous quality improvement and approaches like lean management. During the last decade performance develops into an integral part of external accountability towards government agencies (transparency), insurers (financial incentives and contracts) and patients (information). Gradually the influence of managers on hospital performance increases, and therewith the need for effective cooperation between physicians and managers becomes even more important. According to Powell et. al. (2009) and Walshe (2009) quality management systems however, often do not take existing professional standards into account, which could lead to reduced implementation levels and possible adversarial feelings felt by physicians towards these systems.

Literature describes the existence of a conflicting relationship between physicians and managers in hospitals (Ong \& Schepers, 1998; Davies and Harrison, 2003; Edwards, 2003; Rundall \& Davies, 2004). Plochg et. al. (2003) and Edwards (2003) state that the difficulties in the relationship between physicians and managers are independent of national healthcare organisational characteristics and are a common feature of many healthcare systems. One of the most apparent differences is that both groups differ in their goal setting. Physicians want to optimally treat individual patients. The primary goal of managers is to provide continuity for the organisation and to deliver high quality and cost effective services to a given population. (Davies et. al., 2003; Kaissi, 2005) For the manageability of hospital organisations, the professional autonomy and organisational position of physicians are important factors. (Kaissi, 2005) Literature describes several other differences negatively affecting the cooperation between physicians and managers, such as, self control versus bureaucratic control, identification with the peer group versus identification with the organisation, professional status versus leadership, and self management versus hierarchical control. (Kaissi, 2005; Davies et. al., 2007) Achieving high performance in quality and safety should however be a shared responsibility for physicians and managers. (IHI, 2010) In literature the focus on solutions to involve physicians in quality management is often based on education and 
integration, for instance through the physician-manager role. (Crosson, 2003, Thomas, 2003) Recent studies (Edwards, 2005; Donnelly et. al., 2009) show that these approaches may not be sufficient; some physicians are even reluctant to get involved in management. Due to the above mentioned findings, we previously explored the complex cooperation between physicians and managers from an intergroup conflict perspective. (Klopper, 2009) In intergroup conflict settings, people tend to exaggerate differences between both groups, leading to stereotyping (Alexander et. al., 2005a). When a group has stereotypical beliefs about another group, information is filtered towards the stereotypical image of the other group, leading to negative images, making it hard to cooperate with members from the other group. Members of different cultural groups tend to exaggerate the experienced differences and diminish similarities (Turner et. al., 1987) and different cultural groups tend to attribute characteristics to all individuals belonging to the other group (the outgroup). The larger the differences, the more difficult it will be to effectively cooperate. (Klopper et. al., 2010; Ross, 1997; Easen et. al., 2000; Gershon et. al., 2004; Taylor, 2006; Roberts \& Perryman, 2007)

Literature suggests that less optimal cooperation between both groups has a negative influence on organisational performance and can be harmful for the patient. (Edwards, 2003; Nash, 2003; Meterko et. al., 2004) In this paper we used the stereotypical gap-, culture gap- and satisfaction gap scores to quantify differences and, according to intergroup theory, therewith the effectiveness of cooperation. The degree of cooperation will be related to quality indicators in search of areas of performance that are possibly linked to the cooperation between physicians and managers.

\section{Methods}

\section{Questionnaires}

The cooperation between physicians and managers was assessed with the GAHPquestionnaire (GAps between Hospital managers and Physicians Questionnaire; Table 1). This questionnaire was validated in two separate studies in five Dutch hospitals leading to a survey instrument, with three domains. (Klopper, 2010) The first domain is based on an organisational culture theory and assesses the differences in perceptions of daily practices, based on the respective professional cultures, of physicians and managers in both the present and preferred situation. The magnitudes of the differences between each pair of doctor and manager (from the same institution) were summed over the 20 culture gap questions. The actual organisational reality as perceived by members of both groups was reflected in answers given on statements about the present situation. Answers given to the statements in the preferred situation reflect the desired order (Berrio, 2003) revealing the inherent cultures of physicians and managers. These are further referred to as "culture gaps". The second domain is based on the Image theory (Alexander et. al., 2005 a/b; Klopper et. al., 2009, 2010); due to different views that physicians and managers have and the professional attachment to their own groups (differences in professional cultures), an 'us versus them' way of thinking is likely to exist. In literature this is referred to as an intergroup conflict setting, leading to possible stereotypical images of each other. We used five questions to measure stereotypical images between physicians and managers. Four concern the relative power related to hospital policy and professional status of physicians and managers and the fifth asks for 
an opinion on the goal compatibility between both groups. The differences in scores between physicians and managers on the questions about relative power, status and goal incompatibility are further referred to as the "stereotypical gaps". The third domain contains three questions on a 10 point scale assessing satisfaction with quality of care, cooperation between physicians and managers, and the way innovations are implemented (further referred to as "satisfaction gaps"). Ten different gaps were derived from the three components of the GAHP-questionnaire: two from the culture gaps (present and preferred gap), five from the stereotypical images (power and status of physicians, power and status of managers, and goal incompatibility), and three from the satisfaction questions (quality, innovation, and cooperation). The gaps were calculated as the magnitude of the difference of all pairings of physicians and managers working within the same institution. For the two culture-gaps, the magnitudes of the differences between the two individuals were summed over the 20 culture gap questions. The association between the size of gaps and particular factors (physician and manager characteristics) were assessed using (mixed effect model) likelihood ratio tests.

The set of annual performance indicators issued by the Dutch Health Care Inspectorate was used to reflect performance of the hospitals. It is a compulsory set consisting of structure-, process- and outcome indicators such as presence of certain facilities, throughput times and numbers of complications. Data from the questionnaires as well as the indicator results were acquired over the year 2007. The indicators had to be suitable for statistical analyses, therefore we selected those that were numerical, showed variety, indicated hospital performance directly or intermediately, and indicators with which a clear link between outcome and performance could be hypothesised. For every indicator we hypothesised the (direction of the) association with performance (Table 2) [insert table 2].

\section{Inclusion}

Executive boards of all Dutch general hospitals were contacted by mail and asked to participate in this study. Of those that agreed all physicians and managers received an invitation by email to complete the questionnaire on our website. After three months physicians and managers in hospitals that had not reacted were reminded with a hard copy sent by post. Physicians and managers in hospitals with a partial response were reminded by email. Hospitals were included in the study if at least one manager and one physician completed the questionnaire.

\section{Statistical Methods}

The response rates, personal characteristics, and questionnaire outcomes from individuals working within the same institution are possibly correlated, and as such all tests should, where possible, account for potential within-institution correlations. Differences between size and region characteristics of participating hospitals were tested using Cochran-Armitage trend test for proportions. The comparison between age and gender characteristics of participating individuals and distributions from the Netherlands national register were tested using binomial tests. Differences in the response rates, age (grouped as 35-44, 45-54, 55+) and gender between participating physicians and managers were tested using Cochran Mantel Haenszel tests stratifying 
by institution. Associations between return rates and the location and type of hospital were tested using logistic mixed effects models with hospital as the random grouping variate. QQplots were used to determine appropriate normality transformations for all questionnaire outcomes and associated gaps. Linear mixed effects models were used to examine differences between the two groups of professionals in the ten within-institution gaps. As with the logistic models, hospital was taken to be the random grouping variate. For these tests the significance level was set at 0.01 .

The associations between hospital indicators and the ten within-institution gaps were determined using both unadjusted (univariate) and adjusted (multivariate) linear mixed effects models, the indicator score being the predictor of primary interest. The outcome is the pairwise difference in questionnaire outcome for all pairs of doctors and managers within each institution. The multivariate models included profession, age and gender as confounders. To ensure that extreme indicator values are not overly influential, a sensitivity analysis was performed in which the significant associations were recalculated, excluding the largest and smallest indicator values. In these models two non-nested random effects structures were implemented using the physician and manager variates as grouping variables to account for multiple differences per individual. Associating the 10 gap scores with a large number of indicators has a reasonable chance of finding at least a few statistically significant relations. Therefore we used a technique of analysis that is more common in studies on techniques as microarrays and proteomics. (Camp, 2008) In the social sciences a parallel advance has occurred with the progress of web based questionnaires and online data sources. (Rhodes, et. al., 2003) These new data gathering tools have allowed scientists to explore much larger datasets and test many more hypotheses than has traditionally been possible. In such exploratory settings, solely reporting $\mathrm{p}$ values generated under the assumption of appropriately powered prespecified hypotheses is misleading due to an excessive Type I error rate. The application of traditional multiple test adjustments is also problematic due to large number of tests, often resulting in an excessive Type II error rate. This scientific dilemma has led to developments in statistics to address such problems. (Shaffer, 1995) One solution has been the development of FDR techniques, one of which utilises the large number of tests to model the empirical null hypothesis (i.e. no true association), estimating the null allows to control falsely discovered "significant" results. Given the large number of multiple tests performed, we report both $\mathrm{p}$ values and false discovery rates (FDR) for associations with FDR values less than 0.3. (Strimmer, 2008) All analyses were performed using $R$ v2.9.2.

\section{Results}

Of the 86 general hospitals in the Netherlands, 46 agreed to participate in our study. Table 3 provides an overview of the characteristics of these participating hospitals in comparison with those that did not participate. There were no apparent associations between participating and non participating, hospital size $(p=0.13)$, or region $(p=0.97)$. Assessing the representation of the participating individuals is more difficult as we have no information concerning those who chose not to participate. However, comparisons with the Dutch national register for physicians indicated that male physicians between 45 and 54 years of age are overrepresented, and conversely female physicians and physicians over 55 years of age are underrepresented in our study population (Table 4). 
In total 3941 physicians and 680 managers received an invitation to complete the questionnaire. Ultimately we received responses from at least one physician and one manager from 37 hospitals. The participating general hospitals were classified as either small, medium, large or teaching hospitals, and geographically spread over the Netherlands (Table 5). From the remaining nine hospitals either only physicians or only managers responded, and as such pairwise gaps were not evaluable. For the hospitals analysed in this study the response rate from physicians $24 \%(888 / 3701)$ was lower than the response rate from managers $45 \%(280 / 616),(p<0.0001)$. The non response bias was tested; no significant association with either location ( $p=0.91$ physicians; and $p=0.07$ managers), or institute type ( $p=0.57$ physicians; and $p=0.33$ managers) was found.

The majority of the physicians were male and between 45 and 54 years of age. The representation of females in management was higher (35\%) than in the physicians group (24\%) ( $\mathrm{p}=0.0002)$; there was a lower representation of managers over 54 years $(14 \%)$ than physicians of that age $(22 \%)(p=0.002) .56 \%$ of the participating physicians reported performing no managerial tasks, $19 \%$ spent up to $10 \%$ of their time on such tasks and $25 \%$ between $11 \%$ and $50 \%$. Seven individuals reported spending more than $50 \%$ of their time on managerial tasks, however still identified themselves (and were scored) as physicians.

The within-institute gaps were compared with the hospital indicator data. The questionnaire distributions were left skewed and the within-individual gaps were right skewed. QQ plots indicated that the gaps were right skewed and after square root transformations the distributions were approximately normal. Figure 1 presents the distributions of the within-institute gaps. Of the satisfaction gaps, cooperation and innovation exhibited the greatest variation in gap scores. All tests were conducted on the transformed variates. Table $6 \mathrm{~A}$ presents the association between the gaps, specified according to domain and the hospital indicators. The results are mapped out on three performance categories which are graded in number and strength of statistical associations. The first category strictly considers the significant associations at the 0.2 FDR threshold together with the indicator scoring a result with at least three gaps. There were 16 associations in this category. The stereotypical gaps and the two culture gaps were each associated with six indicators, while satisfaction gaps accounted for only four. Performance on "Solvability", "Clinical Patient Satisfaction" and "Heart failure readmission above 75 years of age" were each associated with three gaps. In the second category indicators show associations at the 0.2 threshold with less than three gaps scoring or associations at the 0.3 FDR threshold. This category shows weaker associations than the first category, but still shows ten significant statistical associations; examples are the number of AAA (Abdominal Aortic Aneurysm) and OCR (Oesophageal Cancer Resection). The indicators in the third category are presented in table $6 \mathrm{~B}$ and do not show a significant association with the cooperation between physicians and managers. 


\section{Discussion}

The results confirm our hypothesis that aspects reflecting effective cooperation between physicians and managers are positively associated with performance in hospitals. The strongest associations (Table 6A) are found with indicators mostly concerning overall hospital performance or with a relation to organisational aspects. Indicators that measure more monodisciplinary medical performance show weaker associations. The indicators scoring in the first category (strongest association) are: financial solvability, overall patient satisfaction with clinical care and heart failure readmission above 75 years of age. Solvability is the outcome of financial policy and resource allocation over a range of years and patient satisfaction is influenced by multiple aspects of the organisation. The heart failure readmission rate (above 75 years of age) is more medically focused and is at least partly related to the capacity to innovate. The indicators scoring in the second category are: the annual number of AAA surgeries, heart failure readmissions under 75 years of age, annual number of OCR, percentage of surgery after hip fracture, pain measurement on postoperative recovery, measurement of inpatient (mal)nutrition and diabetes fundus control. In the third category we find the indicators without a statistically significant association with cooperation.

In this study we used the FDR method to categorise the associations between hospital indicators and assessed levels of cooperation between physicians and managers into three categories: strong (FDR $<0.2)$, moderate $(0.2<F D R<0.3)$, and weak (FDR $>0.3)$. It is thus reasonably certain that at least those relations are meaningful; it seems however odd that outpatient satisfaction and inpatient pain measurement do not score significant FDR's, but this might reflect registration or implementation priorities.

Although it is not possible to use these data for firm statements on the organisational mechanisms through which culture affects performance, the indicators showing the strongest relations do so on most of the ten within-institution gap scores. This suggests that the underlying aspects are indeed important in their contribution to cooperation. Further insight in the organisational mechanisms could be obtained by analysing the individual data from the 20 culture gap statements (instead of using the sum scores on present and preferred gap) and relate those to a qualitative analysis on the explanations of performing as shown per hospital. In an analysis over years causal mechanisms might thus become apparent. Measuring the actual involvement of physicians in organising efficiency and of managers in better care could in addition produce intermediate indicators of value in measuring efficient cooperation. As culture gaps showed correlations with a number of performance indicator scores, it could be worthwhile to study the use of the statements in an alignment verification checklist. In future research it is relevant to see whether the current reforms towards market orientation/managed competition lead to different scores and correlations with performance. We did not involve other health care professional groups such as nurses and paramedics. Therefore it is not clear what these groups directly or indirectly contribute to effective cooperation. Longitudinal data collection might provide more insight in this relationship. 
In view of the findings it is worthwhile investing in the improvement of the cooperation between managers and physicians. It is not easy, however to deduct direct leads from our findings that may be helpful in doing so but intergroup literature provides methods to improve complex cooperation which might be applied to issues concerning quality and performance in hospitals. Jehn \& Mannix (2001) describe a hierarchy of conflict in three levels: task, process and relationship. Ben-Ari (2004) describes three approaches to tackle these: the information, contact, and meta cognition method. As we described in the introduction culture gaps are scored in the preferred and in the present situation. When statements score culture gaps only in the present situation, conflicts between physicians and managers seem to be moderate and likely on task level. (Jehn \& Mannix, 2001) The will of both groups to improve performance in cooperation could be triggered by simply providing information but when the intergroup differences are too large, this approach will not be sufficient on its own. (Ben-Ari 2004) When there are culture gaps between physicians and managers in the preferred situation and not in the present situation, conflicts are mostly on a process level (Jehn \& Mannix, 2001) and a valuable method to improve intergroup cooperation could be Allport's contact theory. (1954) as described by Ben-Ari. (2004) In his view contact can be facilitated when four conditions are taken care of: describe common goals, arrange the support of authorities for both physicians and managers, avoid competition between the two groups, and respect the medical domain. Culture gaps that scored both in the present and the preferred situation are presumably relating to the relationship level and the most difficult to influence. (Jehn \& Mannix, 2001) In that case the method of meta cognition (Ben-Ari, 2004) might improve cooperation. Meta cognition focuses on the deeper issues of personal and professional values, through analysing and being conscious of why we think and act the way we do. Figure 2 is a visual representation of how the integration of culture gaps and intergroup improvement methods could influence cooperation and therewith hospital performance.

The results and conclusions of this study, are based on data gathered in Dutch hospitals. Although the socioeconomic structure of the Netherlands possibly influences the way physicians and managers (co)operate, the underlying issues in health care (such as the emphasis on efficiency, safety, and quality of care) are major issues in many countries. Difficulties in cooperation between physicians and managers seem to be independent of the health system, (Edwards, 2003; Nash, 2003; Meterko, 2004) therefore we expect that our findings can be generalised to other Western countries.

\section{Conclusion}

Cooperation between physicians and managers, measured through culture gap scores and stereotyping is associated with performance of an organisational nature. Data indicated that quality of monodisciplinary medical performance seems less influenced by cooperation with managers. The study identifies specific areas of performance that associate strongly with cooperation: solvability, patient satisfaction, and heart failure readmission. Based on these findings there is support for investing in cooperative culture and the use of intergroup methods to facilitate more effective cooperation. 


\section{Acknowledgements}

We thank the hospitals, physicians and managers for their participation in this study.

Contributors: HAHJK contributed to the design, data retrieval, analysis and writing of the paper, AV contributed to the analysis and writing of the paper, NM contributed to the analysis and writing of the paper, CPMW contributed to the design and writing of the paper, SS contributed to the design, analysis and writing of the paper, $\mathrm{WHvH}$ contributed to the design, analysis and writing of the paper

The Corresponding Author has the right to grant on behalf of all authors and does grant on behalf of all authors, an exclusive licence (or non exclusive for government employees) on a worldwide basis to the BMJ Publishing Group Ltd and its licensees, to permit this article (if accepted) to be published in BMJ editions and any other BMJPG products and to exploit all subsidiary rights, as set out in our licence (http://resources.bmj.com/bmj/authors/checklists-forms/licence-for-publication)"

All authors have completed the Unified Competing Interest form at www.icmje.org/coi_disclosure.pdf (available on request from the corresponding author) and declare that (1) AHJK, AV, NM, CPMW, SS, WHH have no support for the submitted work; (2) AHJK, AV, NM, CPMW, SS, WHH have no relationships that might have an interest in the submitted work in the previous 3 years; (3) their spouses, partners, or children have no financial relationships that may be relevant to the submitted work; and (4) AHJK, AV, NM, CPMW, SS, WHH have no non-financial interests that may be relevant to the submitted work.

This study does not need ethical approval or informed consent from participants. Accessibility of the data is available for all researchers. Data sharing: technical appendix, statistical code, and dataset available from corresponding author at hannekeklopper@hotmail.com. 


\section{References}

Alexander MG, Brewer MB, Livingston RW. (2005a), Putting stereotype content in context: Image theory and interethnic stereotypes. J Pers Soc Psychol. 2005a;31:78194.

Alexander MG, Levin S, Henry PJ. Image theory, social identity and social dominance: structural characteristics and individual motives underlying international images. Pol Psychol. 2005b;26:27-45.

Allport GW. The nature of prejudice. Reading: Addison-Wesley; 1954.

Ben-Ari R. Coping with the Jewish-Arab Conflict: a comparison among three models. J Soc Issues. 2004;60:307-22.

Berrio AA. An Organizational Culture Assessment Using the Competing Values Framework: A Profile of Ohio State University Extension. [http://www.joe.org/joe/2003april/a3.php] website Journal of Extension. 2003;41.

Camp RL, Neumeister V, Rimm DL. A decade of tissue microarrays: progress in the discovery and validation of cancer biomarkers. J Clin Oncol. 2008;26:5630-7.

Crosson FJ. Kaiser Permanente: a propensity for partnership. BMJ 2003; 326:654.

Davies HTO, Harrison S. Trends in doctor-manager relationships. BMJ. 2003;326:46-9.

Davies HTO, Hodges CL, Rundall TG, Kaiser HJ. Views of doctors and managers on the doctor-manager relationship in the NHS. BMJ. 2003;326:626-8.

Davies HTO, Mannion R, Jacobs R, Powell A, Marshall M. Exploring the Relationship between Senior Management Team Culture and Hospital Performance. Med Care Res Rev. 2007;64:46-65.

Donnelly P, Edwards N, Christie S, Naylor R, Dixon J, McKeon A, Maynard A, Field S, Farrar M. Roundtable. Will the penny drop for clinical mangers? Health Serv J. 2009;119:24-9.

Edwards N. Doctors and managers: poor relationships may be damaging patients what can be done? Qual Saf Health Care. 2003;12:21-4.

Edwards N. Doctors and managers; building a new relationship. Clin Med. 2005;5:577-9.

Executive quality academy, IHI. The responsibilities of senior executives in health care are changing. March 22-24, 2010. 
http://www.ihi.org/lHI/Programs/ProfessionalDevelopment/FromtheTopRoleoftheBoardin QualityandSafetyMarch2009.htm

Grol R. Improving quality of medical care. Building bridges among professional pride, payer profit, and patient satisfaction. JAMA. 2001;286:20.

Jehn KA, Mannix E. The dynamic nature of conflict a longitudinal study of intragroup conflict and group performance. Acad Manage J. 2001;44:238-51.

Kaissi A. Manager-Physician Relationships: an Organisational Theory Perspective. Health Care Manage Rev. 2005;24:165-76.

Klazinga NS. Quality Management of Medical Specialist Care in the Netherland. PhD thesis. Overveen: Belvédère; 1996.

Klopper AHJ, Meerdink N, Harten WH van, Wilderom CPM. Stereotypical images between physicians and managers in hospitals. J Health Organ Manage. 2009;2:216-24.

Klopper AHJ, Siesling S, Meerdink N, Wilderom CPM, Harten WH van. Quantifying culture gaps between physicians and managers in Dutch hospitals: A survey. BMC health serv res. 2010;10:86.

Klopper AHJ, Meerdink N, Harten WH van, Wilderom CPM. Effective Cooperation Influencing Performance, A Study in Dutch Hospitals. Int J Qual Health Care. 2011;23:94-9.

Meterko M, Mohr DC, Young GJ. Teamwork Culture and Patient Satisfaction in Hospitals. Med Care. 2004;42:492-8.

Nash DB. Doctors and managers: mind the gap. BMJ. 2003;326:652-3.

Ong BN, Schepers R. Comparative perspectives on doctors in management in the UK and the Netherlands. J Manag Med. 1998;12:278-90.

Plochg T, Lombarts K, Witman Y, Klazinga N. Problems in Dutch hospitals resemble those in British hospitals. BMJ. 2003;326:656.

Powell A, Rushmer R, Davies H. Effective quality improvement: some necessary conditions. Br J Healthc manag. 2009;15:62-8.

Rhodes SD, Bowie DA, Hergenrather KC. Collecting behavioural data using the world wide web: considerations for researchers. J Epidemiol Community Health. 2003;57:6873.

Rundall TG, Davies HTO. Doctor-manager relationships in the United States and the United Kingdom. J Health Manag. 2004;22:90-6. 
Shaffer JP. Multiple hypothesis testing. Ann Rev Psychol. 1995;46:561-84.

Strimmer K. A unified approach to false discovery rate estimation. BMC Bioinf. 2008;9:114.

Thomas H. Clinical networks for doctors and managers. BMJ; 326:655.

Walshe K. Pseudoinnovation: the development and spread of healthcare quality improvement methodologies. Int J Qual Health Care. 2009;3:153-9. 


\section{Tables}

Table 1: Questions of the GAHP-questionnaire

\section{Culture gap}

In our hospital...

There is a great deal of informal consultation.

There is a close collegial relationship among the physicians.

There is a strong sense of belonging to the group.

We rely heavily on computer based information when seeing a patient.

We have very good methods to assure that our physicians change their practices to include new technologies and research findings.

We encourage internal reporting of patient care adverse events.

There is an open discussion about clinical failures.

We emphasise patient satisfaction.

The business office and administration are considered to be a very important part of our hospital.

We expect our administrators to obtain and provide us with information that helps us improve the cost effectiveness of our patient care.

There is widespread agreement about most moral/ethical issues.

A rapid change occurs in clinical practice among our physicians when studies indicate that we can improve quality/reduce costs.

When purchasing medical equipment, financial considerations are an important factor.

We only hire an extra physician if he/she is cost effective.

Our compensation plan rewards physicians who work hard for our hospital.

There is a high degree of trust in the decisions made by the board of directors.

Innovations by our physicians are highly publicised.

Our policy plans always mention innovative health care items.

There is a feeling that physicians are autonomous but practice in the same organisation for support services.

The professional autonomy of physicians is an important condition for the quality of health care.

Stereotypical gap

What is the level of power physicians have on hospital policy?

What is the level of power hospital managers have on hospital policy?

What is the level of professional status of physicians?

What is the level of professional status of hospital managers?

To what extent align professional goals of physicians and hospital managers?

Satisfaction gap

How satisfied are you with the quality of healthcare in this hospital?

How satisfied are you with the cooperation between physicians and hospital managers?

How satisfied are you with the implementation of quality improvements in your hospital? 
Table 2: Hypothesis associating indicator values with "better" or "worse" outcome; and the hospital indicator medians and ranges.

Inpatient satisfaction

Outpatient satisfaction

Level of sick leave

Solvability

Prevalence decubitus

Decubitus after total hip replacement

Complication after cholestystectomy

Reoperation colonpatient

Reoperation after hernia inguinalis

Surgery cancelled by hospital

Heartfailure readmission $<75$

Heartfailure readmission $>75$

Mortality after $\mathrm{AMI}<65$

Mortality after AMI $>65$

Surgery after hipfracture $<24$ hours

Reoperation mammapatients

$\mathrm{HbA1C}$ control rates

Diabetes fundus control

Measurement of malnutrition

Registration of complications

Pain measurement on recovery

Pain measurement on clinical patients

Number of AAA operations

Number of OCR operations
Hypothesis Missing Med (range)

The higher the better $4 \quad 7.9(7.5-8.8)$

The higher the better $4 \quad 7.9(7.4-8.6)$

The lower the better - $\quad 4.7(3.3-7)$

The higher the better - $\quad 9.3(2.7-23.3)$

The lower the better - $\quad 4.8(0.8-6.6)$

The lower the better $2 \quad 1.3(0-6.3)$

The lower the better $\quad$ - $\quad 0.6(0-1.7)$

The lower the better - $\quad 8(0.5-18.4)$

The lower the better - $\quad 1.2(0-13.7)$

The lower the better - $\quad 0.8(0-3.3)$

The lower the better - $\quad 8.9(0-18.9)$

The lower the better - $\quad 8(0-16.6)$

The lower the better - $\quad 1.2(0-6.8)$

The lower the better - $\quad 8.9(2.1-19)$

The higher the better $\quad$ - $\quad 86.4(46.7-98.8)$

The lower the better - $\quad 8.7(0-27.1)$

The higher the better - $\quad 7.6(6.6-8.2)$

The higher the better - $\quad 85(36.7-100)$

The higher the better - $\quad 42.5(0-89.9)$

The higher the better - $74.2(36-100)$

The higher the better - $100(0-100)$

The higher the better - $\quad 80.1(1.7-100)$

The higher the better - $\quad 49(5-173)$

The higher the better - $10(1-33)$ 
Table 3: A comparison of hospital characteristics between hospitals that agreed to participate with those that did not.

\begin{tabular}{|c|c|c|c|}
\hline & Participating hospitals & Non-participating hospitals & \\
\hline & $\mathrm{N}=46$ & $\mathrm{~N}=40$ & $p$-value \\
\hline Size of region (nr of & esidents) & & 0.97 \\
\hline$>180,000$ & $10(5.4 \%)$ & $9(5.6 \%)$ & \\
\hline $100,000-180,000$ & $13(7.1 \%)$ & $11(6.9 \%)$ & \\
\hline$<100,000$ & $23(12.5 \%)$ & $20(12.5 \%)$ & \\
\hline Size of hospital (nr & employees) & & \\
\hline$>2000$ & $17(9.2 \%)$ & 9 (5.6\%) & 0.13 \\
\hline $1000-2000$ & $13(7.1 \%)$ & $12(7.5 \%)$ & \\
\hline$<2000$ & $16(8.7 \%)$ & $19(11.9 \%)$ & \\
\hline
\end{tabular}


Table 4: Personal characteristics of participating physicians compared with proportions provided by the Netherlands national register of physicians.

\begin{tabular}{clll}
\multicolumn{3}{c}{$\begin{array}{l}\text { Participating } \\
N=929\end{array}$} & $\begin{array}{l}\text { National Register } \\
\%\end{array}$ \\
Age & & & p-value \\
$35-44$ & $334(36.0 \%)$ & 36.5 & $0.76(<45$ vs. $45+)$ \\
$45-54$ & $393(42.3 \%)$ & 34.0 & $<0.0001(<55$ vs. $55+)$ \\
$55+$ & $202(21.7 \%)$ & 29.4 & \\
Gender & & & $<0.0001$ \\
male & $704(75.8 \%)$ & 70 & \\
female & $225(24.2 \%)$ & 30 &
\end{tabular}


Table 5: General characteristics, return rates and numbers for the analysed hospitals $(n=37)$.

\begin{tabular}{|c|c|c|c|c|c|c|}
\hline & Small & Middle & Large & Teaching & Total \\
\hline & & $\mathrm{N}=7$ & $\mathrm{~N}=13$ & $\mathrm{~N}=3$ & $\mathrm{~N}=14$ & $\mathrm{~N}=37$ \\
\hline \multirow[t]{2}{*}{1000 patients/year } & median & 62 & 85.7 & 146.5 & 143.6 & 105.7 \\
\hline & range & $\begin{array}{l}42.8- \\
87.2\end{array}$ & $\begin{array}{l}17.7- \\
129.9\end{array}$ & $\begin{array}{l}136.4- \\
170.3\end{array}$ & $\begin{array}{l}105.7- \\
211.7\end{array}$ & $\begin{array}{l}17.7- \\
211.7\end{array}$ \\
\hline \multirow{2}{*}{$\begin{array}{l}\text { Return Rates } \\
\text { Physicians (\%) }\end{array}$} & median & 26.1 & 21.1 & 32.3 & 27.6 & 26.1 \\
\hline & range & $\begin{array}{l}14.5- \\
41.7\end{array}$ & $11-42.1$ & $1.2-40.8$ & $7.4-62.8$ & $1.2-62.8$ \\
\hline \multirow{2}{*}{$\begin{array}{l}\text { Return Rates } \\
\text { Managers (\%) }\end{array}$} & median & 70 & 46.7 & 50 & 59.2 & 58.3 \\
\hline & range & $21.2-100$ & $\begin{array}{l}10.7- \\
88.9\end{array}$ & $\begin{array}{l}17.5- \\
73.3\end{array}$ & $15.8-100$ & $10.7-100$ \\
\hline \multirow{2}{*}{$\begin{array}{l}\text { Participating } \\
\text { Physicians }\end{array}$} & median & 18 & 13 & 20 & 30.5 & 25 \\
\hline & range & $9-32$ & $4-53$ & $2-51$ & $5-50$ & $2-53$ \\
\hline \multirow{2}{*}{$\begin{array}{l}\text { Participating } \\
\text { Managers }\end{array}$} & median & 5 & 6 & 10 & 7 & 6 \\
\hline & range & $1-14$ & $1-28$ & $5-11$ & $3-22$ & $1-28$ \\
\hline
\end{tabular}


Table 6A: Significant associations (after sensitivity analysis) between within-institution gaps determined using linear mixed effects models. Reported is the coefficient of the association, the interquartile range for the indicator, the change in Gap over the IQR, and the $p$ value of the association.

\begin{tabular}{|c|c|c|c|c|c|c|c|c|}
\hline category & gap & indicators & hypothesis & coef1 & range & gap.range & p.value & FDR \\
\hline 1 & inn.satis & Solvability & The higher the better & $-0,013$ & 21 & $-0,526$ & 0,005 & 0,11 \\
\hline 1 & status.phy & Solvability & The higher the better & $-0,015$ & 21 & $-0,524$ & 0,0022 & 0,077 \\
\hline 1 & coop.satis & Solvability & The higher the better & $-0,012$ & 21 & $-0,463$ & 0,009 & 0,15 \\
\hline 2 & power.phy & Solvability & The higher the better & $-0,012$ & 21 & $-0,55$ & 0,03 & 0,26 \\
\hline 2 & goals & Solvability & The higher the better & $-0,0092$ & 21 & $-0,403$ & 0,0335 & 0,27 \\
\hline 2 & present.gap & Solvability & The higher the better & $-0,01$ & 21 & $-1,9$ & 0,036 & 0,27 \\
\hline 1 & present.gap & Inpatient satisfaction & The higher the better & $-0,18$ & 1,3 & -2 & 0,0145 & 0,19 \\
\hline 1 & inn.satis & Inpatient satisfaction & The higher the better & $-0,27$ & 1,3 & $-0,696$ & $<0,0001$ & 0,012 \\
\hline 1 & power.phy & Inpatient satisfaction & The higher the better & $-0,23$ & 1,3 & $-0,655$ & 0,005 & 0,11 \\
\hline 2 & status.phy & Inpatient satisfaction & The higher the better & $-0,13$ & 1,3 & $-0,307$ & 0,0355 & 0,27 \\
\hline 2 & goals & Inpatient satisfaction & The higher the better & $-0,14$ & 1,3 & $-0,386$ & 0,0265 & 0,24 \\
\hline 1 & power.phy & Heartfailure readmission $\geq 75$ & The lower the better & 0,016 & 17 & 0,61 & 0,0095 & 0,15 \\
\hline 1 & present.gap & Heartfailure readmission $\geq 75$ & The lower the better & 0,025 & 17 & 3,7 & $<0,0001$ & 0,0053 \\
\hline 1 & status.man & Heartfailure readmission $\geq 75$ & The lower the better & 0,021 & 17 & 0,703 & $<0,0001$ & 0,0053 \\
\hline 2 & qual.satis & Heartfailure readmission $\geq 75$ & The lower the better & 0,009 & 17 & 0,221 & 0,041 & 0,29 \\
\hline 2 & goals & Heartfailure readmission $\geq 75$ & The lower the better & 0,011 & 17 & 0,41 & 0,0195 & 0,21 \\
\hline 1 & status.man & Heartfailure readmission $<75$ & The lower the better & 0,01 & 19 & 0,411 & 0,005 & 0,11 \\
\hline 1 & present.gap & Heartfailure readmission $<75$ & The lower the better & 0,012 & 19 & 2 & 0,007 & 0,13 \\
\hline 1 & present.gap & Number of OCR operations & The higher the better & $-0,011$ & 32 & -3 & 0,0047 & 0,11 \\
\hline 1 & pref.gap & Number of OCR operations & The higher the better & $-0,0089$ & 32 & $-2,3$ & 0,0105 & 0,16 \\
\hline 1 & power.man & Surgery after hipfracture within $24 \mathrm{~h}$ & The higher the better & $-0,01$ & 52 & $-1,282$ & 0,0041 & 0,1 \\
\hline 2 & status.phy & Surgery after hipfracture within $24 \mathrm{~h}$ & The higher the better & $-0,0062$ & 52 & $-0,636$ & 0,0215 & 0,22 \\
\hline 1 & pref.gap & Aorta abdominalis surgery & The higher the better & $-0,0014$ & 170 & $-1,9$ & 0,009 & 0,15 \\
\hline 1 & qual.satis & Pain measurement on recovery & The higher the better & $-0,0022$ & 100 & $-0,35$ & 0,0016 & 0,065 \\
\hline 2 & coop.satis & Measurement of malnutrition & The higher the better & $-0,0014$ & 90 & $-0,24$ & 0,02 & 0,22 \\
\hline 2 & power.phy & Diabetes fundus control & The higher the better & $-0,0027$ & 63 & $-0,41$ & 0,0235 & 0,23 \\
\hline
\end{tabular}


Table 6B: nonsignificant scoring indicators $(F D R>0.03)$

\begin{tabular}{|l|}
\hline Decubitus after total hip replacement \\
\hline Outpatient satisfaction \\
\hline Hba1c control rates \\
\hline Mortality after AMI ( $\geq 65$ years of age) \\
\hline Level of sick leave \\
\hline Pain measurement on clinical patients \\
\hline Reoperation mammapatients \\
\hline Reoperation colonpatient \\
\hline Registration of complications \\
\hline Mortality after AMI ( $<65$ years of age) \\
\hline Surgery cancelled by hospital \\
\hline Complication after cholestystectomy \\
\hline Reoperation after hernia inguinalis \\
\hline Prevalence decubitus \\
\hline
\end{tabular}




\section{Figures}

Figure1: Distributions of the institute means of the questionnaire scores and within-institute gaps.

Presented are the median and range of these distributions scaled to lie between 0 and 1 . The theoretical range extremes are listed on the right. The blue and red lines represent the distributions of the physicians' and managers' groups.

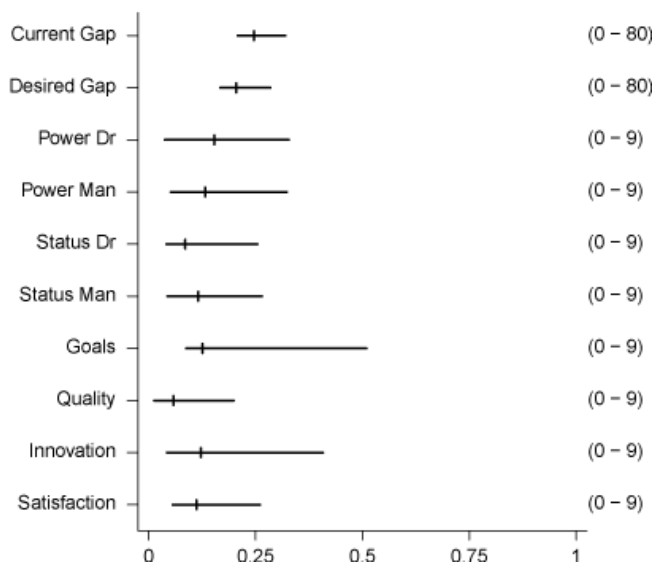


Figure 2: The influence of the cooperation between physicians and managers on hospital performance (Klopper et.al., 2011), integrated with intergroup theories.

\begin{tabular}{|l|l|}
\hline Jehn (2001) & Ben-Ari (2004) \\
\hline Task conflict & Information \\
\hline Process conflict & Contact \\
\hline Relationship conflict & Metacognition \\
\hline
\end{tabular}

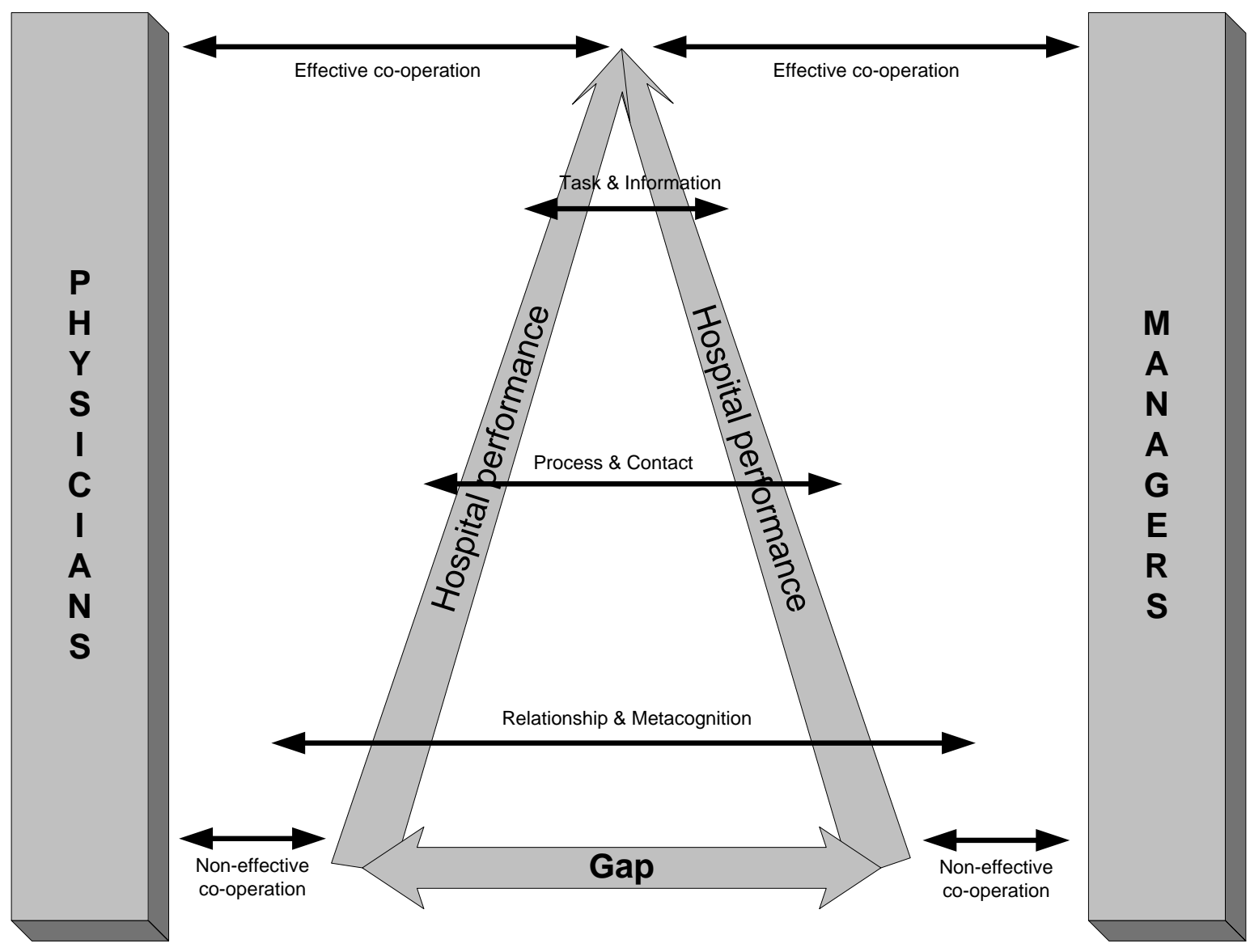


Chapter 7

Findings and Conclusions 


\section{Findings}

Hospitals are complex organisations, one of the reasons for this are the many different professionals working together within one organisation. Of these professionals, physicians tend to have a decisive influence on the total hospital organisation (not only on medical issues, also on organisational outcomes such as finances and policy). This thesis focuses on the cooperation between physicians and managers. An initial assumption in our study is that the differences in professional cultures, and more specified, the different views between physicians and managers in hospitals influence the performance of the hospital. This means that increased professional manageability in hospital organisations should not only be found in changing the coordinating mechanisms or re-structuring activities. A powerful managerial tool could very well be: taking into account the differences between physicians and hospital managers in order to achieve better socialisation and cooperation and therewith enhance quality performance. We hypothesise that cultural differences between physicians and hospital managers are associated with the way quality management initiatives are accepted and implemented, reflected ultimately in hospital performance.

\section{Results chapter 2}

\section{Effective Cooperation Influencing Performance, a Study in Dutch Hospitals}

After an extensive literature review we started our research with a qualitative study among physicians and managers in order to explore their relationship and its possible influence on their mutual cooperation. For this we conducted 30 in-depth, semistructured interviews with physicians and managers from 5 different general hospitals in the Netherlands. The main outcome was a confirmation and specific depiction of the complexity of the relationship between physicians and managers and its perceived link to hospital performance. Aspects such as power and status differences, clarity in decision making, and personal click, were indicated as important in determining the effectiveness of the cooperation between physicians and managers. When asked which aspects of cooperation they would take into account when assessing this cooperation, managers mentioned the formal structure much more often than physicians. A topic of concern to managers is the hierarchical level at which decisions are made within the 
organisation; physicians often want to deal with the board members or top management, even on operational matters. More than half of the respondents found transparency of communication a relevant aspect. Both groups are concerned about clarity in decisionmaking and knowing where, how, and why decisions are made. Most important in the division of responsibilities is the way organisational and clinical responsibilities are distributed between physicians and managers. A manager noted: "Physicians have a large amount of clinical responsibilities, but they do not seem to take on the corresponding managerial responsibilities." The content of cooperation is linked to other aspects such as informal organisation, respect and trust.

Secondly, respondents were asked to note factors that have an impact on their satisfaction with cooperation between physicians and managers. More than half of the physicians said that the more visible management is, the easier things are accomplished. A typical other remark made was that a "personal click" (i.e. a positive perception of the other group or person based on personal characteristics) is needed with trust, warmth, and respect. Also negative aspects of satisfaction were expressed, such as decision making without consent and conflicting interests. A typical remark is: "The attitude and capability of managers is bad." Managers were concerned about the unfamiliarity of physicians with their hospital financial results. All of the respondents agreed that cooperation is an absolute prerequisite to attain a higher quality.

Furthermore we asked respondents which factors influence the satisfaction with hospital performance. An illustration of the responses of managers is found in the following quote, "Many initiatives take place, but they lack a structured approach throughout the hospital." A typical physician response was "Physicians are not using their powers because they are too busy keeping their own shops running; quality initiatives take too much time." Most doctors were unfamiliar with the performance indicators, but all managers had clear opinions about them. This seemed to widen the differences between both groups. 
Finally we asked which aspects of the cooperation between physicians and managers affect a hospital's performance? All managers agreed that "physicians have very little steering power, but do have preventative power. Physicians have informal power, because they can form a front against management; they can influence quality, budget, and production." A physician stated: "Individual physicians are not that bad, but hospital quality would improve if they cooperated more" and "Cooperation needs to be good otherwise you cannot deliver good quality. I do not mean medical quality, but quality of care." Almost all physicians and managers agreed that when the relationship between physicians and managers fails, it ultimately harms the patient.

The results of the qualitative study, as described in the second chapter, suggest that the effectiveness of cooperation between physicians and managers is related to the uptake of quality initiatives and hospital performance. But in literature there is still a need for systemic empirical and quantitative illustrations and explanations for these insights.

\section{Conclusions chapter 2: Effective Cooperation Influencing Performance, a Study in Dutch Hospitals}

From our qualitative interview study we found that cultural factors influence the cooperation, such as status differences, clarity in decision making, and "personal click". The complex relationship between physicians and managers in hospitals is based on their respective professional cultures. In literature, a situation like this is referred to as an intergroup situation. We found that, among others, Allport's contact theory (1954) on improving intergroup relations fits the hospital setting. We applied the key factors of this theory to the aspects found in our study, leading to the following ideas to facilitate effective cooperation between physicians and managers and therewith hospital performance:

1 Address common goals; questioning the added value of management and indicators can be interpreted as an expression of not having common goals between physicians and managers. Many projects focus on either medical or organisational quality. If both types of goals are not included in a hospital project, the risk is an emphasis on the differences between both groups, thereby eliciting the latent rivalry or intergroup competition. The intergroup literature has taught us 
the value of defining super-ordinate goals (Wright et. al., 2005) which addresses the needs of both groups and, at the same time, leads to a mutual goal for the whole group instead of multiple goals for the group members.

2 Create interdependent tasks; The second condition in Allport's theory is "no competition". From the power differences and non-alignments of medical and managerial responsibilities mentioned, we derive that quality initiatives are often seen by physicians as limiting their degree of professional autonomy. This is a potential source of conflict which strengthens feelings of competition and rivalry. In designing quality initiatives the tasks of both groups should be interdependent; the project needs the expertise of both professional domains to be successful. Furthermore, both groups should have the same level of understanding of the intervention.

3 Arrange the support of authorities; To enhance project commitment, support of both professional and organisational authorities need to be used: internal support by means of a medical board and board of directors, and external support by means of health inspectorates, scientific bodies and government agencies.

4 Equal status. Allport's fourth condition is "equal status". From our stereotypical study (chapter 4) we can conclude that there is an inequality in status between physicians and managers which is very difficult to "overcome". An effective quality initiative operation might consider the status gap by approaching the implementation from the medical domain, instead of the commonly used managerial focus. We suggest a change in the label of this condition into: "respect the medical domain".

From the interviews we can conclude that successful implementation of quality initiatives in hospitals needs a bottom-up approach with cooperative efforts by both physicians and managers, in order to improve performance and reduce unnecessary harm to patients. 


\section{Results chapter 3 Quantifying culture gaps between physicians and managers in Dutch hospitals: a survey}

In this study we aimed to develop a questionnaire which provides an opportunity to quantitatively report and elaborate on the size and content of differences between physicians and managers. More in-depth insight gained in these differences might enable us to reflect better on these differences and could provide practical tools to improve cooperation between physicians and managers, with an aim to enhance hospital performance. The questionnaire was based on Kralewski (2005) and was translated and adapted to the Dutch hospital setting. After piloting the questionnaire we measured the differences in how physicians $(n=166)$ and managers $(n=71)$ perceive the organisational work practices (present situation) and in the ways both groups wish reality to be changed (preferred situation). A factor analysis was performed to validate and shorten the questionnaire. This resulted in the Culture-Gap questionnaire (CGquestionnaire) containing 20 statements measuring the size and content of culture differences between both groups. Moreover, differences between both groups in the present and preferred situation could be classified into three categories.

(1) Culture gaps in the present situation and not in the preferred, in which case there apparently is a difference in the way both groups perceive reality. For instance, physicians and managers both agree on the fact that safety and quality in patient care should be guaranteed, and disagree on the level of implementation in the current situation (physicians are more satisfied). In this case physicians and managers do not show an inherent difference in cultures, but differences in perceived practices.

(2) Culture gaps in the preferred situation and not in the present. This means that members of both groups adjust their daily practices to hospital reality. If physicians and managers were given the choice to change the daily practices individually, physicians would change it in a different way than managers would. For instance, publicising about and mentioning the innovativeness of plans and relying on computer-based registration is preferred more by managers than by physicians. Physicians, on the other hand, prefer more informal consultations.

(3) Culture gaps in both situations, this reveals the most imminent aspects of the culture gaps. Therefore, these are presumably the most difficult aspects to change within a hospital organisation. For example physicians' values of the professional autonomy and 
collegiality among physicians are higher than among managers. Moreover, the physicians scored even higher in the preferred situation. Examples given by managers are that the registration of adverse events and the trust in the decisions made by the Board of Directors was higher in the current situation compared to the physicians. Managers want it to be even higher in the preferred situation.

The many culture gaps uncovered by this study confirm that a mere focus on rational organisational elements (process analysis, hierarchical and financial structures) may not be sufficient to improve hospital quality. Moreover, the cultural dimension, when thinking about organisational improvement, can be addressed more specifically. Our results support the next point made earlier in the literature: a focus on cooperation with an explicit eye for intergroup differences should be added to organisational improvement methods (Kaissi et. al., 2004; Williams et. al., 2007). With data from the CGquestionnaire it is possible to measure the size and content of gaps between physicians and managers in the hospital setting. The results of the study described in chapter three enable us to reflect on these differences and provides practical tools for the hospital organisation and for future research.

\section{Conclusions chapter 3: Quantifying culture gaps between physicians and managers in Dutch hospitals: a survey}

With data from the GAHP-questionnaire it is now possible to measure the size and content of culture gaps between physicians and managers in hospitals. Results gained with the CG-questionnaire enables hospitals to reflect on these differences. Combining the results, we distinguished three categories of increasing complexity. (1) culture gaps in the present situation and not in the preferred, (2) culture gaps in the preferred situation and not in the present, and (3) culture gaps in both situations. From an intergroup theoretical point of view these categories require different approaches to improve cooperation between culturally different groups (Ben-Ari, 2004). Clearly, the intergroup literature can provide us with new insights and methods to enhance cooperation in the professional culture difference setting between physicians and managers. Ben-Ari (2004), for instance, describes three types of methods that can be used to lessen intergroup conflict: the information method, the contact method, and the 
meta-cognition method. All three methods are based on the idea that an increased understanding of the other group enhances cooperation. The three different intergroup methods were applied to the three categories of results of our study, as discussed below.

1. In this first category the information method from intergroup literature might be effective to lessen the differences between both groups, because the differences are not based on inherent cultures but on differences in perceptions of daily practices. The information method is based on the theory that knowledge about the other group lessens the stereotypes and therefore enhances cooperation. The method consists of providing objective information about the other group (Triandis, 1980). The limitation of the information method is that if the intergroup differences are too large, this approach will not be sufficient (Ben-Ari, 2004).

2. In the second category, four statements scored culture gaps between physicians and managers in the preferred situation and not in the present situation. An intervention that might help in this case could be a method based on Allport's contact theory (Allport, 1954). This theory has been applied in many studies and has proven its value (Pettigrew \& Tropp, 2006). The contact theory maintains that contact between members of different groups enhances cooperation. According to Allport (1954) there are four conditions to be met for the contact to be effective: having common goals, no competition between groups, support by the authorities, and respect the medical domain. For example, the intervention could be a project in which both groups are given an assignment to mutually design a plan that integrates preferred situations for both groups. The situation in which both the preferred and the present situation are different, can be seen as a persisting intergroup conflict situation.

3. From intergroup literature, the third approach, meta cognition facilitates the overcoming of cognitive obstructions, preventing openness towards information about the other group. A training program could provide insight into the way cognition works and therefore the awareness of one's own prejudices towards the other group. This, in turn, provides the opportunity to reflect on the sources of 
prejudice. Insight into meta-cognitive processes can change people's perceptions and behaviour (Strack \& Hannover, 1996).

At the very least, our findings will increase the awareness of the importance of internal hospital tension, which is kept below the surface, and ultimately hindering effective cooperation. Our results may stimulate research into the relation between the size and content of culture gaps that hinder cooperation between physicians and managers and negatively affect the performance of hospitals.

\section{Results chapter 4 Stereotypical Images Between Physicians and Managers in Hospitals}

In this study we applied the Image theory of Alexander et. al. (2005a/b) to the hospital context in order to enrich current intervention schemes used in health care to facilitate organisational change. Results of this study confirm the applicability of the Image theory to the hospital organisational context. Due to different views which physicians and managers have and the professional attachment to their own groups (differences in professional cultures), an "us versus them" way of thinking is found. In literature this is referred to as an intergroup conflict setting, leading to stereotypical images of each other. The instrument used, measures stereotypical images between physicians and managers in the form of five survey questions. Four questions concern the relative power on hospital policy and professional status of physicians and managers. The fifth question asks for an opinion of the goal compatibility between both groups. The differences in scores between physicians and managers on the questions about relative power, status and goal incompatibility are further referred to as the "stereotypical gaps".

The scores on professional status clearly show that both groups agree on the higher professional status of physicians. The scores on power show that both groups disagree on who is higher in power; physicians see hospital managers as being higher in power and hospital managers see physicians as being higher in power. This means both groups feel relatively "powerless" in the same organisation. Both groups perceive a incompatibility with the outgroup (the other group). This result indicates a possible level 
of friction, or latent conflict, between both groups. According to Alexander et. al. (2005a/b), stereotypical images of physicians lead to a behavioural orientation of defensive protection towards the outgroup (the hospital managers). This means physicians will a priori probably not accept suggested organisational improvements by hospital managers. Organisational improvements, leading to changes in daily medical practices are not likely to be proposed by physicians to hospital managers. In analogy, stereotypical images of hospital managers could lead to feelings of resistance toward the outgroup (Alexander et. al., 2005a/b). This can resolve in negative interpretations by hospital managers of acts performed by physicians, possibly leading to an intensification of existing stereotypical images. These mechanisms may hamper the establishment of more effective cooperation between the two professional groups.

\section{Conclusions chapter 4 Stereotypical Images Between Physicians and Managers in Hospitals}

The results from chapter 4 validate the applicability of the Image theory in the hospital setting and give insight in the strength and direction of the stereotypical images between physicians and hospital managers. A balance has to be found between physicians seeing organisational improvements as limiting the professional freedom and hospital managers seeing physicians as being stubborn and not seeing the greater picture. Insight in the strength and direction of status and power differences and goal incompatibility between physicians and hospital managers, can be the input for defining the difficulties both groups are faced with when cooperating. When phsycians and hospital managers diminish relationship- and process conflict and focus on task conflicts, the effectiveness of cooperation is likely to rise. A starting point for improving the balance and cooperation could be the area we found common understanding between physicians and hospital managers: patient related problems. Based on knowledge from the Image theory, we recommend to start improving the hospital organisation on a micro level. Focusing on improving patient processes on an operational level can align medical and organisational goals, because this is an area where medical professional and organisational improvements can go hand in hand. This could lead to a better cooperation between physicians and hospital managers, so that improvements on the organisational level will be possible to execute. 


\section{GAHP-questionnaire}

In chapter five and six the gaps between physicians and managers were measured with the GAHP-questionnaire (GAps between Hospital managers and Physicians questionnaire). The GAHP-questionnaire was validated in two separate studies in five Dutch hospitals leading to a survey instrument, with three domains (Klopper, 2010). The first domain is based on organisational culture theory and assesses the differences in perceptions of daily practices, based on the respective professional cultures, of physicians and managers in both the present and preferred situation. The magnitudes of the differences between each pair of doctor and manager (from the same institution) were summed over the 20 culture gap questions. The actual organisational reality as perceived by members of both groups was reflected in answers given on statements about the present situation. Answers given to the statements in the preferred situation reflect the desired order (Berrio, 2003) revealing the inherent cultures of physicians and managers. These responses are further analysed as "culture gaps". The second domain is based on Image theory (Alexander et. al., 2005 a/b; Klopper et. al. 2009). We use five questions to measure stereotypical images between physicians and managers; four concern the relative power related to hospital policy and professional status of physicians and managers and the fifth asks for an opinion of the goal compatibility between both groups. The differences in scores between physicians and managers on the questions about relative power, status and goal incompatibility are further referred to as the "stereotypical gaps". The third domain contains three questions on a 10 point scale assessing satisfaction with quality of care, cooperation between physicians and managers, and the way innovations are implemented (further referred to as "satisfaction gaps"). The three domains of the GAHP-questionnaire result in ten within-institution gaps: two culture gaps, five stereotypical gaps and three satisfaction gaps.

\section{Results chapter 5 Intragroup differences between physicians and managers in Dutch hospitals leading to opportunities for better cooperation}

We analysed the intragroup variability within groups of physicians and managers in order to identify subgroups that can be focused on when more effective cooperation with the other group is needed. We found that there are many intragroup gaps within the groups of physicians and managers related to demographic characteristics. Although there are subgroups which show smaller gaps towards the other group, intergroup differences between physicians and managers are larger than the differences within both groups. The underlying assumption in this study is that the degree of difference of opinions (size of gaps) between physicians and managers is associated with the 
effectiveness of cooperation. It could however be argued that some degree of friction (constructive friction) between the two groups is necessary for productive cooperation (Carsten et. al., 2006). As described in the Introduction and supported by the results of previous studies (Klopper et. al., 2009/2010/2011), we conclude that the current degree of friction between physicians and managers is not constructive. Therefore, insight in the content and size of intragroup differences facilitates finding opportunities to enhance the cooperation between physicians and managers.

The scoring pattern of the group of medical physicians on the stereotypical gaps is the most similar to the scoring pattern of the managers. The more time a physician spends on managerial tasks, the more similar he (or she) scores compared to managers in terms of power (influence) of physicians and preferred working conditions. In terms of goal setting, surgical physicians and tactical managers have the largest gaps. Female physicians and female managers are most similar in their reported satisfaction levels. We did not find strong differences among physicians based on age or when they are associated with, or employed by the hospital. The scoring pattern of the group of managers exhibited fewer significant statistical differences than those found among physicians.

Focusing on the stronger associations we found that strategic managers are most similar to physicians in their perception of the power (influence) of managers. Operational managers, however, have the greatest gaps in power perception with physicians. Strategic managers have similar opinions on management influence as female physicians, but greatly differ to male physicians. In contrast, the gaps between tactical or operational managers and physicians were independent of physician gender. As noted above, female managers and female physicians are most similar in their satisfaction levels.

\section{Conclusions chapter 5: Intragroup differences between physicians and managers in Dutch hospitals leading to opportunities for better cooperation}

There is a higher diversity in perceptions, stereotypical images and satisfaction scores among physicians than among managers. Managers have a more homogeneous 
scoring pattern and are more outspoken (absolute scores) in their answering. Although, physicians share their professional training, from our data it appears that the daily practices are so different that they have a heterogeneous scoring pattern. For managers the converse may be true. Managers do not share a professional training but they might tend to be more addressed as a group to adhere to organisational goals, and therewith might have a more homogeneous scoring pattern. From intergroup literature (Cunningham, 2006) we learn that cooperation is hardest when more homogeneous groups merge with more diverse groups. This might be one of the reasons for the complex cooperation between physicians and managers.

From intergroup literature we know that meaningful contact between two groups lessens stereotypical behaviour and therewith enhances cooperation (Pettigrew \& Tropp, 2006). According to the similarity-attraction hypothesis (Rokeach, 1980), this meaningful contact is easier to develop when people are more alike. In the results we find that within the group of physicians the subgroups of medical, female, and physicians with more than 25 percent management tasks, show more resemblance to the group of managers. Furthermore, results indicate that the intergroup differences are larger than intragroup differences. Therefore we might conclude (also according to the similarity-attraction hypothesis) that intragroup members tend to remain more attracted to their own groups; and that the cooperation of one or more physician group members in a working group may have a positive influence on the acceptance of the outcomes of that working group by other physicians.

The data shows no strong differences among subgroups of both physicians and managers when considering age. When we combine this with the result that intergroup differences are larger than intragroup differences, we cannot subscribe to the idea that differences between physicians and managers will "automatically" cease over time with a younger generation.

The diversity within both the groups of physicians and managers provides an opportunity to identify members of subgroups who are more likely to effectively cooperate with each 
other because they indicate smaller gaps towards the other group. From our results we see that management participation by physicians might have a positive influence on cooperation between physicians and managers. Physicians that participate more than $25 \%$ of their time in management show significant smaller differences with managers than colleagues with lower participation levels, and also female and medical specialty physicians indicate smaller differences with managers. Strategic managers indicated the smallest differences, but on the whole, managers had fewer subgroups that exhibited distinct responses. From intergroup literature (Cunningham, 2006) we learn that intergroup bias is highest when more homogeneous groups (managers) merge with more heterogeneous groups (physicians). Managers should be aware of their group perceptions, because it might have an extra negative influence on the cooperation with physicians.

With the results from the study presented in chapter 4 awareness can be raised on effects that the composition of working groups in hospitals can have on the effectiveness of these groups. It gives opportunities for policy makers to select participants in a more focused way. It also provides interesting leads for further research whether effective cooperation can be influenced by training programs. These programs should aim to lessen the differences or create awareness about the effects the differences might have on the relationship between members of subgroups that show large differences towards the other group.

According to our data, female physicians, medical specialty physicians, and physicians who participate in management more than $25 \%$ of their time are the physicians that are most likely to effectively cooperate with managers.

\section{Results chapter 6 Culture differences between physicians and managers and hospital performance; a quantitative exploration}

The within-institute gaps were compared with the hospital indicator data. The questionnaire distributions were left skewed and the within-individual gaps were right skewed. QQ plots indicated that the gaps were right skewed and after square root 
transformations the distributions were approximately normal. Of the satisfaction gaps, cooperation and innovation exhibited the greatest variation in gap scores. All tests were conducted on the transformed variates.

The results were mapped on three performance categories which are graded in number and strength of statistical associations.

1. The first category strictly considers the significant associations at the 0.2 FDR threshold together with the indicator scoring a result with at least three gaps. There were 16 associations in this category. The stereotypical gaps and the two culture gaps were each associated with six indicators, while satisfaction gaps accounted for only four. Performance on "Solvability", "Clinical Patient Satisfaction" and "Heart failure readmission above 75 years of age" were each associated with three gaps.

2. In the second category indicators show associations at the 0.2 threshold with less than three gaps scoring or associations at the 0.3 FDR threshold. This category shows weaker associations than the first category, but still shows ten significant statistical associations; examples are the number of AAA (Abdominal Aortic Aneurysm) and OCR (Oesophageal Cancer Resection).

3. The indicators in the third category do not show a significant association with the cooperation between physicians and managers.

\section{Conclusions chapter 6: Culture differences between physicians and managers and hospital performance; a quantitative exploration}

This study provides a statistical foundation for the importance of more effective cooperation between physicians and managers in order to improve hospital performance. Data on the level of differences between physicians and hospital managers were linked to data on quality indicators in hospitals. In this study we identify the specific areas which are influenced by cooperation: solvability, patient satisfaction and heart failure readmission. Furthermore, we combine the results found in our study to intergroup theories leading to methods which can facilitate effective cooperation and hospital performance. 
The results confirm our hypothesis that effective cooperation between physicians and managers is significantly associated with quality performance in hospitals. The strongest associations are mostly on indicators concerning overall hospital performance (systemic indicators). On the indicators that measure medical quality performance we found weaker or not significant associations. Examples are: not planned re-operations of the colon, and inguinal hernia, and gallway complication after cholecystectomy. Our data point towards a discussion whether medical and managerial integration in quality performance in hospitals is already fully operational.

The results of this study were presented in three groups.

1. In the first group we find strong associations between cooperation and performance. Solvability and patient satisfaction are issues within hospitals on which both physicians and managers agree they have common, overriding goals. According to Jehn and Mannix's intergroup conflict theory (2001) on these quality issues, conflicts between physicians and managers are moderate and probably mostly related on task level. The will for both groups to improve performance might be triggered by simply providing information (Ben-Ari, 2004).

2. The indicators scoring in the second group include indicators that mostly require sufficient organisational conditions to provide high quality of care, such as OCR (Oesophageal Cancer Resection) and AAA (Abdominal Aortic Aneurysm). Effective contact (Allport 1954; Ben-Ari, 2004) between physicians and managers is called for to facilitate the process (and lessen probable process conflict (Jehn \& Mannix, 2001)) of improving the care related to these indicators.

3. In the third group we found no statistically significant associations between cooperation and performance. The indicators in this group were mostly medically oriented. In organisational matters concerning these indicators there might be an underlying relationship conflict (Jehn \& Mannix, 2001) between physicians and managers. In a relationship conflict there could be feelings of incompatibility, frustration, and irritation towards the other group which could be improved by the meta-cognition method (Ben-Ari, 2004). The medically oriented indicators (such as re-operations) have been solely a quality domain of physicians. Recently 
managerial methods such as time-out procedures or break-through projects have been introduced, which may influence the outcomes of these indicators. However, for physicians these methods are often seen as a threat to their professional autonomy, and therefore a possible negative influence on the cooperation between the two groups. The method of meta cognition does not focus on specific tasks or processes, but focuses on the deeper issues of personal and professional values. Consequently this method may help the two groups to (re)discover an understanding of the other's mutual focus on providing high quality care.

This study indicates that the impact of enhanced cooperation between physicians and managers is associated with indicators which are mostly managerially influenced and to a lesser extent medically orientated. The quality of medical performance seems to be predominantly a physician's affair. Improvement of cooperation between physicians and managers would appear to have a direct association with patient satisfaction and financial outcomes of the hospital. The association with medical outcomes is not clear yet. This can be explained by the top down managerial approach with which quality management has been developed within hospitals, but could also be a signal that integral quality performance of hospitals is still lacking. 


\section{Possible limitations}

\section{Differences versus similarity between physicians and managers}

We assume that frequently conflicting cultural values exist between physicians and managers in hospitals and, as a consequence, there is opposition between members of these groups. The authors are aware of the fact that there are many ways in which physicians and managers in hospitals work together successfully. Furthermore, it could be argued that some degree of friction (constructive friction) between the two groups is necessary to create a productive cooperation (Carsten et. al., 2006). In this thesis we conclude that the current degree of friction between physicians and managers is not as constructive as it should be. Therefore, insight in the content and size of the specific intragroup differences facilitates finding opportunities in enhancing the cooperation between physicians and managers. Moreover, the areas which show gaps between the groups, provide opportunities to improve cooperation and therewith the adoption of quality management and process improvements which could lead to improved results. Therefore we studied the differences and not the similarities between both groups.

\section{Organisational structures versus cultures}

In this thesis we do not take organisational structures into account. Although the author is aware of the fact that organisational structures do have an impact on the cooperation in hospitals (Burgoyne \& Lorbiecki, 1993), I choose to focus on the "softer" cultural oriented theories of organisations. In literature, the focus is usually on the structures (Klopper, 2010/2011). The results of this thesis aim to contribute to the current empirical knowledge on the effects of softer phenomena such as cooperation. 


\section{Generalisability to other Western countries}

The socio-economic structure of the Netherlands possibly influences the way physicians and managers (co)operate. The underlying issues in health care (such as the need for more efficiency, safety, and quality of care) are however, major issues in all (Western) countries (Raelin, 1991; Edwards, 2003; Shortell et. al., 2004; Williams et. al., 2007). Furthermore literature describes the complex relationship between physicians and managers as a universal problem. We believe our findings can be relevant for all (Western) countries. Therefore, it could be of interest for hospital organisations outside the Netherlands to apply the GAHP-questionnaire. The applicability and validity should be studied before using the GAHP-questionnaire in other countries. However, there are a number of countries in which the validation process could be easier because of the similarity in the organisation of their health care systems, for example: Germany, Belgium, France and the Scandinavian countries.

\section{Academic versus general hospitals}

We analysed the relationship between physicians and managers in general hospitals. Apart from these there are also (eight) academic hospitals in the Netherlands, and the results cannot automatically be generalised to those. In academic hospitals, physicians have to do research and take care of education in addition to patient care. The physicians in these hospitals are usually employed and have a physician as their hierarchical superior. This is in contrast to the general hospitals where there are "private firms within the hospital setting". Another difference between academic hospitals and general hospitals is the financial structure. These different characteristics are likely to influence the level of cooperation between physicians and managers. Further research could provide insight in the nature of and possible differences in cooperation between physicians and managers within academic hospitals.

\section{Participating hospitals and response rates}

To spread the survey among its intended respondents nationally, we needed the cooperation of general hospitals in the Netherlands $(\mathrm{N}=86)$. The participating general hospitals were classified as small, medium, large, and teaching hospitals, and 
geographically spread over the Netherlands. The spread of the non-participating hospitals did not differ from the participating hospitals. Therefore the sample of 46 hospitals can be seen as a representative sample of the Dutch hospitals. The response rate among the physicians was $24 \%$ (929/3941) and from managers $45 \%$ (310/680). For the 37 hospitals analysed in chapter five and six the response rate from physicians of $24 \%$ (888/3701) was lower than the response from managers of $45 \%$ (280/616), $(p<0.0001)$. These are low response rates and therefore we searched for possible nonresponse bias. We could not find significant associations with either location $(p=0.91$ physicians; and $p=0.07$ managers) or institute type ( $p=0.57$ physicians; and $p=0.33$ managers). Although the analysis of the response bias for both the types of hospitals and the characteristics of the respondents revealed no significant bias, the authors would have preferred the response to be higher as this would have contributed to the power of the findings.

\section{Questionnaire}

The questionnaire statements concerning the organisational culture gaps, measure the size and content of differences between physicians and managers. We constructed the questionnaire based on Kralewski's culture questionnaire (2005) and shortened it from 60 to 20 statements (chapter 3). We selected the statements based on an exploratory factor analysis, intercorrelation coefficients, and Cronbach's alpha's, which resulted in statements which were sensitive to differences between physicians and managers.

In the statistical analyses, we could not confirm Kralewski's nine dimensions. We repeated the factor analysis with Varimax rotation on the results of the original translated statements and this did not show the initial nine dimensions. The following factors could have caused this.

First, our objective was different from the initial goal of Kralewski's questionnaire; the culture gap statements intend to measure the size and content of culture differences between physicians and managers. Kralewski's questionnaire is developed to differentiate between medical groups.

Second, the Dutch hospital system differs from the situation in the USA given the nonprofit type of hospital organisations and more pronounced governmental central 
regulation. The different socio-economic structure possibly influences the way physicians and managers (co)operate. This is also the reason for altering two statements earlier and the addition of one statement (to the dimension "business emphasis") before the pre-test; these three statements were incorporated into the final set of 20 statements comprising our CG-questionnaire. Although we could not confirm the dimensions of Kralewski et. al. statistically, the CG-questionnaire meets our research objective. Data gained with the questionnaire give us practical tools to enhance cooperation between both groups. The high Cronbachs alphas of the CG-questionnaire 0.70 and 0.75 present, 0.76 and 0.79 preferred) show that the statements in the questionnaire form a coherent construction.

\section{Performance indicators}

The ultimate hypothesis examined in this thesis is that the smaller the differences between physicians and managers, the better the cooperation and therewith performance of the hospital. The aim of the sixth chapter in this thesis is to find areas of hospital performance that are influenced by the cooperation between physicians and managers. Defining hospital performance, however, remains difficult (Donabedian, 2005). Currently many institutions aim to measure the quality of hospital performance to monitor (health inspectorate) or finance (insurers) health care. Examples of these are the PATH framework (Veillard et. al., 2005), consisting of 6 interdependent dimensions, and the Consumer Assessment of Health Providers and Systems (CAHPS), which assesses multiple aspects of patient satisfaction (Delnoij et. al., 2006). In this study we used the selection of quality indicators issued by the Dutch Health Care Inspectorate because these indicators cover a wide range of performance areas. These indicators do not represent all areas of health care performance or health care quality as for example patient centeredness (a part of the PATH program) and reports on medication errors (which injure 1,5 million people and cost billions of dollars annually, National Academy, 2006) are missing. Therefore this study does not provide a complete overview of possible aspects of performance associated with cooperation between physicians and managers. Currently, however, a better (i.e. more comprehensive) set of performance indicators is not publicly available. 


\section{Study design and methodology}

Culture related research has to be executed on several aspects of measurable expressions of culture (Schein, 1996), such as perspectives, behaviour, values, rationalisation, emotions, beliefs and opinions. In our study we asked for perceptions of daily practices, perceived differences in power, status and goal compatibility and satisfaction with innovation, cooperation and quality of care. With these we studied several aspects but did not include all possible aspects. Because we included three different gaps, stemming from both organisational culture literature and the intergroup literature, we feel that data gained with our study does sufficiently reflect the relationship between physicians and managers.

In recent decades innovative statistical methods have become available, especially related to the introduction of such techniques as microarrays and proteomics. In the social sciences a parallel progress occurred with the introduction of web-based questionnaires and online data sources. These new tools allowed scientists to explore much larger datasets and test many more hypotheses than has traditionally been possible. In such exploratory settings, solely reporting $p$-values generated under the assumption of appropriately powered pre-specified hypotheses is misleading due to an excessive Type I error rate. Furthermore the application of traditional multiple test adjustments is also problematic due to large number of tests, often resulting in an excessive Type II error rate. This scientific dilemma has motivated scientists to develop appropriate statistics to address such problems. One solution has been the development of the FDR technique, which utilises the large number of tests to model the null hypothesis (i.e. no true association). Estimating the null allows to discover if there is a number of falsely "significant" results. In this study we used the FDR method to categorise the associations between hospital indicators and the ten within-institution gaps into three categories: strong $(F D R<0.2)$, moderate $(0.2<F D R<0.3)$ and weak 
(FDR $>0.3$ ). The study design does not provide the possibility to deduct causal relations between cooperation and performance, therefore this study indicates associations.

The significant associations found could have been influenced by intermediate variables. For instance: effective cooperation between physicians and managers can have a positive influence on the work atmosphere in the hospital. This in turn could influence the motivation and satisfaction of the nursing staff, leading to a possible increase in performance.

Hospitals occupy many groups of professionals, such as nurses and paramedics. Nevertheless physicians are likely to be the most important stakeholder group when improving hospital operations. The influence of the cooperation between managers and other occupational groups such as nurses and paramedics could be studied in future research, however their relative power and position should be taken into account.

\section{Independence of principal researcher}

The studies were done by a manager in a hospital which had advantages and disadvantages for this $\mathrm{PhD}$ thesis. Being a manager herself she had to be constantly aware of the threat of losing her objectivity as a researcher, and of the multiple angles to tackle the study questions, instead of performing this study from the managerial point of view. However, working in the hospital context herself provided a practical (realistic) point of view. The many discussions she had with her co-researchers and promotors helped her in guarding the objectivity and research focus needed for this thesis. Working in the field herself gave her the opportunity to more easily obtain data from, and access to, physicians and managers. Another example of an advantage was the possibility to receive feedback and discuss the face validity of the results. 


\section{Further research}

In order to gain more (multidisciplinary) empirical knowledge on possible intergroup interventions that enhance inter-professional group relations in hospitals, further research is advised to include a longitudinal action-research type case-study in which the insights that we gained theoretically in this study are applied to an intervention. These studies could include implementation projects within hospitals which are designed with an explicit eye on Allport's and Ben-Ari's intergroup's methods. Also studying the relation between different gap sizes between physicians and managers and the effectiveness of their cooperation coul be relevant; it is possible that an optimal gap exists that could be hypothesised as causing productive friction. Either longitudinal studies using interventions, or studies covering large numbers in cross-sectional designs, could lead to new and creative insights to significantly enhance the effectiveness of the cooperation. The need for effective cooperation between members of professional groups within hospitals is not restricted to physicians and hospital managers. It would need to be studied in further research whether the aspects and mechanisms we found in this research apply to the cooperation between these other professionals and managers as well. The study is performed in Dutch general hospitals, therefore, the applicability of the questionnaire may seem restricted to this setting. Based on the literature review and the results of this study we expect the questionnaire to be largely suitable for other health care settings, such as academic, non-Dutch, profit and categorical hospitals. However, before applying the GAHP-questionnaire in other settings, validation is required. The applicability of our questionnaire should also be tested before using the questionnaire with other groups (nurses, physiotherapists, psychologists etc.) in hospital settings.

Discussing complex organizational themes within the hospitals around a superordinate goal, in which differences of viewpoints and opinions have to be discussed, might enhance outcomes (Allport, 1954). An example of this could be the introduction of market elements and its translation in the hospital organisation. This creates a possible external threat and therewith a superordinate goal of for example preservation of patient volumes. The probable different viewpoints physicians and managers have on solutions 
for the problem can be seen as a task conflict (physicians will probably focus on extra capacity, while managers search for more efficiency). If the organisation handles this well, the focus will be on task conflicts instead of relationship- or process conflicts. When mututal collaboration is necessary for the successful completion of an interdependent task, it will promote better understanding and therewith cooperation between groups (Galinsky, 2002). Purposefully defining superordinate goals and using the positive effects of task conflict (Jehn \& Mannix, 2001) could be the input for reducing relationship conflict. Future research could be aimed at exploring these conclusions.

Hospitals try to enhance cooperation between physicians and managers by implementing structure solutions aiming to incorporate interdependency between physicians and management (Weiner et. al. 1997) such as management or financial participation of physicians. We found that physicians with a higher degree of management participation show more similar opinions towards those of managers. Although we did not study whether this is because the physicians who participate in management have differing perceptions at the start or that their perceptions change when they participate in management, these results underline the positive effect of the efforts taken by hospitals to implement structures that involve physicians in management. Further research is required to investigate the optimal balance between physicians' medical and managerial tasks. Our study provides insight with which awareness can be aroused on effects that the composition of working groups in hospitals can have on the effectiveness of that group. Future research might also study whether effective cooperation can be influenced by a training program that either aims to lessen the perceptual differences or creates awareness about the effects differences might have on the relationship between members of subgroups that show large differences towards the other group.

It seems worth studying also whether further involvement of managers in medically orientated quality performance programs, and physicians in quality management systems, leads to better performance of the hospital. Future research could assess if the current reforms towards market orientation, transparency, and the implementation of 
quality systems may lead to a better cooperation between physicians and managers and enhanced performance of hospitals. From literature (Alexander, 2005a/b; Klopper, 2009) we know that the lesser the power, status and goal differences between both groups, the better the cooperation is. It would be interesting to study whether this is the same for the other differences between physicians and managers (Kaissi, 2005), such as, the autonomy of physicians; the peer identification (physicians) versus the hospital identification (managers); and the acceptation of bureaucratic control by physicians versus acceptation of self control by managers. Other future research on subgroups of physicians and managers may study if there is a difference in association between cooperation and performance at the subgroup level; it could be hypothesised that members of certain subgroups are more willing to cooperate, this could positively facilitate performance improvement. In this thesis we used the set of indicators of the Dutch Health Inspectorate that is published on the Internet and therewith available for research. Further research would need to include other or more performance indicators in order to generalise the found associations in this study, and longitudinal studies are needed to find out whether the associations between intergroup cooperation and hospital performance change or grow stronger. 


\section{Overall conclusion}

The aim of this thesis is to provide a basis that enables better understanding of the social interaction between physicians and managers in hospitals, in order to safeguard and improve the quality of care patients receive. We emphasise that one of the key mechanisms influencing effective manageability of hospitals pertains to the dynamic relations among physicians and managers in hospitals, through all organisational levels. One of the contributions of this thesis is that it provides insight in the complex cooperation between physicians and managers. These aspects have been measured with three different methods: culture gaps, stereotypical gaps and the gaps between the level of satisfaction with quality, innovation and cooperation. Moreover, intergroup literature and methods are introduced to health care. Intergroup conflict theories are suitable for describing the potentially conflicting relationship between physicians and managers. A new aspect in literature, coming from this thesis is that we statistically associated the above mentioned gaps between physicians and managers with the hospital quality indicators. Next to the quantification and statistical association of the relationship between physicians and managers we recommend the application of various intergroup theory based methods for improved cooperation in hospitals. The organisational dynamics and processes between physicians and managers we analysed in this thesis, led to the derivation of a visual framework (see below), depicting the influence of cultural differences involved in effective cooperation between members of the two groups on hospital performance. Especially intergroup literature provides methods to improve complex cooperation which might be applied to issues concerning the effective implementation of quality in hospitals. Jehn and Mannix (2001) describe a hierarchy of conflict in three levels, task, process and relationship. Ben-Ari (2004) describes three approaches to tackle these: the information, contact, and meta-cognition method. If conflicts between physicians and managers are moderate and mostly related on task level, the wish of both groups to improve performance in cooperation could be triggered by simply providing information. A valuable method to improve intergroup cooperation when conflicts are on a process level is Allport's contact theory (1954), BenAri's second approach. The four conditions that have to be met are: common goals, support of authorities, no competition, and respect the professional domain. On conflicts 
on the relationship level the method of meta cognition might improve cooperation. Meta cognition focuses on the deeper issues of personal and professional values, through analysing and being conscious of the way we think and act. In this thesis we combined the intergroup- and organisational culture literature and applied these to a hospital setting. Since culture measurement is very difficult, we felt that research on different culture related topics has to be carried out to achieve better insights on the complex relationship between physicians and hospital managers. As in all culture-related studies, a multi-method approach, with both qualitative and quantitative research was necessary. Quantitative and qualitative data collected in the form of several consecutive empirical studies enabled us to reach our research findings.

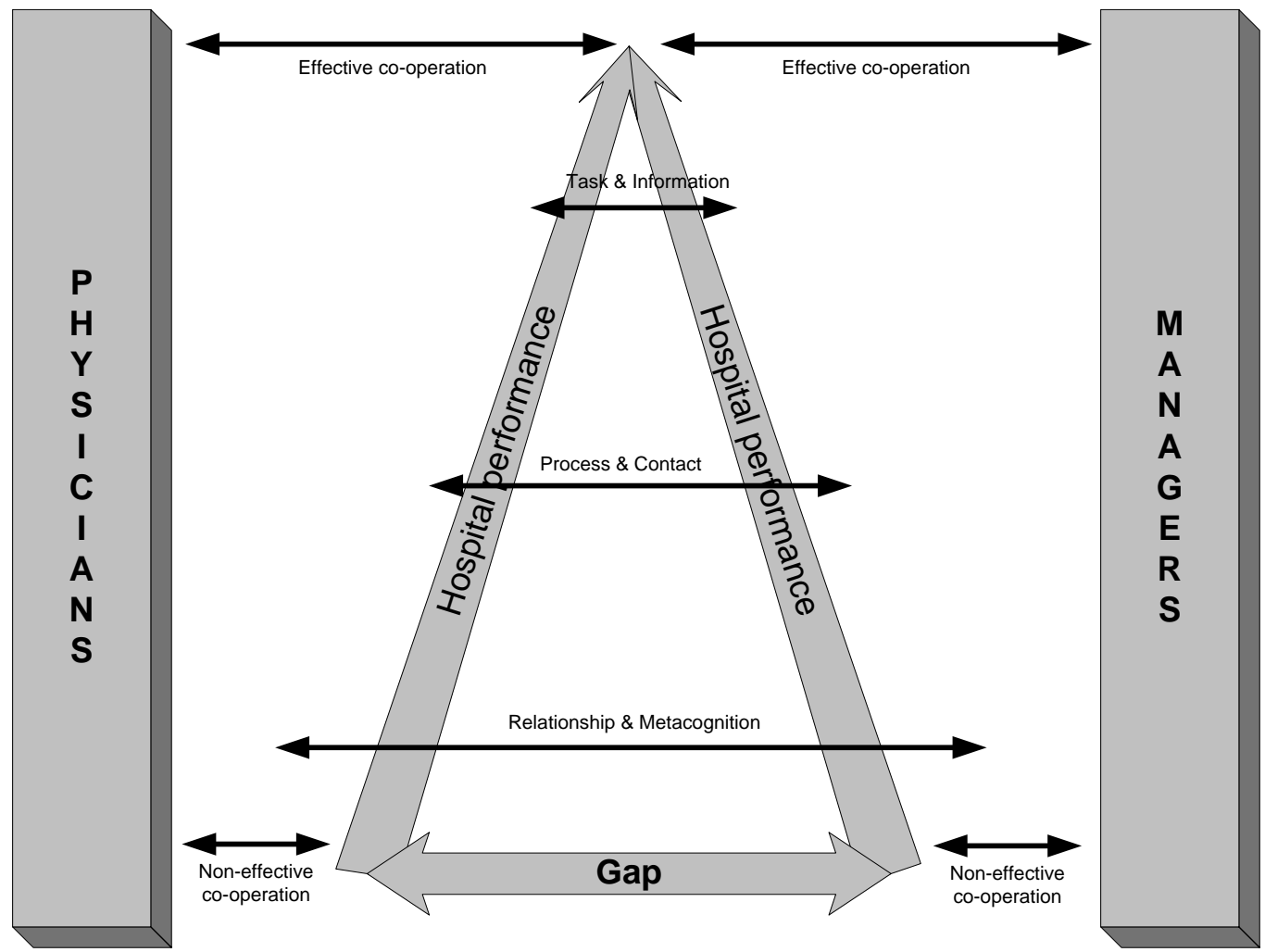

Visual framework illustrating the usage of intergroup intervention methods.

The results of this thesis confirm the existence of the presumed latent conflict between physicians and managers and show that, below the surface of the daily practices, the relationship between (members of) both groups is tense, leading to suboptimal cooperation. This might decrease hospital performance, and could ultimately harm 
patients. One of the biggest challenges in hospitals is to improve quality of care and patient satisfaction, and simultaneously control costs. The results encourage to focus on improved cooperation between physicians and managers when implementing performance initiatives; effective cooperation between physicians and managers may be one of the key factors to face our challenges. 


\section{References}

Alexander MG, Brewer MB, Livingston RW. Putting stereotype content in context: Image theory and interethnic stereotypes. J Pers Soc Psych. 2005a;31:781-94.

Alexander MG, Levin S, Henry PJ. Image theory, social identity and social dominance: structural characteristics and individual motives underlying international images. Polit Psychol. 2005b;26:27-45.

Allport GW. The nature of prejudice. Reading: Addison-Wesley; 1954.

Ben-Ari R. Coping with the Jewish-Arab conflict: a comparison among three models. J Soc Issues. 2004;60:307-22.

Berrio AA. An organizational culture assessment using the Competing Values Framework: A profile of Ohio State University Extension.

[http://www.joe.org/joe/2003april/a3.php] website

Journal of Extension. 2003;41.

Burgoyne J, Lorbiecki A. Clinicians into management: the experience in context. Health Serv Manage Res. 1993;6:248-59.

Carsten W, De Dreu W, Beersma B. Conflict in organizations: beyond effectiveness and performance. Eur J Work Organ Psy. 2006;14:105-17.

Cunningham GB. The influence of group diversity on intergroup bias following recategorization. J Soc Psychol. 2006;146:533-47.

Delnoij DMJ, Ten Asbroek G, Arah OA, De Koning JS, Stam P, Poll A, Vriens B, Schmidt $P$, Klazinga NS. Made in the USA: the import of American Consumer Assessment of Health Plan Surveys (CAHPS ${ }^{\circledR}$ ) into the Dutch social insurance system. Eur J Public Health. 2006;16:652-9.

Donabedian A. Evaluating the quality of medical care. Milbank Q. 2005;83:691-729.

Edwards N. Doctors and managers: poor relationships may be damaging patients - what can be done? Qual Saf Health Care. 2003;12:21-4.

Galinsky AD. Creating and reducing intergroup conflict: the role of perspective taking in effecting out-group evaluations. Research on managing groups and teams. 2002;4:85113.

Jehn KA, Mannix E. The dynamic nature of conflict a longitudinal study of intragroup conflict and group performance. Acad Manage J. 2001;44:238-51. 
Kaissi A, Kralewski J, Curoe A, Dowd B, Silversmith J. How does the culture of medical group practices influence the types of programs used to assure quality of care? Health Care Manage Rev. 2004;2:129-38.

Kaissi A. Manager-physician relationships: an organizational theory perspective. Health Care Manage Rev. 2005;24:165-76.

Klopper AHJ, Meerdink N, Harten WH van, Wilderom CPM. Stereotypical images between physicians and managers in hospitals. J Health Organ Manage. 2009;2:216-24.

Klopper AHJ, Siesling S, Meerdink N, Wilderom CPM, Harten WH van. Quantifying culture gaps between physicians and managers in Dutch hospitals: A survey. BMC health serv res. 2010;10:86.

Klopper AHJ, Meerdink N, Harten WH van, Wilderom CPM. Effective cooperation influencing performance, a study in Dutch hospitals. Int J Qual Health Care. 2011;23:949.

Kralewski JE, Dowd BE, Kaissi A., Curoe A, Rockwood T. Measuring the culture of medical group practices. Health Care Manage Rev. 2005;30:184-93.

Pettigrew TF, Tropp LR. A meta-analytic test of intergroup contact theory. J Pers Soc Psychol. 2006;90:751-83.

Raelin JA. The clash of cultures: managers managing professionals. Boston: Harvard Business School Press; 1991.

Rokeach M. Some unresolved issues in theories of believes, attitudes, and values. Symposium on Motivation. 1980;27:261-304.

Schein EH. Culture: The missing concept in organization studies. Admin Sci Quart. 1996;41:229-40.

Shortell SM, Marsteller JA, Lin M, Pearson ML, Wu SY, Mendel P, Cretin S, Rosen M. The role of perceived team effectiveness in improving chronic illness care. Med Care. 2004;42:1040-8b.

Strack F, Hannover B. Awareness of influence as a precondition for implementing correctional goals. In The psychology of action: Linking cognition and motivation to behavior. Gollwitzer PM, Bargh JA. (eds.). New York: Guilford Press; 1996:579-96.

Triandis HC. Cultural training, cognitive complexity, and interpersonal attitude. In Crosscultural perspectives on learning. Brislin R, Bochner S, Lonner W. (eds.). New York: Wiley; 1980:39-77. 
Veillard J, Champagne F, Klazinga H, Kazandjian V, Arah OA, Guisset Al. A performance assessment framework for hospitals: the WHO regional office for Europe PATH project. Int J Qual Health Care. 2005;17:487-96.

Weiner BJ, Shortell SM, Alexander J. Promoting clinical involvement in hospital quality improvement efforts: the effect on top management, board, and physician leadership. Health Serv Res. 1997;32:491-510.

Williams ES, Manwell LB, Konrad TR, Linzer M. The relationship of organizational culture, stress, satisfaction, and burnout with physician-reported error and suboptimal patient care: Results from the MEMO study. Health Care Manage Rev. 2007;32:203-12.

Wright SC, Brody SW, Aron A. Intergroup contact: Still our best hope for improving intergroup relations. In Social Psychology of Prejudice: Historical and Contemporary Issues. Seattle: Lewinian Press; 2005. 


\title{
Nederlandse samenvatting
}

\author{
Mind the gap \\ Onderzoek naar effectieve samenwerking tussen medisch specialisten en \\ managers in Nederlandse ziekenhuizen en de relatie van die samenwerking met \\ kwaliteit van het ziekenhuis.
}


Van een afstand gezien lijkt de arts-manager relatie in ziekenhuizen vaak goed. Beide groepen zijn beleefd naar elkaar, op het eerste gezicht aardig. Maar zodra de belangen van beide groepen iets uit elkaar liggen, wordt duidelijk dat dit een lastige relatie met veel tegenstellingen is. Uit de literatuur blijkt dat er tussen de groepen van artsen en managers grote verschillen bestaan, die de samenwerking tussen beide groepen niet vergemakkelijken.

Een voorbeeld van de verschillen is dat de artsen het technisch primaat hebben. Als een manager een arts vraagt naar de inhoud van zijn werk is het wederwoord vaak: "bent u ook arts?" Een manager mag en kan zich niet bemoeien met de inhoud van het medische werk. Artsen hebben een eigen beroepscultuur. Dit is goed te merken bij jonge arts-assistenten; na een paar maanden in opleiding tot specialist hebben ze de houding van een echte "arts", is er iets in ze veranderd. De jonge arts-assistenten worden gevormd tot leden van de beroepscultuur, die zorgt voor een normen en waardenpatroon (wat je wel en niet kunt doen) en een saamhorigheidsgevoel.

De complexe samenwerking tussen artsen en managers is onder andere gebaseerd op de grote verschillen in waardepatronen tussen beide groepen. Medisch specialisten hebben controle over hun eigen werk. De relatie met de patiënt is 1 op 1 in de spreekkamer, de besluiten over de wijze van behandeling en diagnostiek moeten daar door de arts kunnen worden genomen. Wat er binnen de spreekkamers gebeurt, bepaalt wat de organisatie moet organiseren. Specialisten hebben professionele autonomie, hetgeen nodig is in het kader van patiëntzorg.

Managers baseren zich op organisatiestructuren en standaardisatie. Deze verschillen in wijze van ordening van werk conflicteren. Het resulterende organisatiebeeld in een ziekenhuis is dat van een duale hiërarchie (Mintzberg, 1989); er is specialistenhiërarchie en organisatiehiërarchie. Door de vergrote externe verantwoordingdruk is er een kentering in deze zelfcontrole, maar blijft het werk van de arts autonoom, dit is ook wettelijk vastgelegd. De organisatorische tegenhanger van de zelfcontrole van artsen is bureaucratische controle. Managers formuleren beleid in "SMART" doelen. Deze handelswijze is voor artsen lastig te begrijpen en heeft zeker niet voldoende status om daar zo maar naar te gaan handelen. Onder managers bestaat hiërarchische controle; bij een bepaalde functie hoort een verantwoordelijkheid voor de medewerkers en een verantwoording naar de organisatie of leidinggevende. Bij managers wordt status verkregen door het hiërarchisch niveau van de functie. Dit is binnen de groep van specialisten een onbekend fenomeen. Een gevolg is dat de status van managers niet zomaar door artsen wordt geaccepteerd. Specialisten verkrijgen een positie door hun status. De status wordt verworven door bijvoorbeeld het hebben van wetenschappelijke publicaties en door innovatief werken met nieuwe methoden en apparatuur. Bij artsen is de identificatie met de eigen beroepsgroep belangrijk, een arts zal aangeven "wat" hij is: radiotherapeut of internist. De primaire identificatie ligt bij de wetenschappelijke vereniging. Een manager geeft meestal gelijk met zijn functie aan in welk ziekenhuis hij werkt. Hij identificeert zich met de organisatie. De focus van identificatie verschilt tussen artsen en managers. Daarmee is het beroep dat op artsen wordt gedaan om mee te werken aan de doelen van de ziekenhuisorganisatie voor hen niet vanzelfsprekend terwijl het voor managers juist de basis van hun werkzaamheden is. 
Door de vergrote externe verantwoordingsdruk vanuit o.a. de Inspectie voor de Gezondheidszorg, de zorgverzekeraars, door mondiger patiënten, en door bezuinigingen bij de overheid, is in Nederlandse ziekenhuizen, de organisatie van zorg die door de arts eigenstandig bepaald wordt niet meer mogelijk. Met de grotere druk op transparantie en verantwoording is de invloed van managers op het ziekenhuisbeleid groter geworden. Dat versterkt het belang van een goede samenwerking tussen artsen en managers. Managers zijn expert op het terrein van organiseren en budgetteren en eisen daarmee in het ziekenhuis hun eigen terrein op. Het gevolg is een machtsstrijd tussen artsen en managers. Vanwege het primaat dat specialisten in het ziekenhuis hebben doordat zij degenen zijn die de zorg aan de patiënt verlenen, is het voor managers belangrijk te zorgen voor draagvlak. Indien een manager niet zorgt voor begrip en goede samenwerking, raakt hij zijn invloed op de uitvoering van het beleid kwijt. Vanwege de groeiende importantie van efficiënt management is het voor specialisten van toenemend belang dat zij in staat zijn (of gesteld worden) innovaties op gestructureerde en economisch verantwoorde wijze in te brengen om zodoende überhaupt kans te maken op verwerkelijking van hun wensen.

Vanuit de context van de grote verschillen tussen artsen en managers is de hoofdhypothese van dit proefschrift geformuleerd: hoe kleiner de verschillen tussen artsen en managers, des te beter de samenwerking en daarmee de kwaliteit van het ziekenhuis.

Om deze hypothese te toetsen bij artsen en managers in algemene ziekenhuizen is dit onderzoek gestart met het afnemen van interviews bij in totaal 30 artsen en managers in vijf ziekenhuizen. Het gesprek ging over de perceptie van de respondenten over de samenwerking tussen artsen en managers en hoe zij de invloed van die samenwerking op de kwaliteit van het ziekenhuis ervaren. Door de informatie uit deze interviews werd de vooronderstelling, dat er een relatie bestond tussen de samenwerking van artsen en managers en de ziekenhuisresultaten, gesterkt. De volgende stap was het ontwikkelen van een valide instrument om kwantitatieve vergelijkingen van de samenwerking tussen artsen en managers mogelijk te maken. Kwantitatief vergelijken is belangrijk, omdat er in de literatuur nog geen kwantitatieve vaststelling van de relatie tussen de samenwerking tussen artsen en managers en de associatie met kwaliteit van ziekenhuizen is gepubliceerd. Daarnaast was voor mij, als manager in een ziekenhuis, de objectivering van een kwantitatief onderzoek belangrijk.

De voor het proefschrift ontwikkelde vragenlijst (GAHP-questionnaire) bestaat uit drie delen die de mate van samenwerking tussen specialisten en managers vanuit verschillende theoretisch verantwoorde benaderingen meet: de organisatiecultuur benadering, de intergroep benadering en drie vragen die direct de tevredenheid met samenwerking, kwaliteit en innovaties bevragen.

De organisatie cultuurvragenlijst (CG-vragenlijst, een van de drie onderdelen van de GAHP-questionnaire) is gebaseerd op Kralewski (2005) en is in twee studies gevalideerd. De lijst bestaat uit 20 stellingen, waarbij naar de perceptie van de huidige en de gewenste dagelijkse werkpraktijk wordt gevraagd. Volgens Hofstede et. al. (1990) is het vragen naar de dagelijkse praktijk de meest accurate benadering van de 
werkelijkheid. Het vragen naar zowel de huidige als de gewenste praktijk voegt een dimensie toe. Antwoorden op de vragen naar de percepties in de huidige situatie geven informatie over de percepties van de bestaande samenwerking tussen artsen en managers. De informatie die wordt verkregen als gevraagd wordt naar de gewenste situatie geeft inzicht in de werkelijke visie van de respondenten, zonder dat daar de dagelijkse invloed van andere partijen bij betrokken is. Deze informatie bevat eigen normen en waarden van de respondenten.

De tweede benadering van de vragenlijst is gebaseerd op de intergroep literatuur. In de beginfase van deze promotiestudie werd ik geattendeerd op onderzoek resultaten van Kelman (1997). Kelman heeft gedurende lange tijd onderzoek gedaan naar de verschillen tussen Palestijnen en Israëlieten en de wijze waarop deze groepen zouden kunnen toewerken naar een vreedzame samenleving. Hij baseert zich daarbij op de intergroep literatuur die zijn fundatie kent in het onderzoek naar de samenwerking tussen blanken en zwarten in Amerika. Gezien de grote cultuurverschillen tussen artsen en managers leken de methoden en technieken uit de intergroep literatuur toepasbaar op deze samenwerking. Bij bestudering van die literatuur bleek dat er niet alleen een scala aan onderzoeksmogelijkheden naar de relatie tussen artsen en managers mogelijk was geworden, maar bleek deze ook verbeteringmethoden te herbergen Allport, 1954, Jehn en Mannix, 2001, Ben-Ari, 2004, Pettigrew \& Tropp, 2006). De intergroep literatuur stelt zich ten doel de volgende vraag te beantwoorden: "Door middel van welke methoden en technieken kunnen twee groepen die zeer van elkaar verschillen worden gestimuleerd om effectief samen te werken?" Een begrip binnen de intergroep literatuur is stereotypering. Stereotypering is een onderdeel van de image theorie en wordt gedefinieerd als; "het generaliseren van een eigenschap van een deel van een groep dat leidt tot een stabiel, gesimplificeerd en overdreven beeld van die groep" (Tajfel, 1978; Turner et. al., 1987). Voorbeelden hiervan zijn, alle Afrikanen kunnen goed dansen, alle Nederlanders dragen klompen, alle Amerikanen zijn dik en Duitsers hebben geen humor. Hoe sterker de stereotypering, hoe minder de kennis van de andere groep. De sterkte van de stereotypering kan worden gemeten door middel van de sterkte van drie factoren: relatieve status, relatieve macht en mate waarin doelstellingen overeen komen. Uit deze drie factoren wordt door de image theorie stereotype beelden samengesteld.

Het derde onderdeel van de vragenlijst wordt gevormd door drie directe tevredenheidsvragen: Hoe tevreden bent $u$ met a. de samenwerking tussen artsen en managers in uw ziekenhuis, b. de mate van innovaties in uw ziekenhuis en c. de kwaliteit van zorg in uw ziekenhuis.

De vragenlijst is verstuurd naar 46 algemene ziekenhuizen in Nederland die bereid waren te participeren in het onderzoek. Aan deze ziekenhuizen is gevraagd de internetvragenlijst door te mailen aan alle, binnen dat ziekenhuis werkzame, artsen en managers. Dit heeft geresulteerd in een respons van 929 artsen (24\%) en 310 managers (46\%). De respondenten waren goed verdeeld over de groepen, waardoor ondanks het lage responspercentage onder de artsen, er toch van een representatieve steekproef mag worden gesproken. 
De resultaten van de organisatie cultuurvragenlijst (hoofdstuk 3) zijn geclassificeerd in drie opeenvolgende categorieën.

1. Categorie 1: Verschillen tussen artsen en managers in de huidige maar niet in de gewenste situatie. Dan is er verschil in de wijze waarop artsen en managers de werkelijkheid ervaren. Een van de voorbeelden hiervan is dat artsen en managers het met elkaar eens zijn dat veiligheid en kwaliteit voor patiënten moet worden gegarandeerd, maar ze verschillen van mening over de wijze waarop kwaliteit nu is geïmplementeerd. Artsen blijken met de huidige implementatie tevredener te zijn dan managers. In deze categorie (wel verschillen in de huidige en niet in de gewenste situatie), wordt geen werkelijk verschil in cultuur gemeten tussen artsen en managers maar is er slechts sprake van een verschil in de gepercipieerde werkelijkheid tussen beide groepen. Vanuit de intergroep literatuur zou volgens Ben-Ari (2004) in een dergelijke situatie het uitwisselen van informatie voldoende zijn om de situatie te kunnen verbeteren.

2. In de tweede categorie scoren artsen en managers verschillend in de gewenste maar niet in de huidige situatie. Voorbeelden van gevonden cultuurverschillen in deze tweede categorie zijn het vertrouwen in door de computer gegenereerde informatie en het noemen van innovaties in beleidsstukken. Volgens verwachting scoren de managers hierop hoger dan de artsen. Bij de artsen scoren daarentegen de informele consultaties significant hoger. In deze tweede categorie zouden artsen en managers sommige zaken willen veranderen tegen de wensen van de andere groep in. Hieruit volgt dat beide groepen op deze aspecten hun dagelijkse praktijk verschillend zouden aanpassen indien dat mogelijk zou zijn. De intergroep methodiek die op deze situaties kan worden toegepast is Allport's contact theorie (1954). Deze methode is al vaak met succes toegepast in andere complexe intergroep relaties (Pettigrew \& Tropp, 2006). Volgens deze theorie kan contact tussen groepen worden bevorderd door aan vier condities te voldoen: het hebben van gelijke doelen, geen competitie in de relatie, respect voor het professionele domein van de ander en ondersteuning door autoriteiten.

3. In de derde categorie zijn er verschillen tussen artsen en managers in zowel de gewenste als de huidige situatie. Aspecten in deze categorieën laten de meest gefundeerde verschillen tussen leden van de groepen zien en zijn daarom het lastigst te veranderen. Voorbeelden van aspecten in deze categorie zijn de waarde die artsen hechten aan hun professionele autonomie en collegialiteit binnen hun groep tegenover de hoge scores van managers inzake het belang van de registratie van incidenten in de zorg en het hebben van vertrouwen in de besluiten van de Raad van Bestuur. Volgens intergroep theorie (Ben-Ari, 2004) vraagt deze derde categorie om een aanpak gebaseerd op metacognitie. Bij metacognitie is het van belang om groepen bewust te maken van hun eigen vooroordelen en grondig na te denken over de herkomst van die vooroordelen.

De resultaten van de tweede studie over de intergroep benadering van stereotype beelden (hoofdstuk 4) zijn dat managers artsen beschouwen als: hoger in professionele status en ook hoger in macht maar met ongelijke doelstellingen. Artsen beschouwen managers als machtiger met minder status en ongelijke doelstellingen. Volgens de Intergroep literatuur (Alexander, 2005a en b) leiden de stereotyperingen van artsen naar 
managers tot een defensieve houding; artsen zullen waarschijnlijk a priori door managers voorgestelde organisatie verbeteringen niet accepteren. Ook zullen artsen managers waarschijnlijk niet consulteren over wijzigingen die zij in hun medische praktijken willen doorvoeren. De stereotype beelden die managers van artsen hebben, leiden conform de intergroep theorie tot gevoelens van weerstand. Dit kan er toe leiden dat managers acties van dokters negatief interpreteren, hetgeen de stereotypering kan versterken. Zowel het mechanisme van artsen naar managers (defensieve houding) als het mechanisme van managers (weerstand) hinderen effectieve samenwerking tussen beide groepen.

De resultaten komend uit de vragen naar de tevredenheid van beide groepen met onderlinge samenwerking, innovatie en kwaliteit van zorg zijn dat artsen meer tevreden zijn met de kwaliteit van zorg en managers meer tevreden met de samenwerking en de implementatie van innovaties. Hieruit kunnen wij concluderen dat, ook uit dit onderzoek blijkt dat, mensen meer tevredenheid ervaren ten aanzien van zaken waarvoor ze zich zelf verantwoordelijk voelen.

Bovengenoemde verschillen zijn gemeten op groepsniveau tussen artsen en managers. Een volgende stap in het onderzoek is een analyse van verschillen binnen de groepen (intragroep verschillen) vanuit de "Similarity Attraction Hypothesis" (Rokeach, 1980), een onderdeel van intergroep theorie (hoofdstuk 5). Deze theorie stelt dat als mensen meer op elkaar lijken, de kans op effectieve samenwerking groter is. Er is geanalyseerd of er binnen de groepen van artsen en managers subgroepen zijn die minder verschillen ten opzichte van de andere groep en daardoor beter zouden kunnen samenwerken. Voorbeelden hiervan zijn of vrouwelijke managers beter kunnen samenwerken met artsen of dat er verschillen zijn tussen de manier waarop beschouwende, snijdende of ondersteunende medisch specialisten kunnen samenwerken met managers. Uit de resultaten blijkt dat er veel intragroep verschillen zijn, maar dat die verschillen kleiner zijn dan de verschillen tussen de groepen. Hieruit volgt dat de verschillen tussen managers en artsen groter zijn dan de verschillen binnen de groepen. Binnen de groepen van artsen en managers zijn wel subgroepen te identificeren die ten opzichte van elkaar waarschijnlijk beter met de andere groep kunnen samenwerken. De resultaten zijn dat met name vrouwelijke artsen het meest op managers lijken in hun tevredenheid en dat de zogenaamde beschouwende specialisten (0.a. internisten en cardiologen) het minst stereotyperen ten opzichte van managers. Ook is geconstateerd dat het hebben van managementtaken voor meer dan $25 \%$ van de werktijd bij artsen leidt tot een kleiner verschil met managers. De groep van managers vertoont een homogener scoringspatroon dan de groep artsen. Hieruit kan worden geconcludeerd dat er binnen de managersgroep minder subgroep-verschillen zijn. Wel is binnen de managers gemeten dat strategische managers (ten opzichte van tactische en operationele managers) het meest op artsen lijken in de manier waarop ze machtverschillen tussen artsen en managers ervaren. De conclusie die we mogen trekken is dat er een diversiteit binnen de groepen van ziekenhuis artsen en managers bestaat. Daardoor hebben we mogelijkheden om subgroepen te identificeren die waarschijnlijk beter kunnen samenwerken met leden van de andere groep. Ook belangrijk is dat managementparticipatie van artsen leidt tot betere samenwerking met managers. Wat daarbij niet is gemeten, hetgeen interessant is voor een toekomstig 
onderzoek, is of managementparticipatie op dit moment uitgevoerd wordt door artsen die intrinsiek gemotiveerd zijn voor deze extra taak of dat de participatie zelf er voor zorgt dat de perceptie van de werkpraktijk meer overeenkomsten gaat vertonen met die van managers.

Een interessant aspect van het homogene scoringspatroon van managers is dat de stereotyperingen ten opzichte van de andere groepen het grootst zijn als homogene groepen samenwerken met minder homogene (of meer heterogene) groepen. Beide groepen zouden zich bewust moeten zijn van hun verschillen in homogeniteit, omdat dat een positieve invloed kan hebben op hun onderlinge samenwerking.

Dit proefschrift wordt afgesloten met een onderzoek naar de samenwerking tussen artsen en managers en de associatie daarvan met ziekenhuisresultaten (hoofdstuk 6). Het betreft een kwantitatief onderzoek gebaseerd op dezelfde dataset waarbij de samenwerking tussen artsen en managers en de resultaten van ziekenhuizen zijn geanalyseerd. De samenwerking tussen artsen en managers werd gekwantificeerd en vervolgens statistisch geassocieerd met IGZ indicatoren op intervalniveau. In dit onderzoek kon een samenhang worden vastgesteld tussen de samenwerking tussen artsen en managers en de kwaliteit van het ziekenhuis. Deze samenhang is gegroepeerd in drie categorieën, die toenemend zijn in sterkte van relatie tussen de samenwerking van artsen en managers met kwaliteit. De eerste categorie (met de sterkste samenhang) bevat voornamelijk organisatorische indicatoren, zoals patiënttevredenheid en solvabiliteit. De tweede categorie bevat vooral organisatorische indicatoren met een meer medische gerichtheid maar waarbij organisatie van de zorg invloed heeft op de uitkomst, zoals bijvoorbeeld het aantal oesophagus-, en aorta operaties. De derde categorie bevat de indicatoren die geen associaties tussen samenwerking en kwaliteit tonen, dit zijn voornamelijk medisch inhoudelijke indicatoren. Hieruit kan worden opgemaakt dat de samenwerking tussen artsen en managers voor het grootste gedeelte op organisatorisch gebied plaats lijkt te vinden en minder op medisch gebied. Vanuit formele instanties (oa IGZ, NIAZ) worden echter eisen gesteld aan ziekenhuizen om een duidelijke samenhang te tonen tussen de medische en de organisatorische processen. De resultaten uit dit onderzoek doen vermoeden dat deze samenhang nog onvoldoende wordt gepraktiseerd. Uit dit onderzoek komt naar voren dat effectieve samenwerking tussen artsen en managers en de kwaliteit van het ziekenhuis met elkaar samenhangen.

De resultaten van deze studie zijn zodanig gelieerd aan intergroep theorieën dat adviezen kunnen worden geformuleerd over verbetering van de samenwerking tussen artsen en managers en bij welke soort problemen welke beïnvloeding vanuit de intergroep theorieën zou kunnen passen. In 2001 hebben Jehn en Mannix gepubliceerd over de relatie tussen verschillende soorten groepsconflicten (relatie-, proces-, of taakconflicten) en de invloed daarvan op de resultaten van ziekenhuizen. Een andere methodiek is beschreven door Ben-Ari (2004); de metacognitie-, contact-, en de informatiemethode. Beide theorieën, zowel van Jehn en Mannix als Ben-Ari, beschrijven methodieken die toe te passen zijn op conflicten van toenemende complexiteit. In dit proefschrift worden deze methodieken toegepast op de voortgaande complexiteit die besloten is in de 3 categorieën waarin de resultaten van het onderzoek naar de 
associatie van de samenwerking tussen artsen en managers en kwaliteit van het ziekenhuis zijn ingedeeld.

1. De eerste categorie betreft de indicatoren die sterk correleren met de samenwerking tussen artsen en managers, de organisatie-indicatoren zoals patiënttevredenheid en solvabiliteit. De bijbehorende probleemdefinitie van Jehn en Mannix (2001) is een organisatieprobleem op taakniveau. Hierbij volstaat (conform Ben-Ari, 2004) een praktische benadering van het probleem zodat op inhoud met elkaar gewerkt kan worden aan de verbetering.

2. De tweede categorie, medische indicatoren met een relatie tot de organisatie, is minder conflictueus maar er is nog steeds verbetering nodig. Jehn en Mannix (2001) benoemen dit als een procesconflict, waarbij er verbinding tussen het organisatorische en het medische domein moet worden gemaakt. Volgens Ben-Ari past bij een procesconflict een aanpak vanuit de contact theorie van Allport (1954) (eerder in deze samenvatting beschreven). De vier door Allport beschreven condities voor een goede samenwerking zijn; streven naar gezamenlijke doelen, geen competitie in de relatie, respect voor het professionele domein van de ander en de ondersteuning door autoriteiten.

3. Bij de medisch georiënteerde indicatoren kan worden gesteld dat het onderliggend relatieconflict tussen artsen en managers hierbij een belangrijke rol speelt. Uit eerder onderzoek blijkt dat de twee groepen ten opzichte van elkaar incompatibiliteit, frustratie en irritatie voelen. Vanuit de methode van Ben-Ari (2004) past bij dit soort problemen de toepassing van metacognitie. Bij metacognitie wordt niet op de inhoud of het proces waar je mee bezig bent gefocust, maar wordt aandacht gegeven aan de relatie en de onderliggende gevoelens en houding ten opzichte van elkaar.

\section{Beperkingen van dit onderzoek en aanbevelingen voor toekomstig onderzoek}

In dit proefschrift wordt uitgegaan van een problematische relatie tussen artsen en managers. De onderzoekers zijn er zich van bewust dat er ook voorbeelden zijn van succesvolle samenwerking tussen artsen en managers. De CG-vragenlijst is ontwikkeld uit Kralewski's vragenlijst door die items te selecteren die onderscheiden tussen artsen en managers. Daarmee meet de vragenlijst de inhoud en grootte van verschillen tussen artsen en managers en niet de mogelijke overeenkomsten. Informatie over de inhoud en grootte van de verschillen in percepties tussen beide groepen biedt de mogelijkheid om aanknopingspunten voor verbeteringen te vinden. Alhoewel in dit onderzoek buiten beschouwing gelaten, heeft ook de organisatiestructuur van ziekenhuizen invloed op de wijze waarop de samenwerking tussen artsen en managers verloopt. De organisatiestructuur van ziekenhuizen is onderwerp van vele studies. De keuze voor het onderzoeken vanuit de cultuurbenadering wordt ondersteund doordat in de literatuur de problematische relatie tussen artsen en managers in vele Westerse landen wordt beschreven. Hierbij lijkt deze niet geassocieerd met de in die landen voorkomende verschillende systemen of organisatiestructuren.

De gegevens zijn verzameld binnen algemene ziekenhuizen in Nederland, de acht academische ziekenhuizen zijn geëxcludeerd. Vanwege de verschillen tussen academische en algemene ziekenhuizen, zoals de budgetteringssystematiek en taakinhouden, kunnen de resultaten niet worden veralgemeniseerd naar de 
academische ziekenhuizen. Het gebruikte instrument zou voor toepassing buiten algemene ziekenhuizen opnieuw moeten worden gevalideerd. Ook voor gebruik in landen anders dan Nederland zou de vragenlijst gevalideerd moeten worden voor gebruik.

Het responspercentage in deze studie was 24\% (929/3941) onder artsen en $45 \%$ $(310 / 680)$ onder managers. Omdat dit lage percentages zijn, is de respons bias getest. Hieruit bleek dat statistisch gezien geen reden is om aan te nemen dat de spreiding in de populatie afwijkt van de spreiding in de steekproef. Echter, een hoger response percentage zou wenselijker zijn geweest.

Het gegeven dat de promovenda zelf manager is in een ziekenhuis heeft zowel voor- als nadelen voor deze studie. De toegankelijkheid tot de data werd hiermee verhoogd, echter de objectiviteit van onderzoeken kon in het gevaar komen. Daardoor is een constant bewustzijn van het verschil in standpunt onderzoeker versus manager essentieel en is bewust gekozen voor een combinatie van kwalitatieve en kwantitatieve onderzoeksmethoden. Dit, omdat in de kwantitatieve dataverzameling de mogelijke subjectiviteit van de onderzoeker een minimale rol speelt.

Tot slot, de hoofdhypothese van dit proefschrift is dat verschillen tussen artsen en managers geassocieerd zijn met ziekenhuisprestaties. De definitie van ziekenhuisprestaties blijft echter problematisch (Donabedian, 2005). Veel instanties richten zich op het meten en kenbaar maken van kwaliteit en resultaten van ziekenhuizen. De indicatoren die voor deze studie zijn gebruikt, zijn die van de Inspectie voor de Gezondheidszorg, zoals gepubliceerd op internet. Deze indicatoren representeren niet alle resultaatsgebieden van ziekenhuizen en daardoor claimt deze studie ook geen weergave te herbergen van een valide totaaloverzicht van ziekenhuisprestaties. Op dit moment is er echter nog geen beter alternatief voorhanden.

\section{Toekomstig onderzoek}

In dit proefschrift zijn methoden en technieken van de theoretisch zwaar verankerde Intergroep literatuur binnen de ziekenhuissetting geïntroduceerd. In toekomstig onderzoek zou het interessant zijn om vanuit de intergroep theorie plannen van aanpak te schrijven en verbeteringen in ziekenhuisorganisaties te ontwikkelen, waarmee ook de empirische geldigheid van de resultaten zou kunnen worden getoetst. Zoals eerder gemeld zijn in dit onderzoek de verschillen in percepties tussen artsen en managers gemeten, en wellicht zou een kleine mate van frictie in de samenwerking een positieve associatie kunnen laten zien met ziekenhuisprestaties. Daarbij zijn in het ziekenhuis meer groepen professionals aanwezig (zoals verpleegkundigen en paramedici), waarbij het interessant zou zijn de relaties van representanten van deze groepen met leden van het management te onderzoeken. Een andere mogelijkheid zou zijn te onderzoeken of een goede relatie tussen bijvoorbeeld verpleegkundigen en artsen invloed heeft op de relatie tussen managers en artsen. In dit onderzoek is aangetoond dat artsen met een managementparticipatie van meer dan $25 \%$ van hun tijd, kleinere verschillen in percepties tonen ten opzichte van managers dan artsen met weinig tot geen managementparticipatie. Hierbij is niet onderzocht of deze kleinere verschillen een relatie hebben met het doen van managementtaken of dat juist artsen die 
managementinteresse hebben, kiezen voor meer managementtaken. De invloed van managers op de inhoud van het medische werk van artsen lijkt nog beperkt. Daarmee is niet gezegd dat invloed van managers ook een positieve invloed zou hebben op de kwaliteit van de medische inhoud. Verder worden in het Nederlandse zorgsysteem marktelementen geïntroduceerd die ook zouden kunnen zorgen voor een wijziging van de relaties tussen professionals in ziekenhuizen. Toekomstig onderzoek zou deze veranderende omstandigheden en hun invloed op deze relaties in kaart kunnen brengen. Een van de grootste uitdagingen in de aankomende jaren voor ziekenhuizen is de kwaliteit van zorg en patiënttevredenheid te verbeteren en tegelijkertijd de kosten in de hand houden. Een van de sleutels hiervoor zou een verbeterde samenwerking tussen artsen en managers kunnen zijn die met gebruikmaking van intergroep technieken kan worden gestimuleerd. 


\section{References}

Alexander MG, Brewer MB, Livingston RW. Putting stereotype content in context: Image theory and interethnic stereotypes. J Pers Soc Psychol. 2005;31:781-94.

Alexander MG, Levin S, Henry PJ. Image theory, social identity and social dominance: structural characteristics and individual motives underlying international images. Polit Psychol. 2005;26:27-45.

Allport GW. The nature of prejudice. Reading: Addison-Wesley; 1954.

Ben-Ari R. Coping with the Jewish-Arab Conflict: a comparison among three models. J Soc Issues. 2004;60:307-22.

Donabedian A. Evaluating the quality of medical care. Milbank Q. 2005;83:691-729.

Hofstede G, Neuijen B, Ohayv DD, Sanders G. Measuring organizational cultures: a qualitative and quantitative study across twenty cases. Adm Sci Q. 1990;2:286-316.

Jehn KA, Mannix E. The dynamic nature of conflict: a longitudinal study of intragroup conflict and group performance. Acad Manage J. 2001;44:238-51.

Kelman HC. Social-psychological dimensions of international conflict. In: Peacemaking in international conflict: methods. IW Zartman (ed.). Washington DC: Insitute of Peace; 1997.

Kralewski JE, Dowd BE, Kaissi A., Curoe A, Rockwood T. Measuring the culture of medical group practices. Health Care Manage Rev. 2005;30:184-93.

Mintzberg H. Mintzberg on management. New York/London: The Free Press; 1989.

Pettigrew TF, Tropp LR. A meta-analytic test of intergroup contact theory. J Pers Soc Psychol. 2006;90:751-83.

Rokeach M. Some unresolved issues in theories of believes, attitudes, and values. Symposium on Motivation. 1980;27:261-304.

Tajfel H. Social psychology of intergroup relations. Annu Rev Psychol. 1982;33:1-39.

Turner JC, Hogg MA, Oakes PJ, Reicher SD, Wetherell MS. Rediscovering the social group: a self-categorization theory. Oxford: Blackwell; 1987. 


\section{Dankwoord}

Het is een platitude dat een proefschrift nooit alleen geschreven kan worden. Maar wel een hele ware! In het navolgende doe ik mijn best een ieder die een bijdrage aan dit proefschrift heeft geleverd te eren, echter, indien $u$ als lezer ook vindt dat $u$ een bijdrage heeft geleverd en u niet wordt genoemd, geef uzelf dan de eer!

Zoals in het voorwoord reeds geschreven is het plan voor dit proefschrift geboren in New Orleans tijdens een IHI congres. Prof. dr. Wim van Harten ken ik uit mijn werkzame periode in revalidatiecentrum Het Roessingh. Hij was ook op het $\mathrm{IHI}$ congres en Wim vertelde mij dat hij bezig was met het opzetten van onderzoekslijnen. Hij was op zoek naar ziekenhuizen waarmee hij langdurige onderzoeksrelaties kon leggen. Die vraag liet mij niet los en een maand later heb ik hem gebeld en gevraagd of het mogelijk was dat ik zelf met hem die langdurige onderzoeksrelatie zou aangaan; het resultaat kunt $u$ nu lezen. Wim is een bijzonder mens, hij is kritisch, analytisch sterk en een tikje afstandelijk. Zijn adviezen zijn raak, als hij een passage uit een artikel niet begreep, betekende dat steevast dat ik het niet goed had verwoord, of een denkfout maakte. Wim dank voor je niet aflatende altijd snelle en goede adviezen.

Aangezien het proefschrift een culturele theoretische basis heeft, en Wim een leerstoel Kwaliteit heeft, was een tweede promotor met kennis van de organisatieliteratuur onontbeerlijk. Prof. dr. Celeste Wilderom werd door Wim benaderd en zij wilde deze taak op zich nemen. Zeker in de beginperiode van mijn onderzoek is Celeste van zeer grote waarde geweest. Zij heeft er voor gezorgd dat ik uiteindelijk 1500 artikelen heb gelezen. Zodra ik voor mijn gevoel de goede richting en theorie had, wist Celeste mij door het stellen van veel vragen duidelijk te maken dat er meer keuzes mogelijk zijn die waarschijnlijk beter geschikt waren voor mijn onderzoek. Ook heeft zij mij zeer waardevolle kritiek gegeven en mijn eerste presentatie op een internationaal congres (EGOS) mogelijk gemaakt, waardoor ik mijn presentatievaardigheden heb kunnen verbeteren. Celeste dank voor je vasthoudendheid en grote kennis van de organisatieliteratuur.

Al snel werd duidelijk dat het onderzoek ook een kwantitatief gedeelte zou krijgen. Alhoewel ik tijdens mijn studie psychologie uitgebreid statistiek heb gehad, vond ik ondersteuning op dat vlak wel belangrijk. Dr. Sabine Siesling, die hoofd onderzoek bij het Integraal Kankerinstituut is, wilde mij hierbij helpen. Samen met haar is het onderzoeksinstrument dat gebruikt is voor dit proefschrift tot stand gekomen. Sabine is, buiten haar werk voor de kankerregistratie, ook werkzaam op de Universiteit Twente; gezien haar belangrijke bijdrage aan mijn proefschrift is zij assistent promotor geworden. Tijdens een van onze statistiek sessies bleken wij een gezamenlijke passie voor paarden te hebben. Dit resulteerde in meer dan alleen een "zakelijke" relatie. Sabine, ik hoop dat we nu eindelijk tijd maken om een keer samen op de paarden de bossen in te gaan, ik heb er nu al heel veel zin in! 
De overige leden van de promotiecommissie prof. dr. H.J.J.M. Berden, prof. dr. M.J. IJzerman, prof. dr. J.H. Kingma en prof. dr. A.P.W.P. van Montfort dank ik voor de bereidheid dit proefschrift te evalueren.

Nienke Meerdink kwam in 2006 bij mij voor een afstudeeropdracht. Het leek een prima meid en dus ging ik met haar in gesprek over de relatie tussen dokters en managers. Ik vertelde haar over de grote verschillen tussen beide groepen en over de beelden die beide groepen over elkaar hebben. Nienke dacht dat ik overdreef om de afstudeeropdracht interessanter voor te stellen. Om mijn verhaal geloofwaardiger te maken nam ik haar mee op een rondleiding door het ziekenhuis, en ja hoor, de eerste dokter die wij tegenkwamen zei "Zeg, hebben managers niets beter te doen dan zomaar rond te lopen?". Na die rondleiding wilde Nienke heel graag afstuderen op het onderwerp van de relatie tussen artsen en managers. Aan het eind van haar afstuderen is ze gebleven in het ziekenhuis en een fantastische kwaliteitsmedewerker geworden. Vanaf maart 2011 heeft ze een nieuwe uitdaging in het ziekenhuis in Arnhem geaccepteerd. Nienke, de lange discussies en kritische houding van jou op mijn proefschrift hebben veel bijgedragen. Zeker aan de kwaliteit maar (misschien nog belangrijker); door jou associeer ik het maken van proefschrift met ontzettend veel plezier. Ik heb er enorm van genoten! Af en toe hebben we de tranen in de ogen gelachen (Topperrrrr van de week en T-mails), dat hielp zeker bij het plezier houden in het werk aan het proefschrift. Een memorabel voorval is dat toen ik in 2007 geopereerd was aan mijn rug, ik een aantal weken thuis was. Om het onderzoek geen vertraging op te laten lopen zijn Sabine en Nienke naar Mander gekomen, alwaar zij, zittend in de keuken, en ik, liggend in de keuken, discussies over methodieken hebben gevoerd. Dit ging alles in een zeer goede stemming (zie foto) Sabine merkte op dat zij tot op dat moment zich nooit had gerealiseerd dat promoveren zo leuk was!!

$\mathrm{Na}$ de nationale dataverzameling, verricht in het kader van deze promotie, was het resultaat een enorme hoeveelheid gegevens die statistisch geanalyseerd moesten worden. Bij een dataverzameling van deze omvang kan het een groot probleem zijn dat er allerlei relaties uit de data komen die uitsluitend worden gevormd door de statistische methoden die worden gebruikt en geen relatie met de werkelijkheid hebben. Dit zou natuurlijk een niet wenselijke uitkomst zijn, de relaties die worden beschreven in deze these moeten voldoende betrouwbaar en valide zijn. Wim van Harten verwees mij hiervoor naar de statistische afdeling binnen het NKI. Ik kwam in contact met Andrew Vincent. In de gesprekken die volgden met Andrew, Wim, Sabine, Nienke en mijzelf werd duidelijk hoe lastig het construct van dit proefschrift te begrijpen is voor buitenstaanders. Andrew gaf echter niet op (Wim, Sabine, Nienke en ik ook niet) en na 8 bezoeken aan Amsterdam, (fijne bijkomstigheid waren de bezoekjes aan de Albert Cuypmarkt en de slager in Weesp; ik kwam steevast met heel veel lekkers thuis) presenteerde Andrew een betrouwbare analyse die echt goede resultaten te zien gaf. Hiervoor gebruikte Andrew uiteindelijk de meest geavanceerde en nieuwe statistische methoden gericht op het vermijden van schijnuitslagen. Door Andrew zijn enthousiasme, denkvermogen en statistische kennis is het mogelijk geweest de hoofdstukken over de intragroep verschillen en over de relatie tussen samenwerking en kwaliteit te maken. 
De contacten met medewerkers van de Universiteit Twente die ik in de loop van de jaren heb opgedaan waren ook heel plezierig. Mijn eerste presentatie op een congres was EGOS in Berlijn. Daar ging ik (dacht ik) alleen naar toe. In de trein kwam ik Svetlana tegen. Svetlana was bijna klaar met haar proefschrift en ik kende haar omdat ik een aantal malen een middag met haar in dezelfde kamer aan mijn onderzoek gewerkt had. Eenmaal met haar in gesprek bleek dat we met 12 PhD-ers vanuit Twente op weg waren naar Berlijn, uiteindelijk hebben wij 3 dagen lang enorm veel gediscussieerd, gelachen, geleerd en 's avonds heerlijk gegeten (iemand in de groep had gestudeerd in Berlijn en kende echt alle goede adresjes). Vooral met Jeff en Michel heb ik later ook nog fijn contact gehouden. Via Wim van Harten kwam ik ook in contact met Erwin Hans, dit heeft vooral veel effect gehad voor de club van logistiek medewerkers die in ZGT aan de slag zijn gegaan. Maar ook de bijdrage van de Van Hoytemastichting aan het symposium is via hem verlopen, Erwin, dank daarvoor! De stagiaires Marlies Oost en Carolien van Merkstein verdienen ook een vermelding, zij hebben op gebied van kwaliteitsystemen (Marlies) en de relatie tussen artsen en specialisten en kwaliteit (Carolien) scripties geschreven waar ik uit heb kunnen putten voor mijn thesis.

Ook opeenvolgende bestuurders van ZGT die dit onderzoek ondersteunden wil ik bedanken; vooral Paul Oostinga, die bij mijn plannenmakerij voor dit proefschrift direct enthousiast was. Er zijn 2 personen die zeker een ereplaats in dit proefschrift verdienen: Erna en José, mijn super secretaresses die mij tijdens mijn ZGT periode fantastisch hebben ondersteund. Toen mijn plannen voor dit proefschrift ontstonden zei Erna: "Ik vind het best, maar ik wil dan wel in het proefschrift vermeld worden". Nou meid, hierbij, en zeker verdiend!! Ook Alice Geerdink en Dick Maas verdienen een vermelding voor hun fantastische opzoekwerk in de bibliotheek. Onno Verschuur heeft met heel veel creatief talent de omslag van dit boekje gemaakt, waar Sjef van Baal zich als fotomodel voor heeft ingezet. En dan de grote verassing van de prima kennis van de Engelse taal van Ellen van Vooren, en ze vond editen nog leuk werk ook! Het is een voorrecht om met zulke fijne mensen te mogen werken.

Een aparte waardering voor alle artsen en managers die de vragenlijsten hebben ingevuld is op zijn plaats, zonder $u$ had ik geen data gekregen. Er zijn teveel mensen om geheel te kunnen beschrijven die direct of indirect een bijdrage hebben geleverd aan dit proefschrift, daarom een (niet limitatieve) opsomming: Elisabeth (Lot), Cor, Astrid, Gerdie, Michel, Jasper, Manon, Ad, Dini, Lucas, Rick, Agnes, Anneke, Yvonne, Patrick, Thymen, Arlette, Rene, Nel, Harry, Martin, Johan, Paul, Joke, Arend Jan, Maarten, Tim, Peggy, Henk, Hennie, Joost, Aart, Johan, Hans, Francisca, Said, Wim, Hein, Peter, Vincent, Detlev, etc.

Vanaf april 2011 heb ik mijn entree gemaakt bij de Rugpoli. Michiel, Frank, Ine en alle andere medewerkers dank voor jullie warme onthaal. Jullie toewijding en kwaliteit van zorg voor rugpatiënten verdient veel respect en navolging.

En dan lest best, de thuisbasis. Simon, elke dag weer naar Mander te mogen is een groot voorrecht. De dieren, de omgeving en natuurlijk jij maken mij zeer gelukkig. Ik hoop dat we nog heel lang zo door kunnen! 


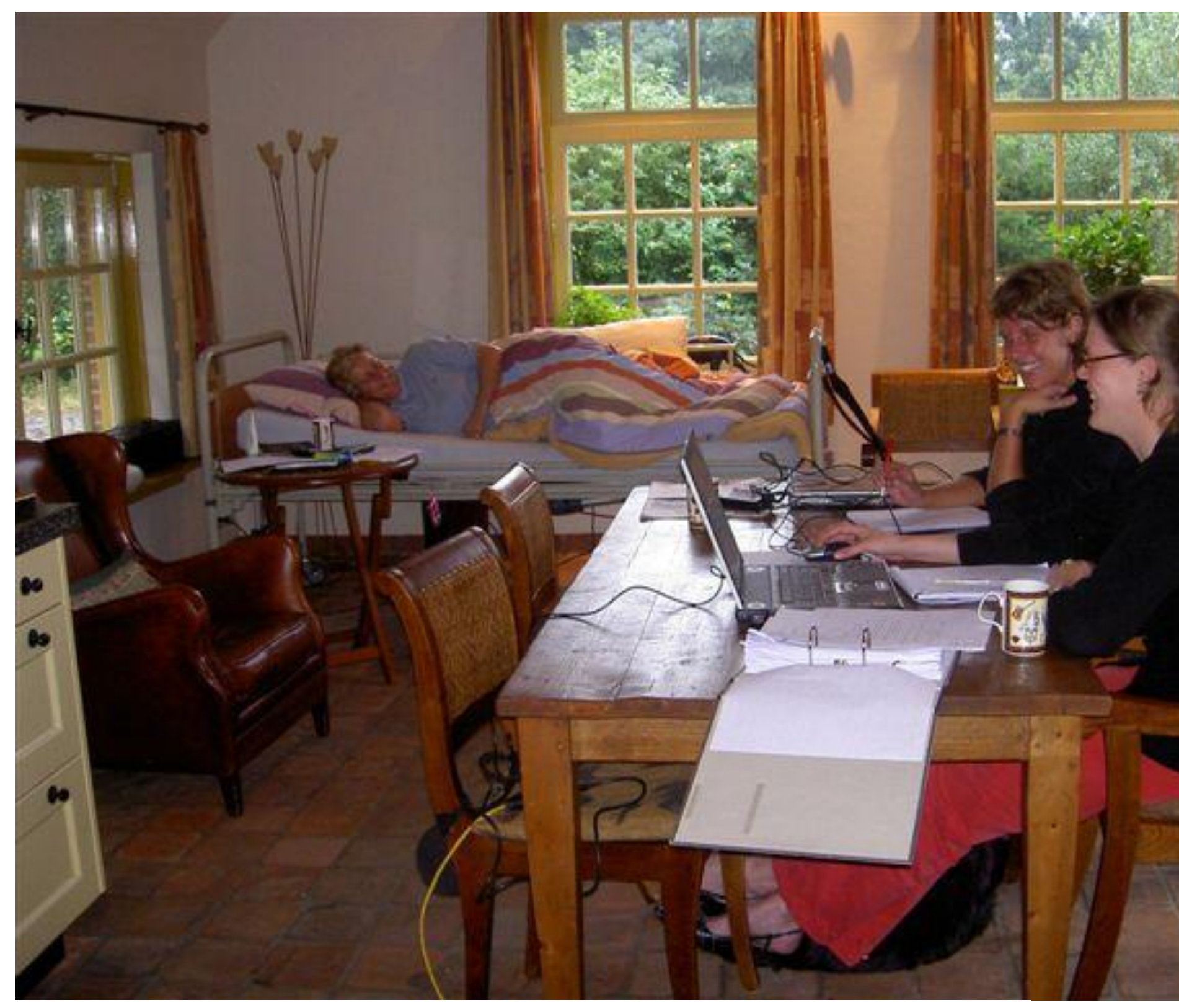




\section{Over de auteur}

Hanneke Klopper werd geboren op 22 juli 1964 te Haarlem. Hier volgde zij ook haar middelbare school. $\mathrm{Na}$ haar schoolperiode heeft ze een aantal jaren in commerciële bedrijven gewerkt, uiteindelijk was zij manager op een uitzendbureau. Door deze baan werd haar interesse voor de menselijke kant van het organiseren getrokken. Dat resulteerde in de start van een universitaire studie psychologie aan de Open Universiteit in haar $29^{\mathrm{e}}$ levensjaar. Op haar $34^{\mathrm{e}}$ studeerde zij af in de richting arbeid en organisatie. Tijdens haar studie kwam zij in contact met het Thoraxcentrum van het Dijkzigt ziekenhuis in Rotterdam. Het Thoraxcentrum stelde haar in de gelegenheid binnen het centrum af te studeren, het titel was "Het hart van het hartcentrum", de invloed van artsen op de ziekenhuisorganisatie. Na haar afstuderen kreeg zij een functie binnen het hartcentrum aangeboden. Na haar periode in Rotterdam verhuisde ze naar het mooie Twente in het oosten van Nederland. Hier werkte zij in personeel en organisatie adviesfuncties in het Medisch Spectrum Twente en Revalidatiecentrum Het Roessingh. In 2002 kreeg zij managementverantwoordelijkheid voor de zorg in ZGT. Tijdens deze functie heeft zij vanaf eind 2004 onderzoek gedaan naar de samenwerking tussen artsen en managers en de invloed die dat heeft op ziekenhuiskwaliteit, waar dit proefschrift het resultaat van is. Vanaf 2008 werd zij directeur zorg binnen ZGT. In april 2011 heeft zij een nieuwe uitdaging aangenomen als directeur/bestuurder van de Rugpoli in Delden, een multidisciplinair zelfstandig behandelcentrum voor rugproblematiek.

\section{Short biography}

For her Masters in organisational psychology Hanneke Klopper studied the manageability of a University Cardiac-care Centre. From literature she derived the importance of organisational culture within professional service organisations on both the manageability and quality performance. After her Masters she worked as an organisational consultant in several hospitals. From August 2002 she was director in the Hospital Group Twente in Almelo, The Netherlands. In April 2011 she found a new challenge and started working for De Rugpoli in Delden, a private clinic specialised in back injuries. Her work inspires her to study the complex relationships and dynamics in healthcare organisations. Therefore she started a PhD study on the effective cooperation between medical doctors and managers and the influence of this cooperation on hospital quality performance. In November 2004 she became an associated researcher at the faculty of Technology and Management of the University of Twente. This thesis is a result from her study. 